\title{
Honokiol: A Review of Its Anticancer Potential and Mechanisms
}

\author{
Chon Phin Ong ${ }^{\mathbb{D}}$, Wai Leong Lee, Yin Quan Tang * and Wei Hsum Yap *iD \\ School of Biosciences, Faculty of Health and Medical Sciences, Taylor's University Lakeside Campus, No. 1, \\ Jalan Taylor's, Subang Jaya 47500, Malaysia; chonphin96@gmail.com (C.P.O.); leew10108@gmail.com (W.L.L.) \\ * Correspondence: yinquan.tang@taylors.edu.my (Y.Q.T.); weihsum.yap@taylors.edu.my (W.H.Y.)
}

Received: 30 November 2019; Accepted: 19 December 2019; Published: 22 December 2019

\begin{abstract}
Cancer is characterised by uncontrolled cell division and abnormal cell growth, which is largely caused by a variety of gene mutations. There are continuous efforts being made to develop effective cancer treatments as resistance to current anticancer drugs has been on the rise. Natural products represent a promising source in the search for anticancer treatments as they possess unique chemical structures and combinations of compounds that may be effective against cancer with a minimal toxicity profile or few side effects compared to standard anticancer therapy. Extensive research on natural products has shown that bioactive natural compounds target multiple cellular processes and pathways involved in cancer progression. In this review, we discuss honokiol, a plant bioactive compound that originates mainly from the Magnolia species. Various studies have proven that honokiol exerts broad-range anticancer activity in vitro and in vivo by regulating numerous signalling pathways. These include induction of G0/G1 and G2/M cell cycle arrest (via the regulation of cyclin-dependent kinase (CDK) and cyclin proteins), epithelial-mesenchymal transition inhibition via the downregulation of mesenchymal markers and upregulation of epithelial markers. Additionally, honokiol possesses the capability to supress cell migration and invasion via the downregulation of several matrix-metalloproteinases (activation of 5' AMP-activated protein kinase (AMPK) and KISS1/KISS1R signalling), inhibiting cell migration, invasion, and metastasis, as well as inducing anti-angiogenesis activity (via the down-regulation of vascular endothelial growth factor (VEGFR) and vascular endothelial growth factor (VEGF)). Combining these studies provides significant insights for the potential of honokiol to be a promising candidate natural compound for chemoprevention and treatment.
\end{abstract}

Keywords: honokiol; anticancer; mechanism; signalling pathway

\section{Introduction}

Cancer is the outcome of rampant cell division which is associated with cell cycle disorganisation [1], leading to uncontrolled cell proliferation. In addition, it also involves the dysregulation of apoptosis, immune evasion, inflammatory responses, and ultimately, metastatic spread [2]. Over the last few decades, our progressive understanding of the aetiology of cancer together with advancement of cancer treatment, detection, and prevention, have contributed towards receding cancer mortality around the world [3]. However, more than half of cancer cases were diagnosed at a later stage of cancer progression [4]. According to a study by Bray et al. [5], the worldwide estimated number of new cancer cases for the year 2018 was 18.1 million in both sexes and across all ages. Amongst all the cancer types, lung, breast, and colorectum have topped the charts with approximately 2.1 million, 2.1 million, and 1.8 million cases, respectively. On the other hand, the estimated number of deaths was approximately 9.6 million. Asia accounted for more than half of the cancer deaths ( $57.3 \%)$, followed by Europe $(20.3 \%)$, and America (14.4\%). Lung cancer has caused the highest number of deaths due to substandard 
prognoses. Attempts to develop the effective prevention of cancer may diminish the incidence rate for some cancers, for instance lung cancer in North America and Northern Europe. These western countries have implemented tobacco control in order to avert involuntary exposure to tobacco and minimise active smoking within the community. Unfortunately, a majority of the population are still facing an upsurge of cancer diagnosis, demanding treatment and care [5].

The common treatment regimens for cancer patients include surgery, chemotherapy, and radiotherapy [6]. Although some of these regimens represent the first-in-line options for cancer treatment, the lack of selectivity towards neoplastic cells and the development of drug toxicity has caused these therapeutic effects to recede slowly, rendering it ineffective over the years [7]. Additionally, multidrug resistance tumours pose a severe threat and have been responsible for numerous cancer-related deaths [8]. A modern approach to target multiple cell regulating pathways is mandatory in order to provide highly efficient and targeted cancer therapy. For instance, combination therapy that targets different pathways exhibit significantly lower toxicity towards normal cells compared to mono-therapy [9]. Currently, the development of anticancer drugs possessing the capability to overcome common mechanisms of chemoresistance with minimal toxicity effects would be considered a breakthrough in cancer research [2].

Approximately $70-95 \%$ of the world population continues to use traditional medicinal herbs, plants, and fruits which contain valuable bioactive compounds with therapeutic effects to maintain health, as well as to prevent or treat physical and mental illnesses [10]. These biologically active compounds provide extensive opportunities in uncovering competent anticancer agents [2,11]. A majority of the anticancer drugs that are currently in use originate from plants, marine organisms, and microorganisms, such as the well-known plant-derived anti-cancer drugs Paclitaxel (Taxol ${ }^{\circledR}$ ) and Camptothecin (CPT) [12].

The Magnolia genus is widely distributed throughout the world, especially in East and South-East Asia [13]. Among the Magnolia species, Magnolia officinalis and Magnolia obovata are commonly used in traditional Chinese (known as "Houpu") and Japanese herbal medicine [13,14]. The traditional prescriptions named Hange-koboku-to and Sai-boku-to, which contain the Magnolia bark, are still used in modern clinical practice in Japan [15]. There are several potent bioactive compounds in the Magnolia species have been identified including honokiol, magnolol, obovatol, 4-O-methylhonokiol, and several other neolignan compounds $[13,15,16]$. This paper highlights the potential anticancer effect of a simple biphenyl neolignan found in this Magnolia family, namely honokiol.

Honokiol was traditionally used for anxiety and stroke treatment, as well as the alleviation of flu symptoms [14]. In recent studies, this natural product displayed diverse biological activities, including anti-arrhythmic, anti-inflammatory, anti-oxidative, anti-depressant, anti-thrombocytic, and anxiolytic activities $[13,14,16]$. Furthermore, it was also shown to exert potent broad-spectrum anti-fungal, antimicrobial, and anti-human immunodeficiency virus (HIV) activities [13]. Due to its ability to cross the blood-brain barrier, honokiol has been deemed beneficial towards neuronal protection through various mechanism, such as the preservation of $\mathrm{Na}^{+} / \mathrm{K}^{+}$ATPase, phosphorylation of pro-survival factors, preservation of mitochondria, prevention of glucose, reactive oxgen species (ROS), and inflammatory mediated damage [17]. Hence, honokiol was described as a promiscuous rather than selective agent due to its known pharmacologic effects. Recent studies have been focused on the anti-cancer properties of honokiol, emphasising its tremendous potential as an anticancer agent. In this review, we summarise the anti-cancer properties of honokiol, together with its mechanism of action, based on in vitro and in vivo experimental evidence. In addition, we also summarize the current data on its pharmacological relevance and potential delivery routes for future applications in cancer prevention and treatment.

\section{Research Methodology}

A systematic search was performed to identify all relevant research papers published on the use of honokiol as a potent anticancer treatment using PubMed (1994-present) and Web of 
Sciences (1994-present). The search strategy was performed using several keywords to track down the relevant research articles including 'honokiol', 'cancer', 'cancer statistics', 'structural', 'metabolites', 'mechanism', 'cell death', 'apoptosis', 'anti-inflammatory', 'anti-tumour', 'antioxidant', 'cell proliferation', 'cytotoxicity', 'cell cycle arrest', 'metastasis', 'tumour', 'angiogenesis', 'absorption', 'metabolism', 'toxicity', 'distribution', 'elimination', 'solubility', 'nanoparticles', and 'delivery'.

\section{Structure Activity Relationship and Its Derivatives}

Honokiol bioactive compounds are easily found in the root and stem bark of the Magnolia species, although some studies have also found them in seed cones $[13,18]$. Due to the structural resemblance of both honokiol and magnolol in the Magnolia bark, the extraction of pure honokiol and magnolol cannot be achieved using conventional column chromatography nor thin-layer chromatography. Eventually, their purification process requires a costly alternative like electromigration [16]. The only difference between honokiol and magnolol in terms of structure is only in the position of the hydroxyl group, as shown in Figure 1. In 2007, Chen et al. developed a rapid separation technique using high-capacity high-speed counter-current chromatography (HSCCC) to isolate and purify honokiol and magnolol from crude extracts of Magnolia plants. Within $20 \mathrm{~min}$, the resulting fraction has a purity of $98.6 \%$ honokiol, indicating that this method exhibited substantial efficiency in honokiol extraction [19]. Two years later, another team of researchers formulated a time-effective synthetic method while providing higher yielding honokiol using Suzuki-Miyaura coupling and Claisen rearrangement as key steps of the synthetic pathway of honokiol. The five steps of the honokiol synthesis pathway includes bromination, Suzuki coupling, allylation, one-pot Claisen's rearrangement, and demethylation, eventually resulting in a $32 \%$ overall yield [20]. The emergence of the synthetic method for honokiol has alleviated the risk of extinction of the Magnolia species.

Natural bioactive compounds often serve as lead templates and are subjected to structural modification to improve pharmacological activity, physiochemical properties, along with pharmacokinetics, to generate clinically useful structures [21]. According to Anand et al. [22], a comprehensive study of the natural and synthetic analogues of a drug molecule is crucial to determining its fundamental pharmacophores. As seen in Figure 1, honokiol contains two phenyl rings substituted with hydroxyl and allyl groups. In a study conducted by Bohmdorfer et al. [23], it was found that the predominant metabolic pathways of honokiol in the human liver was through sulfation and glucuronidation (Phase II metabolism) of the free hydroxyl groups, inducing rapid excretion and shortening its half-life [23]. Moreover, Lin et al. [24] have hypothesised that the hydroxyl groups on the biphenyl skeleton of honokiol could be subjected to metabolic oxidation by Phase I enzymes, thus diminishing its efficacy.

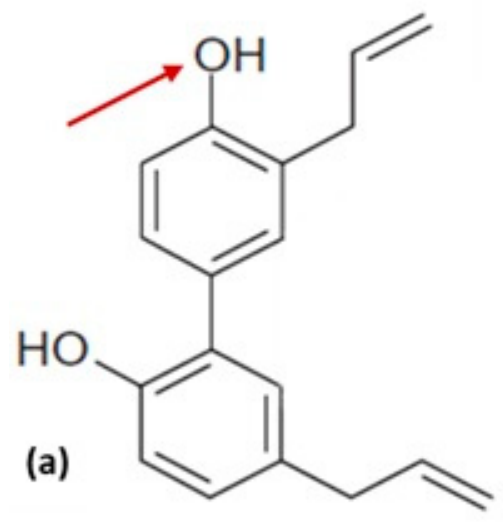

(b)

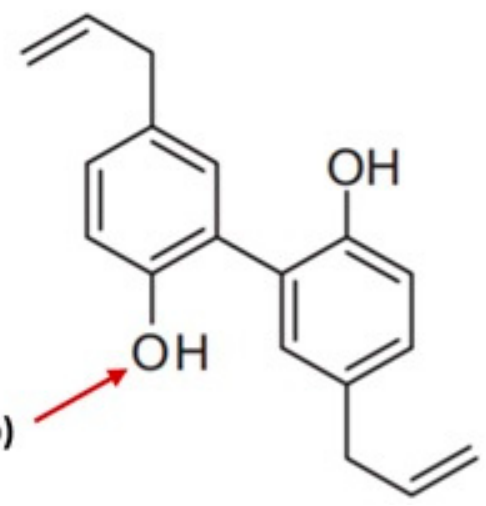

Figure 1. (a): The structure of honokiol [24]; (b): The structure of magnolol [25]. Arrow indicates the difference in the position of hydroxyl group between honokiol and magnolol. 
Through the alteration of the top and bottom rings by changing the substitution pattern at its bottom ring and replacing the hydroxyl group in the top ring with a methoxy group, six different analogues were produced, as shown in Figure 2. A structure-activity relationship (SAR) study was conducted and it was found that replacing the hydroxyl group in the top ring of honokiol with a methoxy group greatly improved its cytotoxicity against lung, melanoma, and colon cancer cells. The two hydroxyl group substituted analogues ( $3^{\prime}$-Bromo-3, $5^{\prime}$-dy-allyl-2' hydroxyl-4-methoxy-1, $1^{\prime}$-biphenyl and 3,3'-Diallyl-4-methoxy-4'-hydroxy-1,1'-biphenyl) have induced G0/G1 phase cell cycle arrest and a swift decrement in Cdk1 and cyclin B1 protein levels, similarly to the parental honokiol compound [24]. Overall, obstruction of the potential oxidation of the phenolic hydroxyl group in the biphenyl group skeleton of honokiol improved its anti-cancer effect.

(a)<smiles>C=CCc1ccc(O)c(-c2ccc(OC)c(CC=C)c2)c1</smiles>

(d)

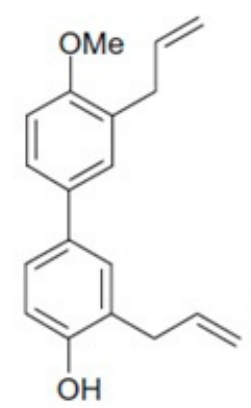

(b)<smiles>C=CCc1cc(Br)c(O)c(-c2ccc(OC)c(CC=C)c2)c1</smiles>

(e)

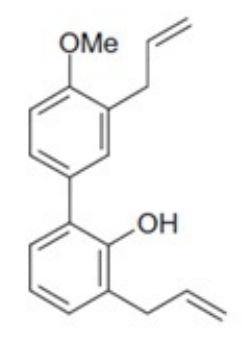

(c)

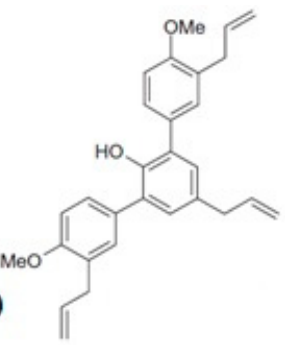

(f)

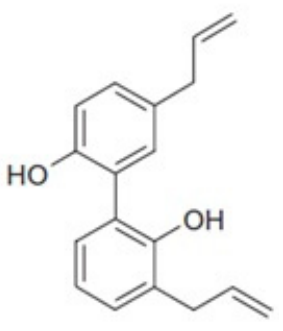

Figure 2. The structure of honokiol analogues. (a): 3,5'-Diallyl-2'-hydroxyl-4-methoxy-1,1'-biphenyl; (b): $\quad 3^{\prime}$-Bromo-3,5'-di-allyl-2'-hydroxyl-4-methoxy-1,1'-biphenyl; $\quad$ (c): 2,6-Di-(4'-methoxy3'-allylphenyl)-1-phenol; (d): 3,3'-Diallyl-4-methoxy-4'-hydroxy-1,1'-biphenyl; (e): 3,3' Diallyl$2^{\prime}$-hydroxyl-4-methoxy-1,1'-biphenyl; (f): 3',5-Diallyl-2,2'-di-hydroxy-1,1'-biphenyl [24].

\section{Anticancer Properties of Honokiol}

\subsection{In Vitro Studies}

Honokiol has been shown to exhibit antiproliferation effects against numerous cancer cells, including bone, bladder, brain, breast, blood, and colon, as shown in Table 1. Generally, the concentrations used for the in vitro studies are between 0-150 $\mu \mathrm{M}$, which majority of these concentration ranges have been shown to significantly inhibit cell proliferation or cell viability of various cancer cell lines. The trend for the $\mathrm{IC}_{50}$ values of numerous cancer cell lines were time-dependent, whereby the $\mathrm{IC}_{50}$ values decreases as duration of the experiment increases. As seen in Table 1, human blood cancer Raji cells were highly susceptible to honokiol treatment $\left(\mathrm{IC}_{50}=0.092\right)$ compared to highly resistant human nasopharyngeal cancer HNE-1 cells $\left(\mathrm{IC}_{50}=144.71 \mu \mathrm{M}\right)$. Interestingly, honokiol has been shown to exhibit minimal cytotoxicity against on normal cell lines, including human fibroblast FB-1, FB-2, Hs68, and NIH-3T3 cells [25-28]. The low cytotoxicity of honokiol treatment against normal cell lines should be emphasised as current chemotherapeutic regimens have a considerable amount of side effects that harm cancer patients.

Many chemotherapeutic agents have been shown to induce severe systemic toxicity and several side effects due to their deficient pharmacokinetic profiles and non-specific distribution in the body [29]. In Yang et al.'s study [30], they have encapsulated honokiol into nanopolymers to enhance its 
permeability and specificity against cancer cells. They utilised the active targeting nanoparticles-loaded honokiol (ANTH) in their in vitro studies against human nasopharyngeal cancer HNE-1 cells, and this incorporation exhibited significantly lower $\mathrm{IC}_{50}$ values compared to free honokiol treatment. As a result, the incorporation or encapsulation of honokiol in transporting vehicles can improve the anticancer effects and concurrently overcome the water solubility issue of honokiol itself. This has shown to be a promising regimen for anticancer treatment in the future.

Furthermore, it is worthy to note that honokiol can enhance the antineoplastic effects of several chemotherapeutic agents when cells are treated in combination treatment of both honokiol and the chemotherapeutic agent. In Wang et al.'s study [31], they have shown that honokiol has enhanced the in vitro cytotoxicity of paclitaxel against human cervix cancer cell lines. The combination treatment has resulted in approximately $10-60 \%$ increase of apoptotic cells and inhibition of cell viability when compared to honokiol treatment alone [31]. In another study, honokiol potentiated the apoptotic effect of both doxorubicin and paclitaxel against human liver cancer HepG2 cells. Honokiol enhanced the apoptotic effects of paclitaxel and doxorubicin by $22 \%$ and $24 \%$ respectively [32]. 
Table 1. The anticancer effects of honokiol against cancer cells in in vitro experiments.

\begin{tabular}{|c|c|c|c|c|c|}
\hline & 1 Lines & Mechanism of Action & Concentration Used & Efficacy//IC $\mathrm{I}_{50}$ (Exposure Time) & References \\
\hline \multirow{5}{*}{ Colorectal cancer } & RKO & $\begin{array}{c}\text { Inhibit cell proliferation } \\
\text { Induce G1 phase cell cycle arrest } \\
\text { Induce apoptosis } \downarrow \text { Bcl-xL; } \uparrow \text { Caspase-3 \& caspase-9 }\end{array}$ & $0-150 \mu \mathrm{M}$ & $\begin{array}{c}46.76 \mu \mathrm{M} \\
(68 \mathrm{~h})\end{array}$ & [33] \\
\hline & $\begin{array}{l}\text { HCT116, HCT116-CH2, } \\
\text { HCT116-CH3 }\end{array}$ & $\begin{array}{c}\text { Inhibit cell proliferation } \\
\text { Induce G0/G1 \& G2/M phase cell cycle } \\
\text { arrest: } \downarrow \text { cyclin D1 \& A1; } \uparrow \text { p53 phosphorylation } \\
\text { Induce apoptosis: } \downarrow \text { Caspase-3; } \downarrow \text { Bcl-2; } \uparrow \text { Bax protein }\end{array}$ & $\begin{array}{l}25 \mu \mathrm{M} \text { Honokiol with } \\
2.5 \text { or } 5.0 \text { Gy IR }\end{array}$ & N/A & [34] \\
\hline & HT-29 & $\begin{array}{c}\text { Inhibit cell growth \& proliferation } \\
\text { Induce G1 phase cell cycle arrest: } \downarrow \text { Cdk1 \& cyclin B1 }\end{array}$ & $\begin{array}{c}0-50 \mu \mathrm{M} \text { followed by } \\
0-5 \text { Gy IR }\end{array}$ & $\begin{array}{l}23.05 \mu \mathrm{M}(24 \mathrm{~h}) \\
13.24 \mu \mathrm{M}(72 \mathrm{~h})\end{array}$ & [24] \\
\hline & HCT116 \& SW480 & 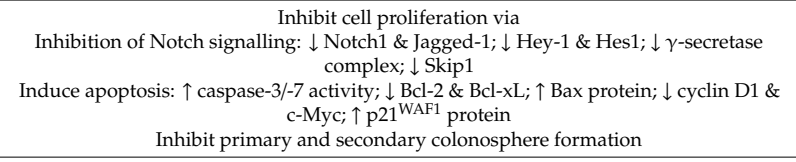 & $0-50 \mu \mathrm{M}$ & N/A & [35] \\
\hline & RKO \& HCT116 & $\begin{array}{l}\text { Inhibit cell viability } \\
\text { Induce apoptosis: } \uparrow \text { caspase-3, } \\
\text { proteins; } \uparrow \uparrow \text { survivinin protein; } \uparrow \text { phosphorylated p } 53 \text { \& } 3 \text { p } 53 \text { proteins; } \downarrow \text { PUMA protein }\end{array}$ & $0-60 \mu \mathrm{M}$ & $\begin{array}{c}\text { RKO: } \\
38.25 \mu \mathrm{MM}(24 \mathrm{~h}) \\
\text { HCT116: } \\
39.64 \mu \mathrm{M}(24 \mathrm{~h})\end{array}$ & [36] \\
\hline \multirow[b]{2}{*}{ Blood cancer } & B-CLL & $\begin{array}{c}\text { Inhibit cell viability } \\
\text { Induce apoptosis: } \uparrow \text { caspase-3 activity; } \uparrow \text { caspase-8 \& caspase-9 activation; } \downarrow \text { caspase-9; } \uparrow \\
\text { Bax protein; } \downarrow \downarrow \text { Mcl-1 protein }\end{array}$ & $0-100 \mu \mathrm{M}$ & $\begin{array}{l}49 \mu \mathrm{M}(6 \mathrm{~h}) \\
38 \mu \mathrm{M}(24 \mathrm{~h})\end{array}$ & [37] \\
\hline & Raji, Molt-4 & $\begin{array}{c}\text { Inhibit cell growth: } \downarrow \downarrow p 65 ; \downarrow \text { NF-kB } \\
\text { Induce apoptosisi } \uparrow \text { JNK activation } \\
\text { Increase ROS activity: } \uparrow \text { Nrf2 \& c-Jun protein activation }\end{array}$ & $0-2.5 \mu \mathrm{M}$ & $\begin{array}{c}\text { Raji: } \\
3.500 \mu \mathrm{M}(24 \mathrm{~h}) \\
0.092 \mu \mathrm{M}(72 \mathrm{~h}) \\
\quad \mathrm{Molt}-4: \\
0.521 \mu \mathrm{M}(24 \mathrm{~h}) \\
\end{array}$ & [38] \\
\hline \multirow[t]{3}{*}{ Breast cancer } & $\begin{array}{l}\text { MCF-7, MDA-MB-231, } \\
\text { SKBR-3, ZR-75-1, BT-474 }\end{array}$ & $\begin{array}{l}\text { Inhibit cell viability and growth: } \downarrow \text { EFGR; } \downarrow \text { MAPK/PI3K pathway activity } \\
\text { Induce apoptosis: } \uparrow \text { PARP protein degradation; } \downarrow \text { caspase- } 8 ; \uparrow \text { Bax proteins } \\
\text { Induce } 1 \text { phase cell cycle arrest: } \downarrow \text { cyclin D1; } \uparrow \text { p21 \& p27 }\end{array}$ & $0-100 \mu \mathrm{M}$ & $\begin{array}{c}\text { MCF-7: } \\
40 \mu \mathrm{M}(24 \mathrm{~h}) \\
\text { MDA-MB-231: } 3 \mu \mathrm{\mu M}(24 \mathrm{~h}) \\
\text { SKBR-3: } \\
29 \mu \mathrm{M}(24 \mathrm{~h}) \\
\text { ZR-75-1: } \\
39 \mu \mathrm{M}(24 \mathrm{~h}) \\
\text { BT-474: } \\
50 \mu \mathrm{M}(24 \mathrm{~h})\end{array}$ & [39] \\
\hline & MCF-7, MDA-MB-231 & 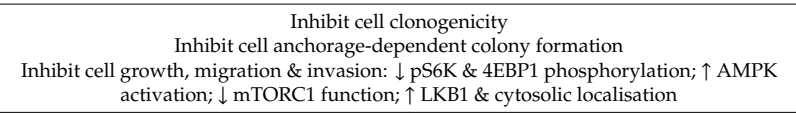 & $1-25 \mu \mathrm{M}$ & N/A & [40] \\
\hline & $\begin{array}{l}\text { MCF-7, MDA-MB-231, } \\
\text { SUM149, SUM159 }\end{array}$ & $\begin{array}{c}\text { Inhibit cell migration \& invasion: } \uparrow \text { AMPK phosphorylation; } \uparrow \text { LKB1 } \\
\text { Inhibit stem-like characteristics: } \downarrow \begin{array}{c}\text { Oct4, Nanog \& Sox4 protein; } \downarrow \text { STAT3; } \downarrow \text { i iPSC inducer } \\
\text { mRNA }\end{array}\end{array}$ & $5 \mu \mathrm{M}$ & N/A & [41] \\
\hline
\end{tabular}


Table 1. Cont.

\begin{tabular}{|c|c|c|c|c|}
\hline Cell Lines & Mechanism of Action & Concentration Used & Efficacy/IC S0 $_{50}$ (Exposure Time) & References \\
\hline $\begin{array}{l}\text { MCF-7, MDA-MB-231, } \\
\text { T47D, SKBR-3, Zr-75, } \\
\text { BT-474 }\end{array}$ & $\begin{array}{c}\text { Inhibit cell growth: } \downarrow \text { PIJK/Akt/mTOR signalling } \\
\text { Inhibit cell invasion } \\
\text { Induce G0/G1 phase cell cycle arrest: } \downarrow \text { cyclin D1 \& cyclin E; } \downarrow \downarrow \text { Cdk2 \& c-myc; } \uparrow \text { PTEN } \\
\text { Induce apoptosis: } \uparrow \text { caspase- } 3 \text {, caspase-6 \& caspase-9 activation }\end{array}$ & $0-40 \mu \mathrm{M}$ & $\begin{array}{c}\text { MCF7: } \\
34.9 \mu \mathrm{M}(24 \mathrm{~h}) \\
13.7 \mu \mathrm{M}(48 \mathrm{~h}) \\
13.5 \mu \mathrm{M}(72 \mathrm{~h}) \\
10.5 \mu \mathrm{M}(96 \mathrm{~h}) \\
\text { MDA-MB-231: } \\
56.9 \mu \mathrm{M}(24 \mathrm{~h}) \\
44.4 \mu \mathrm{M}(48 \mathrm{~h}) \\
16.0 \mu \mathrm{M}(7 \mathrm{~h}) \\
12.0 \mu \mathrm{M}(96 \mathrm{~h}) \\
\mathrm{T}) \\
477 \mathrm{D}: \\
47.7 \mu \mathrm{M}(24 \mathrm{~h}) \\
41.6 \mu \mathrm{M}(48 \mathrm{~h}) \\
17.6 \mu \mathrm{M}(72 \mathrm{~h}) \\
7.1 \mu \mathrm{M}(96 \mathrm{~h}) \\
\mathrm{SKBR}-3: \\
76.1 \mu \mathrm{M}(24 \mathrm{~h}) \\
68.1 \mu \mathrm{M}(48 \mathrm{~h}) \\
62.7 \mu \mathrm{M}(72 \mathrm{~h}) \\
15.7 \mu \mathrm{M}(96 \mathrm{~h}) \\
\mathrm{ZR}-75: \\
71.1 \mu \mathrm{M}(24 \mathrm{~h}) \\
58.1 \mu \mathrm{M}(48 \mathrm{~h}) \\
28.7 \mu \mathrm{M}(72 \mathrm{~h}) \\
14.5 \mu \mathrm{M}(96 \mathrm{~h}) \\
\mathrm{BT}-474: \\
80.2 \mu \mathrm{M}(24 \mathrm{~h}) \\
65.6 \mu \mathrm{M}(48 \mathrm{~h}) \\
39.5 \mu \mathrm{M}(72 \mathrm{~h}) \\
15.1 \mu \mathrm{M}(96 \mathrm{~h})\end{array}$ & [42] \\
\hline MDA-MB-231 & 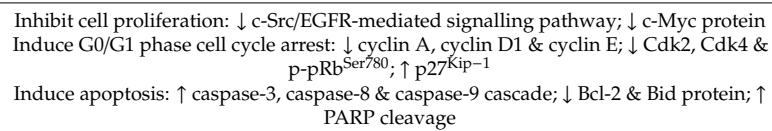 & $0-100 \mu \mathrm{M}$ & $59.5 \mu \mathrm{M}(72 \mathrm{~h})$ & [43] \\
\hline
\end{tabular}


Table 1. Cont.

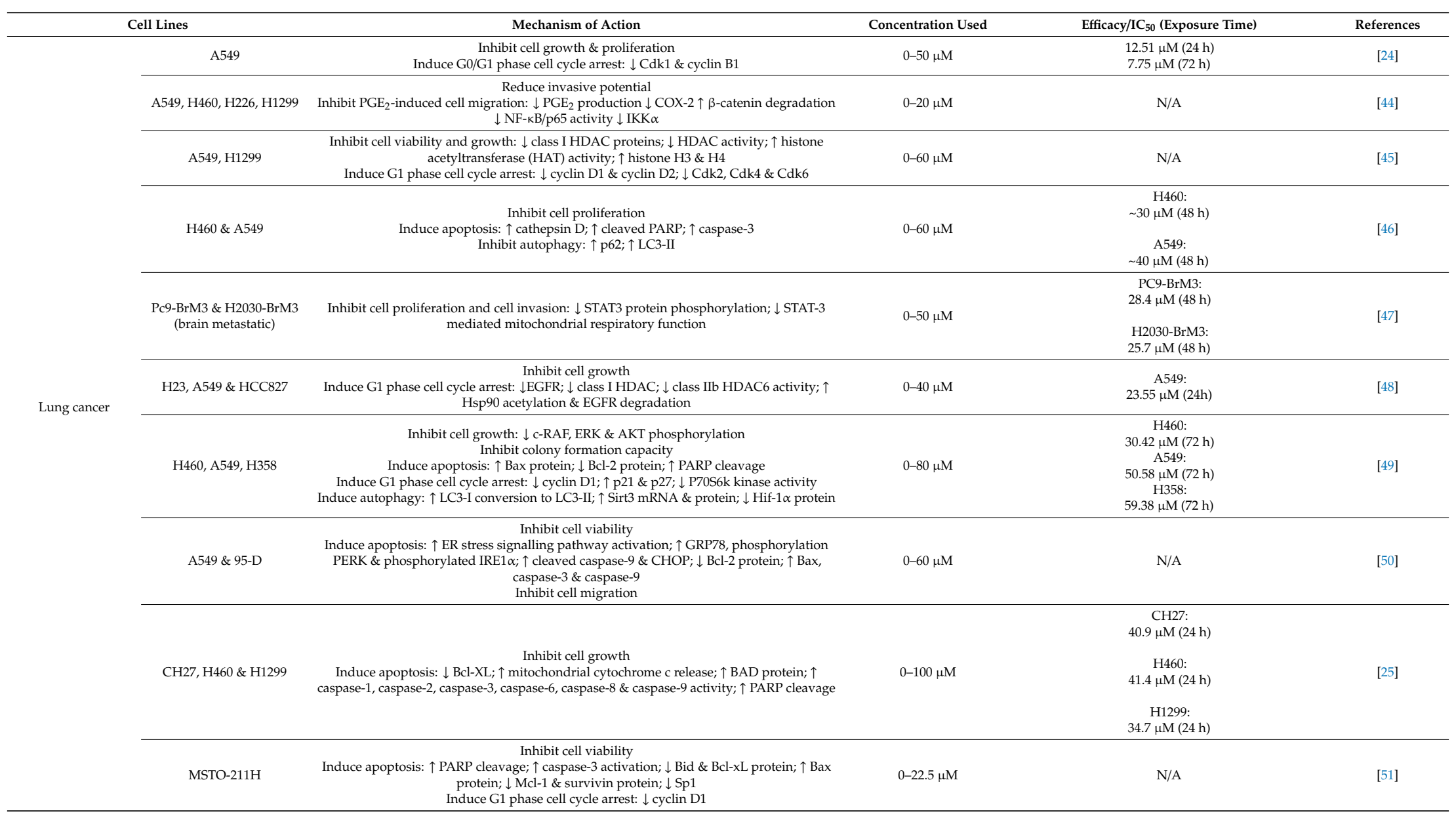


Table 1. Cont.

\begin{tabular}{|c|c|c|c|c|c|}
\hline & $\begin{array}{l}\text { Cell Lines } \\
\end{array}$ & Mechanism of Action & Concentration Used & Efficacy//IC 50 (Exposure Time) & References \\
\hline \multirow{7}{*}{ Skin cancer } & SK-MEL2 \& MeWo & $\begin{array}{l}\text { Inhibit cell growth \& cell proliferation } \\
\text { Induce apoptosis via DNA degradation } \\
\text { Induce cell death via mitochondrial depolarization }\end{array}$ & $0-100 \mu \mathrm{M}$ & N/A & [52] \\
\hline & A431 & $\begin{array}{l}\text { Inhibit cell viability \& proliferation } \\
\text { Induce G0/G1 phase cell cycle arrest: } \downarrow \text { cyclin } \mathrm{A} \text {, cyclin D1, cyclin D2 \& cyclin E; } \downarrow \text { Cdk2, } \\
\text { Cdkk \& C Cdk6; p21 \& p27 } \\
\text { Induce cell apoptosis: } \uparrow \text { PARP }\end{array}$ & $0-75 \mu \mathrm{M}$ & N/A & [53] \\
\hline & B16-F10 & $\begin{array}{c}\text { Inhibit cell proliferation } \\
\text { Induce cell death: } \uparrow \text { Autophagosome (vacuoles) formation; } \downarrow \text { cyclin D1; } \downarrow \text { AKT/mTOR \& } \\
\text { Notch signalling }\end{array}$ & $0-50 \mu \mathrm{M}$ & N/A & [54] \\
\hline & B16/F-10 \& SKMEL-28 & $\begin{array}{c}\text { Inhibit cell proliferation \& viability: } \downarrow \text { Notch signalling; } \downarrow \text { TACE \& } \gamma \text {-secretase complex } \\
\text { proteins } \\
\text { Inhibit clonogenicity } \\
\text { Induce G/G/1 phase cell cycle arrest } \\
\text { Induce autophagy: } \uparrow \text { autophagosome formation; } \uparrow \text { LC3B cleavage } \\
\text { Inhibit cell stemness: } \downarrow \text { CD271, CD166, Jarid1B \& ABCB5 }\end{array}$ & $0-60 \mu \mathrm{M}$ & N/A & [55] \\
\hline & UACC903 & Inhibit cell growth \& proliferation & $0-50 \mu \mathrm{M}$ & $\begin{array}{l}7.45 \mu \mathrm{M}(24 \mathrm{~h}) \\
5.10 \mu \mathrm{M}(72 \mathrm{~h})\end{array}$ & [24] \\
\hline & SKMEL-2 & $\begin{array}{c}\text { Inhibit cell proliferation \& viability } \\
\text { Induce apoptotic death: } \uparrow \text { caspase- } 3 \text {, caspase- } 6 \text {, caspase-8 \& caspase-9; } \uparrow \text { PARP cleavage; } \downarrow \\
\text { procaspase-3, procaspase-8 \& procaspase-9 } \downarrow \\
\text { Induce G2/M phase cell cycle arrest: } \downarrow \text { cyclin B1, cyclin D1, cyclin D2 \& PCNA; } \downarrow \text { C Cdk2 \& } \\
\text { Cdk4 } 4 \uparrow \uparrow \text { p 21 \& p53 }\end{array}$ & $0-100 \mu \mathrm{M}$ & N/A & [56] \\
\hline & UACC- 62 & 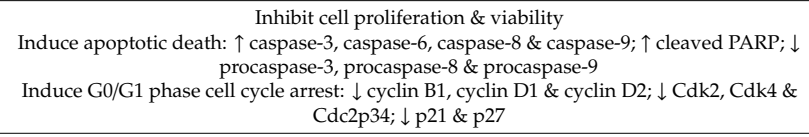 & $0-100 \mu \mathrm{M}$ & N/A & [56] \\
\hline Renal cancer & A498 & $\begin{array}{c}\text { Inhibit cell proliferation } \\
\text { Inhibit colony formation capability } \\
\text { Inhibitit cell migration and invasion: } \downarrow \text { Epithelial-mesenchymal transition (EMT); } \downarrow \downarrow \text { cancer } \\
\text { stem cells (CSC) properties; } \uparrow \text { miR-141; } 1 \downarrow \text { ZEBB2 } \\
\text { Inhibitit tumoursphere formation }\end{array}$ & $0-80 \mu \mathrm{M}$ & $\sim 12 \mu \mathrm{M}(72 \mathrm{~h})$ & [57] \\
\hline Cervix cancer & $\begin{array}{l}\text { KB-3-1, KB-8-5, KB-C1, } \\
\text { KB-V1 }\end{array}$ & $\begin{array}{l}\text { Inhibit cell viability: } \downarrow \text { EGFR-STAT3 signalling } \\
\text { Induce mitochondria-dependent \& death receptor-dependent apoptosis: } \downarrow \text { Bcl-2, Mcl-1 \& } \\
\text { survivin; } \uparrow \text { PARP \& caspase-3 cleavage; } \uparrow \text { mitochondrial release of cytochrome c; } \uparrow \text { DR5 } \\
\text { Enhances in vitro cytotoxicity of Paclitaxel }\end{array}$ & $0-75 \mu \mathrm{M}$ & $\begin{array}{c}\text { KB-3-1: } \\
12.56 \mu \mathrm{M}(72 \mathrm{~h}) \\
\text { KB-8-5: } \\
12.08 \mu \mathrm{M}(72 \mathrm{~h}) \\
\mathrm{KB}-\mathrm{Cl}: \\
11.40 \mu \mathrm{M}(72 \mathrm{~h}) \\
\mathrm{KB}-\mathrm{V} 1: \\
10.39 \mu \mathrm{M}(72 \mathrm{~h}) \\
\end{array}$ & [31] \\
\hline
\end{tabular}


Table 1. Cont.

\begin{tabular}{|c|c|c|c|c|c|}
\hline \multirow[b]{3}{*}{ Pancreatic cancer } & 11 Lines & \multirow{2}{*}{$\begin{array}{c}\text { Mechanism of Action } \\
\text { Suppress plating efficiency of cells } \\
\text { Reduce anchorage-independent clonogenicity growth } \\
\text { Suppress migration and invasion ability }\end{array}$} & \multirow{2}{*}{$\begin{array}{c}\text { Concentration Used } \\
0-5 \mu \mathrm{M}\end{array}$} & \multirow{2}{*}{$\begin{array}{c}\text { Efficacy/IC } 50 \text { (Exposure Time) } \\
\mathrm{N} / \mathrm{A}\end{array}$} & \multirow{2}{*}{$\begin{array}{c}\text { References } \\
{[58]}\end{array}$} \\
\hline & MiaPaCa \& Colo-357 & & & & \\
\hline & MiaPaCa \& Panc1 & $\begin{array}{l}\text { Inhibit cell growth } \\
\text { Induce G1 phase cell cycle arrest: } \downarrow \text { cyclin D1 \& cyclin E; } \downarrow \text { Cdk2 \& Cdk4; } \uparrow \text { p21 \& p } 27 \\
\text { Induce apoptosis: } \downarrow \text { Bcl-2 \& Bcl-rL proteins } ; \text { Bax protein; } \downarrow \text { IKB- } \alpha \text { phosphorylation; } \downarrow \\
\text { NF-kB constitutive activation }\end{array}$ & $0-60 \mu \mathrm{M}$ & $\begin{array}{c}\text { MiaPaCa: } \\
43.25 \mu \mathrm{M}(24 \mathrm{~h}) \\
31.08 \mu \mathrm{M}(48 \mathrm{~h}) \\
18.54 \mu \mathrm{M}(72 \mathrm{~h}) \\
\quad \text { Panc1: } \\
47.44 \mu \mathrm{M}(24 \mathrm{~h}) \\
34.17 \mathrm{MM}(48 \mathrm{~h}) \\
21.86 \mu \mathrm{M}(72 \mathrm{~h}) \\
\end{array}$ & [59] \\
\hline Thyroid cancer & ARO, WRO & $\begin{array}{c}\text { Inhibit cell growth \& proliferation: } \downarrow \text { ERK, JNK \& } \mathrm{p} 37 \text { activation and expression; } \downarrow \text { mTOR \& } \\
\text { p7006 } \\
\text { Inhibit colony formation } \\
\text { Induce apoptosis: } \uparrow \text { PARP cleavage; } \uparrow \text { caspase-3, caspase-8 \& PARP activation; } \downarrow \text { PI3K/AKT } \\
\text { \& MAPK pathways } \\
\text { Induce G0/G1 cell cycle arrest: } \downarrow \text { cyclin D1; } \downarrow \text { Cdk2 \& C Cdk4; } \uparrow \text { p21 \& p27 } \\
\text { Induce autophagy \& autophagy flux: } \uparrow \text { LC3-II }\end{array}$ & $\begin{array}{l}\text { ARO \& WRO: } \\
\text { 0-60 } \mu \mathrm{M} \\
\text { SW579: } \\
0-40 \mu \mathrm{M}\end{array}$ & $\begin{array}{c}\text { ARO: } \\
36.3 \mu \mathrm{M}(24 \mathrm{~h}) \\
40.1 \mu \mathrm{M}(48 \mathrm{~h}) \\
44.8 \mu \mathrm{M}(72 \mathrm{~h}) \\
\text { WRO: } \\
37.7 \mu \mathrm{M}(24 \mathrm{~h}) \\
31.8 \mu \mathrm{M}(48 \mathrm{~h}) \\
30.7 \mu \mathrm{M}(72 \mathrm{~h}) \\
\mathrm{SW} 579: \\
19.9 \mu \mathrm{M}(24 \mathrm{~h}) \\
10.5 \mu \mathrm{M}(48 \mathrm{~h}) \\
8.8 \mu \mathrm{M}(72 \mathrm{~h})\end{array}$ & [60] \\
\hline $\begin{array}{l}\text { Nasopharyngeal } \\
\text { cancer }\end{array}$ & HNE-1 & $\begin{array}{l}\text { Inhibit cell growth } \\
\text { Induce apoptosis } \\
\text { Induce G1 phase cell cycle arrest }\end{array}$ & $\begin{array}{c}0-150 \mu \mathrm{M}(\text { Honokiol \& } \\
\text { ATNH }- \text { Active targeting } \\
\text { nanoparticles-loaded } \\
\text { honokiol) }\end{array}$ & $\begin{array}{c}\text { Honokiol: } \\
144.71 \mu \mathrm{M}(24 \mathrm{~h}) \\
\text { ATNH: } \\
69.04 \mu \mathrm{M}(24 \mathrm{~h}) \\
\end{array}$ & [30] \\
\hline \multirow{4}{*}{ Brain cancer } & U251 & $\begin{array}{l}\text { Inhibit cell growth } \\
\text { Inhibit cell proliferation } \\
\text { Induce apoptosis } \\
\end{array}$ & $0-120 \mu \mathrm{M}$ & $61.43 \mu \mathrm{M}(24 \mathrm{~h})$ & [61] \\
\hline & T98G & $\begin{array}{c}\text { Inhibit cell viability } \\
\text { Inhibit cell invasion } \\
\text { Induce cell apoptosis: } \uparrow \text { Bax protein; } \downarrow \text { Bcl-2; } \uparrow \text { Bax/Bcl-2 ratio } \\
\end{array}$ & $0-50 \mu \mathrm{M}$ & N/A & [62] \\
\hline & $\begin{array}{l}\text { GBM8401 (Parental) \& } \\
\text { GBM8401 SP }\end{array}$ & $\begin{array}{l}\text { Inhibit cell proliferation \& viability } \\
\text { Induce sub-G1 phase cell cycle arrest } \\
\text { Induce apoptosis: } \downarrow \text { Notch3/Hes1 pathway }\end{array}$ & $0-20 \mu \mathrm{M}$ & $\begin{array}{l}\text { GBM8401 (Parental): } \\
5.30 \mu \mathrm{M}(48 \mathrm{~h}) \\
\text { GBM8401 SP: } \\
11.20 \mu \mathrm{M}(48 \mathrm{~h})\end{array}$ & [36] \\
\hline & U251 \& U-87 MG & $\begin{array}{c}\text { Inhibit cell viability \& proliferation: } \downarrow \text { PI3K/Akt \& MAPK/Erk signalling pathways } \\
\text { Inhibit cell invasion \& migration: } \downarrow \text { MMP2 \& MMP9; } \downarrow \text { NF-kB-mediated E-cadherin } \\
\text { pathway } \\
\text { Inhibit colony formation } \\
\text { Induce apoptosis: } \downarrow \text { Bcl-2, p-AKT \& p--ERK; } ; \text { Fax protein; } \uparrow \text { caspase-3 cleavage; } \downarrow \\
\text { EGFR-STAT3 signalling } \\
\text { Reduce spheroid formation: } \downarrow \text { CD133 \& Nestin protein }\end{array}$ & $0-60 \mu \mathrm{M}$ & $\begin{array}{l}\text { U251: } \\
54.00 \mu \mathrm{M}(24 \mathrm{~h}) \\
\text { U-87 MG: } \\
62.50 \mu \mathrm{M}(24 \mathrm{~h})\end{array}$ & [63] \\
\hline
\end{tabular}


Table 1. Cont.

\begin{tabular}{|c|c|c|c|c|c|}
\hline \multicolumn{2}{|c|}{ Cell Lines } & Mechanism of Action & Concentration Used & Efficacy/IC $\mathrm{IC}_{50}$ (Exposure Time) & References \\
\hline & DBTRG-05MG & $\begin{array}{c}\text { Inhibit cell growth } \\
\text { Induce apoptosis: } \downarrow \text { Rb protein; } \uparrow \text { PARP \& Bcl-x(S/L) cleavage } \\
\text { Induce autophagy: } \uparrow \text { Beclin-1 \& LC3-II }\end{array}$ & $0-50 \mu \mathrm{M}$ & $\sim 30 \mu \mathrm{M}$ & [64] \\
\hline & $\begin{array}{l}\text { U87 MG (Human) } \\
\text { BMEC (Mouse) }\end{array}$ & 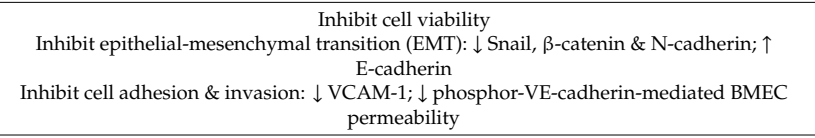 & $0-20 \mu \mathrm{M}$ & $\begin{array}{c}\text { U87MG: } \\
22.66 \mu \mathrm{M}(24 \mathrm{~h}) \\
\text { BMEC: } \\
13.09 \mu \mathrm{M}(24 \mathrm{~h}) \\
\end{array}$ & [65] \\
\hline & U87 MG & 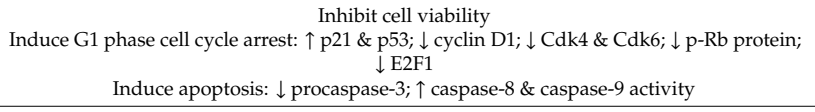 & $0-100 \mu \mathrm{M}$ & $52.70 \mu \mathrm{M}$ & [66] \\
\hline \multirow{3}{*}{ Bone cancer } & HOS \& U20S & $\begin{array}{c}\text { Inhibit cell proliferation } \\
\text { Inhibit tolony formation } \\
\text { Induce G0/G1 phase cell cycle arrest: } \downarrow \text { cyclin D1 \& cyclin E; } ; \downarrow \text { Cdk4 } \\
\text { Induce mitochondria-mediated apoptosis: } \uparrow \text { caspase- } 3 \& \text { caspase-9 activation; } \uparrow \text { PARP } \\
\text { cleavage; } \downarrow \text { Bcl-2, Bcl-xL \& survivini; } \uparrow \text { ERK activation; } \downarrow \text { p proteasome activity; } \uparrow \text { ER stress } \\
\text { and subsequent ROS overgeneration; } \uparrow \text { GRP78 } \\
\text { Induce autophagy: } \uparrow \text { Atg7 protein activation; } \uparrow \text { Atg5; } \uparrow \text { LC3B-II }\end{array}$ & $0-30 \mu \mathrm{M}$ & $\begin{array}{l}\text { HOS: } \\
17.70 \mu \mathrm{M}(24 \mathrm{~h}) \\
\text { U20S: } \\
21.50 \mu \mathrm{M}(24 \mathrm{~h})\end{array}$ & [67] \\
\hline & $\begin{array}{l}\text { SAOS-2, HOS, 143B, } \\
\text { MG-63 M8, HU09, HU09 } \\
\text { M132 } \\
\text { Dunn, LM5, LM8 \& } \\
\text { LM8-LacZ (Mouse) }\end{array}$ & $\begin{array}{l}\text { Inhibit cell metabolic activity } \\
\text { Inhibit cell proliferation } \\
\text { Inhibit cell migration } \\
\text { Induce rapid cell death via Honokiol-provoked vacuolation }\end{array}$ & $0-150 \mu \mathrm{M}$ & 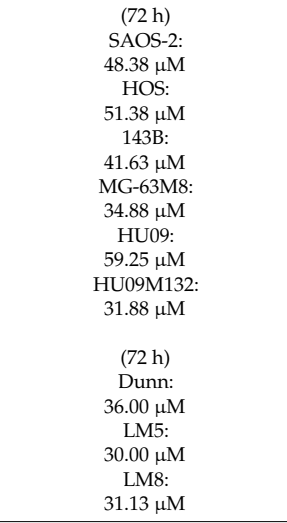 & [68] \\
\hline & Saos-2 \& MG-63 & $\begin{array}{c}\text { Inhibit cell viability } \\
\text { Induce apoptosis: } \uparrow \text { caspase-3 \& PARP cleavage; } \uparrow \text { Bax protein; } \downarrow \text { Bcl-2; } \downarrow \text { PI3K/AKT } \\
\text { signalling pathway; } \downarrow \text { miR-21 }\end{array}$ & 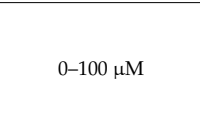 & $\begin{array}{c}\text { Saos-2: } \\
37.85 \mu \mathrm{M}(24 \mathrm{~h}) \\
\text { MG-63: } \\
38.24 \mu \mathrm{M}(24 \mathrm{~h})\end{array}$ & [69] \\
\hline
\end{tabular}


Table 1. Cont.

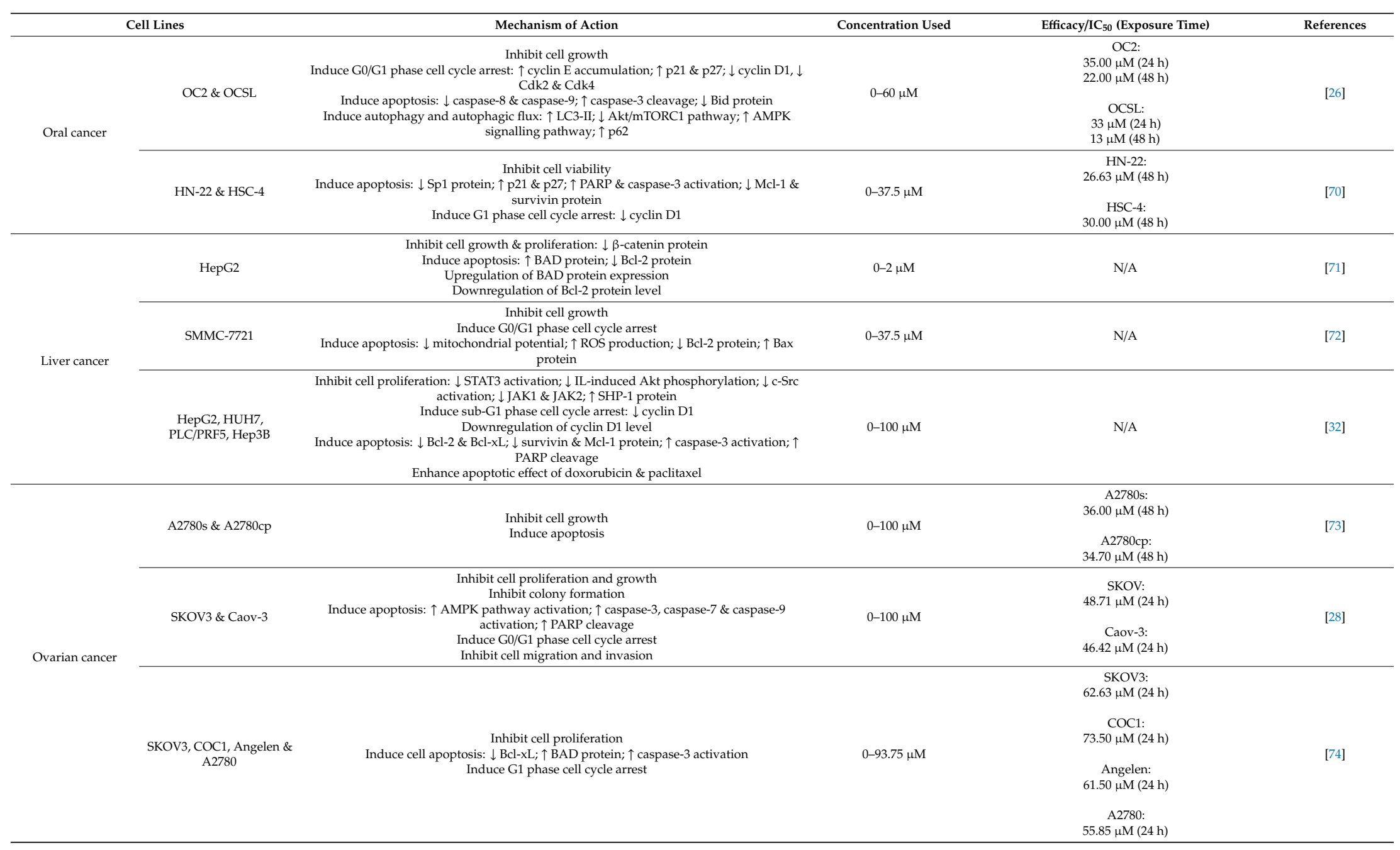


Table 1. Cont.

\begin{tabular}{|c|c|c|c|c|c|}
\hline & Lines & Mechanism of Action & Concentration Used & Efficacy/II ${ }_{50}$ (Exposure Time) & References \\
\hline \multirow{3}{*}{ Prostate cancer } & PC-3 \& LNCaP & 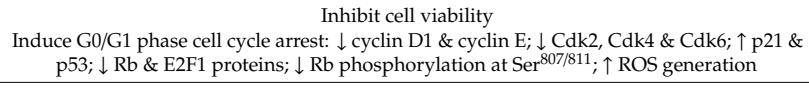 & $0-60 \mu \mathrm{M}$ & N/A & [75] \\
\hline & PC-3, LNCaP \& C4-2 & $\begin{array}{l}\text { Inhibit cell growth } \\
\text { Induce apoptosis: } \uparrow \text { caspase-3, caspase-8 \& caspase-9 activation; } \uparrow \text { PARP cleavage } \\
\text { Induce apoptosis via DNA fragmentation: } \uparrow \text { Bax \& Bak proteins; } \downarrow \text { Mcl-1 } 1 \text { protein } \\
\end{array}$ & $0-75 \mu \mathrm{M}$ & $18.75-37.50 \mu \mathrm{M}(24 \mathrm{~h})$ & [76] \\
\hline & PC-3, LNCaP & $\begin{array}{c}\text { Inhibit cell viability } \\
\text { Induce autophagy: } \uparrow \text { LC3-BII protein; } \downarrow \text { mTOR pathway } \\
\text { Induce apoptosis via DNA fragmentation: } \uparrow \text { ROS generation }\end{array}$ & $0-40 \mu \mathrm{M}$ & N/A & [77] \\
\hline $\begin{array}{l}\text { Head \& neck } \\
\text { squamous cancer }\end{array}$ & Cal-33 \& MD-1483 & $\begin{array}{l}\text { Inhibit cell growth } \\
\text { Induce cell apoptosis and cell cycle arrest: } \downarrow \text { GEFR signalling pathway; } \downarrow \text { STAT3 signalling } \\
\text { pathway; } \downarrow \text { Bcl-xL \& cyclin D1 } \downarrow \text { phosphorylation p } 22 / \text { p } 44 \text { MAPK \& phosphorylated Akt }\end{array}$ & $0-100 \mu \mathrm{M}$ & $\begin{array}{c}\text { Cal-33: } \\
3.80 \mu \mathrm{M}(72 \mathrm{~h}) \\
1483: \\
7.44 \mu \mathrm{M}(72 \mathrm{~h}) \\
\end{array}$ & [78] \\
\hline \multirow[b]{2}{*}{ Neuroblastoma } & Neuro-2a & $\begin{array}{c}\text { Induce apoptosis via DNA fragmentation: } \uparrow \text { caspase- } 3 \text {, caspase- } 6 \text { \& caspase-9 activation; } \uparrow \uparrow \\
\text { Bax protein; } \downarrow \text { mitochondrial membrane potentiali; } \uparrow \text { cytochrome c releaselnduce sub-G1 } \\
\text { phase cell cycle arrest }\end{array}$ & $0-100 \mu \mathrm{M}$ & $63.3 \mu \mathrm{M}(72 \mathrm{~h})$ & [79] \\
\hline & Neuro-2a \& NB41A33 & $\begin{array}{c}\text { Inhibit cell viability } \\
\text { Induce autophagy: } \uparrow \text { LCB-II; } \uparrow \text { PI3K/Akt/mTOR signalling pathway; } \uparrow \text { Grp78; } \uparrow \text { ROS } \\
\text { generation; } \uparrow \text { ERK1/2; } \uparrow \text { p-EKK1IInduce apoptosis via DNA fragmentation } \\
\text { Inhibit cell migration }\end{array}$ & $0-100 \mu \mathrm{M}$ & $\begin{array}{c}\text { Neuro-2a: } \\
\sim 50 \mu \mathrm{M}(72 \mathrm{~h})\end{array}$ & [80] \\
\hline Bladder cancer & $\mathrm{T} 24 \& 5637$ & 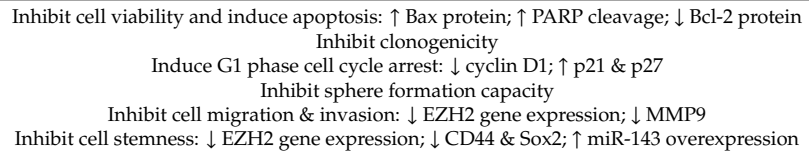 & $0-72 \mu \mathrm{M}$ & N/A & [81] \\
\hline
\end{tabular}




\subsection{In Vivo Studies}

Based on the in vivo studies, honokiol possessed the capability to inhibit tumour growth, metastasis, and angiogenesis using different animal models, as shown in Table 2. The degree of tumour inhibition was shown to be significantly effective against each distinct cancer cell line, ranging from 0-150 mg/kg via various delivery methods of honokiol between oral gavage or injection (intraperitoneal, caudal vein, or intravenous). Honokiol was shown to downregulate the expression of Oct4, Nanog, and Sox 2 which were known to be expressed in osteosarcoma, breast carcinoma and germ cell tumours [41]. According to Wang et al.'s study, they have found that the average tumour size was significantly lower than the control group without affecting their body weight, suggesting inconsequential toxicity under tested conditions when treated with a combination of honokiol and paclitaxel [31]. Indisputably, honokiol was once again proven to exhibit minor to no toxicity against normal cells.

Over the years, the development of chemo-resistance in ovarian cancer cells has hindered the outcome of treatment regimen towards ovarian cancer [82]. Despite the effectiveness of honokiol to inhibit cancer cell proliferation, delivering effective concentration towards the tumour site was deemed challenging due to its water insolubility [73]. The encapsulation of honokiol in liposome, namely Lipo-HNK by Luo and his team has displayed substantial efficacy against cisplatin-resistance ovarian cancer cell line A2780cp. The tumour volume for Lipo-HNK treated mice was $408 \pm 165$ $\mathrm{mm}^{3}$ compared to liposome-treated mice and control mice were $2575 \pm 701 \mathrm{~mm}^{3}$ and $2828 \pm 796 \mathrm{~mm}^{3}$ respectively after 21 days [73]. In addition, Lipo-HNK was also shown to prolong survival and induce intra-tumoral apoptosis in vivo. The promising in vivo properties of honokiol should consolidate its importance as a potential anticancer agent for future researches.

Zebrafish (Danio rerio) model has emerged as a newly important cancer model that complements against traditional cell culture assays and mice model due to its small size, heavy brood, and rapid maturation time. Importantly, its transparent body wall enables visibility of tumour progression and the ease of experimentation $[83,84]$. It was known that juvenile zebrafish (Danio rerio) or zebrafish embryos have the competency to study cancer cell invasion, metastasis, tumour-induced angiogenesis. Honokiol reduced U-87 MG human glioma/glioblastoma cell proliferation and migration in zebrafish yolk sac and in vivo xenograft nude mouse model [63]. These observations are associated with a reduction in EGFR, phosphorylated STAT3, CD133 and Nestin levels, thus highlighting the regulation of honokiol in EGFR-mediated STAT3/JAK signalling pathway to induce anti-tumour and anti-metastasis.

The subsections below will further discuss the mechanism of anticancer actions of honokiol including the induction of cancer cell death, inhibition of cell cycle progression, induction of autophagy, prevention of epithelial-mesenchymal transition (EMT), as well as the suppression of migration, invasion, and angiogenesis of cancer cells. 
Table 2. The antitumour effect of honokiol in in vivo tumour bearing animal models.

\begin{tabular}{|c|c|c|c|c|c|}
\hline Cancer Cell Line & $\begin{array}{l}\text { Animal Model \& Site of } \\
\text { Tumour Xenograft }\end{array}$ & Dose, Duration \& Route of Administration & $\begin{array}{l}\text { Observation \& Mechanism of } \\
\text { Action }\end{array}$ & Efficacy on Tumour Inhibition & References \\
\hline \multicolumn{6}{|c|}{ Breast cancer } \\
\hline MDA-MB-231 cells & $\begin{array}{l}\text { Both flanks of athymic } \\
\text { nude mice }\end{array}$ & $\begin{array}{l}100 \mathrm{mg} / \mathrm{kg} / \text { day } \\
28 \text { days } \\
\text { IP }\end{array}$ & Induce tumour growth arrest & $\begin{array}{l}\text { Complete arrest of tumour growth from } \\
\text { week } 2 \text { onwards }\end{array}$ & [39] \\
\hline MDA-MB-231 cells & $\begin{array}{l}\text { Right gluteal region of } \\
\text { athymic nude mice }\end{array}$ & $\begin{array}{c}3 \mathrm{mg} / \text { mouse/day } \\
\text { Three times a week } \\
28 \text { days } \\
\text { IP }\end{array}$ & $\begin{array}{c}\text { Inhibit tumour progression: } \\
\downarrow \text { Ki-67; } \uparrow \text { LKB1 \& pAMPK; } \uparrow \text { ACC } \\
\text { phosphorylation, } \downarrow \text { pS6K \& } 4 \text { EBP1 } \\
\text { phosphorylation } \\
\end{array}$ & $\begin{array}{c}\text { Tumour weight of honokiol-treated group } \\
\text { was } 0.22 \mathrm{~g} \text { compared to control group which } \\
\text { was } 1.58 \mathrm{~g}\end{array}$ & [40] \\
\hline $\begin{array}{l}\text { MDA-MB-231-pLKO.1 \& } \\
\text { MDA-MB-231-LKB1 } \\
\text { shRNA cells }\end{array}$ & $\begin{array}{l}\text { Right gluteal region of } \\
\text { athymic nude mice }\end{array}$ & $\begin{array}{c}3 \mathrm{mg} / \mathrm{mouse} / \text { day } \\
\text { Three times a week } \\
42 \text { days } \\
\text { Oral gavage }\end{array}$ & $\begin{array}{l}\text { Inhibit cell stemness: } \downarrow \text { Oct4, Nanog \& } \\
\text { Sox2; } \downarrow \text { pSTAT3 \& Ki-67 } \\
\text { Inhibit mammosphere formation }\end{array}$ & $\begin{array}{l}\text { Decreased expression of Oct4, Nanog, Sox2 } \\
\text { Reduce number of tumour cells showing } \\
\text { Ki-67 \& pStat3 expression }\end{array}$ & [41] \\
\hline \multicolumn{6}{|c|}{ Colorectal cancer } \\
\hline RKO cells & $\begin{array}{l}\text { Axilla of BALB/c nude } \\
\text { mice }\end{array}$ & $\begin{array}{c}80 \mathrm{mg} / \mathrm{kg} / \mathrm{day} \\
\text { Treatment on days } 8-11,14-17,21-24,28-31 \\
51 \text { days } \\
\text { IP }\end{array}$ & $\begin{array}{l}\text { Inhibit tumour growth } \\
\text { Prolong survival of mice }\end{array}$ & $\begin{array}{l}\text { 709.9\% increase in tumour growth rate in } \\
\text { honokiol-treated group compared to } 1627.6 \% \\
\text { and } 1408.2 \% \text { in control and vehicle groups } \\
\text { respectively }\end{array}$ & [33] \\
\hline HCT116 cells & $\begin{array}{l}\text { Flank of athymic nude } \\
\text { mice }\end{array}$ & $\begin{array}{c}200 \mu \mathrm{g} / \mathrm{kg} / \text { day }+5 \mathrm{~Gy} \text { irradiation } \\
\text { Once a week } \\
21 \text { days } \\
\text { IP } \\
\end{array}$ & $\begin{array}{c}\text { Inhibit tumour growth: } \downarrow \text { CSC } \\
\text { proteins } \rightarrow \downarrow \text { DCLK1, Sox-9, CD133 \& } \\
\text { CD44 }\end{array}$ & $\begin{array}{l}\text { Significantly lower tumour weight }(<800 \mathrm{mg}) \\
\text { in honokiol-IR combination, }(\sim 1500 \mathrm{mg}) \text { in } \\
\text { honokiol treatment group compared to } \\
(\sim 3300 \mathrm{mg}) \text { in control group }\end{array}$ & [35] \\
\hline \multicolumn{6}{|c|}{ Lung cancer } \\
\hline H2030-BrM3 cells & $\begin{array}{l}\text { Left ventricle of } \\
\text { NOD/SCID mice }\end{array}$ & $\begin{array}{c}2 \text { or } 10 \mathrm{mg} / \mathrm{kg} / \text { day } \\
28 \text { days } \\
\text { Oral gavage }\end{array}$ & $\begin{array}{l}\text { Prevent metastasis of lung cancer cells } \\
\text { to brain }\end{array}$ & $\begin{array}{c}10 \mathrm{mg} / \mathrm{kg} \text { : Decrease brain metastasis for } \\
\qquad>70 \%\end{array}$ & [47] \\
\hline H2030-BrM3 cells & $\begin{array}{l}\text { Left lung via left ribcage } \\
\text { of athymic nude mice }\end{array}$ & $\begin{array}{c}2 \text { or } 10 \mathrm{mg} / \mathrm{kg} / \text { day } \\
\text { Five days a week } \\
28 \text { days } \\
\text { Oral gavage }\end{array}$ & $\begin{array}{l}\text { Decrease lung tumour growth } \\
\text { Inhibit metastasis to lymph node }\end{array}$ & $\begin{array}{l}10 \mathrm{mg} / \mathrm{kg} \text { : Significantly reduce incidence of } \\
\text { mediastinal adenopathy, decrement of } \\
\text { weight of mediastinal lymph node for }>80 \% \text {, } \\
\text { only } 2 / 6 \text { mice have lymphatic metastasis }\end{array}$ & [47] \\
\hline
\end{tabular}


Table 2. Cont.

\begin{tabular}{|c|c|c|c|c|c|}
\hline Cancer Cell Line & $\begin{array}{c}\text { Animal Model \& Site of } \\
\text { Tumour Xenograft }\end{array}$ & Dose, Duration \& Route of Administration & $\begin{array}{l}\text { Observation \& Mechanism of } \\
\text { Action }\end{array}$ & Efficacy on Tumour Inhibition & References \\
\hline \multicolumn{6}{|c|}{ Blood cancer } \\
\hline Raji cells & Back of BALB/c nude mice & $\begin{array}{c}5 \mathrm{mg} / 20 \mathrm{~g} \& \\
10 \mathrm{mg} / 20 \mathrm{~g} \\
20 \text { days } \\
\text { Treatment on } 15-19 \\
\text { (Route of administration not specified) }\end{array}$ & $\begin{array}{l}\text { Inhibit cell proliferation } \\
\text { Inhibit tumour growth }\end{array}$ & $\begin{array}{l}\text { Tumour growth of honokiol-treated mice } \\
\text { was significantly lower }\left(\sim 90 \mathrm{~cm}^{3}\right) \text { compared } \\
\text { to control mice }\left(\sim 270 \mathrm{~cm}^{3}\right)\end{array}$ & [38] \\
\hline HL60 cells & $\begin{array}{l}\text { Inoculated } \\
\text { intraperitoneally into } \\
\text { SCID mice }\end{array}$ & $\begin{array}{c}100 \mathrm{mg} / \mathrm{kg} / \text { day } \\
\text { Treatment on Day 1-6 } \\
47 \text { days } \\
\text { IP }\end{array}$ & Prolong survival of mice & $\begin{array}{l}\text { Median survival time of honokiol-treated } \\
\text { mice are longer ( } 37.5 \text { days) compared to } \\
\text { vehicle-treated mice ( } 24.5 \text { days) }\end{array}$ & [85] \\
\hline MiaPaCa cells & $\begin{array}{l}\text { Pancreas of } \\
\text { immunocompromised } \\
\text { mice }\end{array}$ & $\begin{array}{l}150 \mathrm{mg} / \mathrm{kg} / \text { day } \\
28 \text { days } \\
\text { IP }\end{array}$ & $\begin{array}{c}\text { Suppress tumour growth } \\
\text { Inhibit metastasis: } \downarrow \text { CXCR \& SHH; } \downarrow \\
\text { NF-kB \& downstream pathway } \\
\text { Inhibit desmoplastic reaction: } \\
\downarrow \text { ECM protein; } \downarrow \text { collagen I }\end{array}$ & $\begin{array}{l}\text { Significant decrease in tumour growth for } \\
\text { honokiol-treated mice }\left(99.6 \mathrm{~mm}^{3}\right) \text { compared } \\
\text { to vehicle-treated mice }\left(1361.0 \mathrm{~mm}^{3}\right)\end{array}$ & [58] \\
\hline \multicolumn{6}{|c|}{ Skin cancer } \\
\hline SKMEL-2 or UACC-62 cells & $\begin{array}{l}\text { Right flank of athymic } \\
\text { nude mice }\end{array}$ & $\begin{array}{c}50 \mathrm{mg} / \mathrm{kg} \\
\text { Three times a week } \\
14-54 \text { days } \\
\text { IP }\end{array}$ & Decrease tumour growth & $\begin{array}{l}\text { SKMEL-2: } \\
40 \% \text { reduction in tumour volume } \\
\text { UACC-62: } \\
50 \% \text { reduction in tumour volume }\end{array}$ & [56] \\
\hline ARO cells & $\begin{array}{l}\text { BALB/CAnN.Cg-Foxn1nu/CrlNa } \\
\text { mice (site of xenograft not } \\
\text { stated) }\end{array}$ & $\begin{array}{c}5 \text { or } 15 \mathrm{mg} / \mathrm{kg} / \text { mouse } \\
\text { Every three days } \\
21 \text { days } \\
\text { Oral gavage }\end{array}$ & $\begin{array}{c}\text { Decrease tumour volume \& tumour } \\
\text { weight } \\
\text { Induce apoptosis \& autophagy }\end{array}$ & $\begin{array}{l}\text { Control: } ~ 1000 \mathrm{~mm}^{3} ; 700 \mathrm{mg} \\
5 \mathrm{mg} / \mathrm{kg} \mathrm{Honokiol:} \\
\sim 600 \mathrm{~mm}^{3} ; 400 \mathrm{mg} \\
15 \mathrm{mg} / \mathrm{kg} \mathrm{Honokiol:}^{3} ; 200 \mathrm{mg}\end{array}$ & [60] \\
\hline \multicolumn{6}{|c|}{ Nasopharyngeal cancer } \\
\hline HNE-1 cells & $\begin{array}{l}\text { Right dorsal aspect of } \\
\text { right foot of BALB/c } \\
\text { athymic nude mice }\end{array}$ & $\begin{array}{l}\text { ctive-targeting nanoparticles-loaded HK (ATNH), } \\
\text { Non-active-targeting nanoparticles-loaded HK } \\
\text { (NATNH), Free Honokiol (HK) } \\
3 \mathrm{mg} / \text { mouse/day } \\
\text { Every three days } \\
\text { Euthanise } 50 \% \text { mice after } 12 \text { days, rest are left to } \\
\text { observe tumour growth \& survival time up to } \\
60 \text { days; } \\
\text { IV }\end{array}$ & $\begin{array}{c}\text { Inhibit tumour progression, Induce } \\
\text { apoptosis } \\
\text { Potential inhibitor of angiogenesis \& } \\
\text { proliferation }\end{array}$ & $\begin{array}{l}\text { Efficiency in tumour delay: } \\
\text { ATNH > NATNH > Free HK } \\
\\
\text { Median survival time: } \\
\text { Control: } 28.5 \text { days } \\
\text { Free HK: } 34 \text { days } \\
\text { NATNH: } 42.5 \text { days } \\
\text { ATNH: } 57.5 \text { days }\end{array}$ & [30] \\
\hline
\end{tabular}


Table 2. Cont.

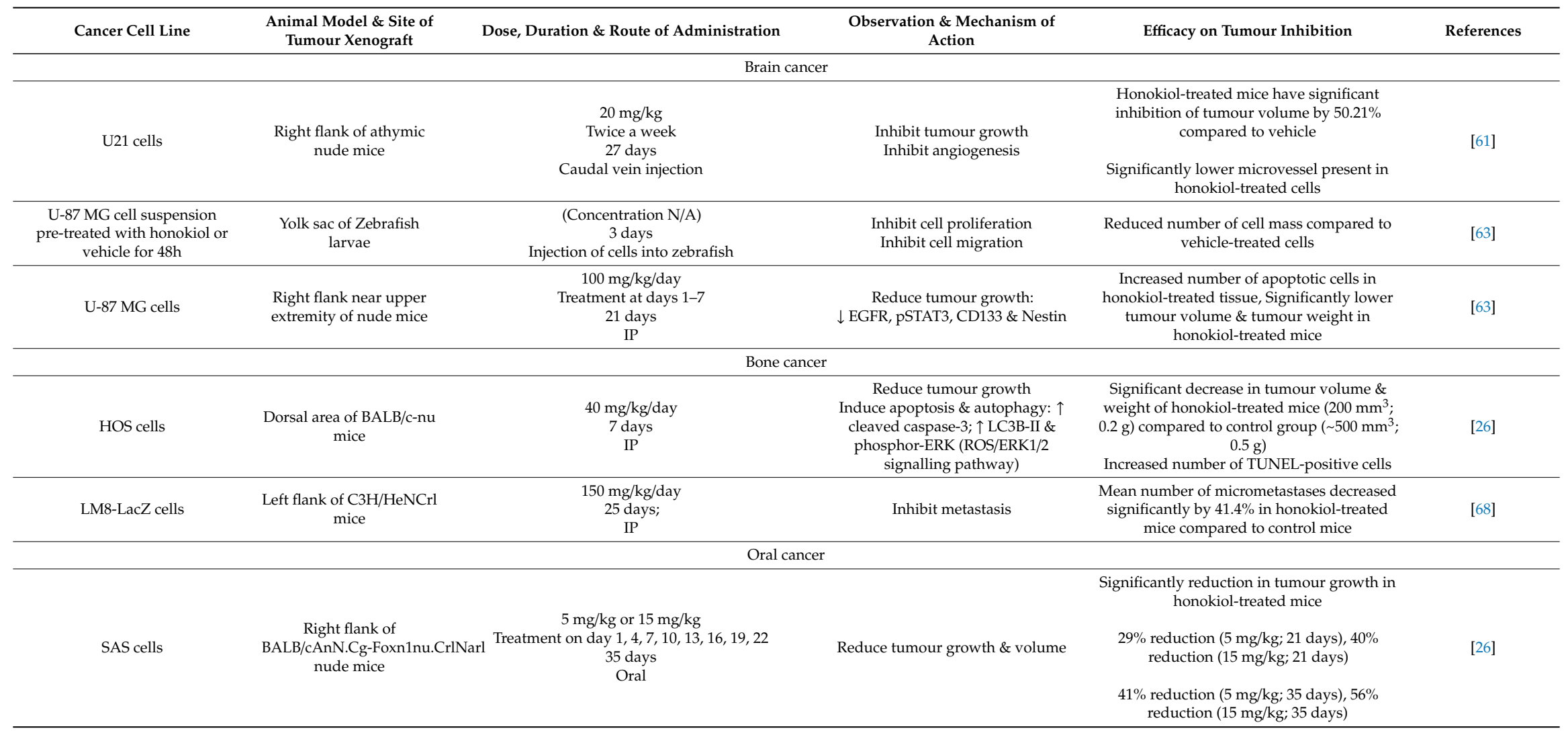


Table 2. Cont.

\begin{tabular}{|c|c|c|c|c|c|}
\hline Cancer Cell Line & $\begin{array}{c}\text { Animal Model \& Site of } \\
\text { Tumour Xenograft }\end{array}$ & Dose, Duration \& Route of Administration & $\begin{array}{l}\text { Observation \& Mechanism of } \\
\text { Action }\end{array}$ & Efficacy on Tumour Inhibition & References \\
\hline \multicolumn{6}{|c|}{ Prostate cancer } \\
\hline C4-2 cells & $\begin{array}{l}\text { Bilateral tibia of BALB/c } \\
\text { nu/nu athymic nude mice }\end{array}$ & $\begin{array}{l}100 \mathrm{mg} / \mathrm{kg} / \mathrm{day} \\
42 \text { days } \\
\text { IP }\end{array}$ & $\begin{array}{c}\text { Inhibit cell proliferation: } \\
\uparrow \text { Ki-67 } \\
\text { Induce apoptosis: } \uparrow \mathrm{M}-31 \\
\text { Inhibit angiogenesis: } \uparrow \mathrm{CD}-31\end{array}$ & $\begin{array}{l}\text { Lower PSA value in honokiol-treated mice } \\
\text { compared to control group }\end{array}$ & [76] \\
\hline PC- 3 cells & $\begin{array}{l}\text { Left \& right flanks above } \\
\text { hind limb of nude mice }\end{array}$ & $\begin{array}{c}1 \text { or } 2 \mathrm{mg} / \text { mice } \\
\text { Monday, Wednesday \& Friday two weeks before } \\
\text { tumour implantation and duration of experiment } \\
\text { after implantation } \\
77 \text { days } \\
\text { Oral gavage }\end{array}$ & $\begin{array}{l}\text { Inhibit tumour growth } \\
\text { Inhibit cell proliferation } \\
\text { Inhibit neovascularisation } \\
\text { Induce apoptosis }\end{array}$ & $\begin{array}{l}\text { Tumour volume of honokiol-treated mice are } \\
\text { significantly lower }\left(\sim 330 \mathrm{~mm}^{3} ; 1 \mathrm{mg}\right),(\sim 50 \\
\left.\mathrm{mm}^{3} ; 2 \mathrm{mg}\right) \text { compared to control }\left(\sim 400 \mathrm{~mm}^{3}\right)\end{array}$ & [18] \\
\hline \multicolumn{6}{|c|}{ Gastric cancer } \\
\hline MKN45 cells & $\begin{array}{l}\text { Dorsal side of BALB/c } \\
\text { nude mice }(\mathrm{nu} / \mathrm{nu})\end{array}$ & $\begin{array}{c}0.5 \mathrm{mg} / \mathrm{kg} / \mathrm{day} \& 1.5 \mathrm{mg} / \mathrm{kg} / \mathrm{day} \\
10 \text { days } \\
\text { Injection (route not stated) }\end{array}$ & $\begin{array}{l}\text { Inhibit tumour growth: } \downarrow \text { GRP94 } \\
\text { overexpression }\end{array}$ & $\begin{array}{c}30 \% \text { reduction in tumour volume } \\
(0.5 \mathrm{mg} / \mathrm{kg}) \\
60 \% \text { reduction in tumour volume } \\
(1.5 \mathrm{mg} / \mathrm{kg})\end{array}$ & [86] \\
\hline & & & & Decreased accumulation of GRP94 & \\
\hline MKN45 \& SCM-1 cells & $\begin{array}{l}\text { Peritoneal cavity of } \\
\text { BALB/c nude mice }\end{array}$ & $\begin{array}{c}5 \mathrm{mg} / \mathrm{kg} \\
\text { Twice a week } \\
28 \text { days } \\
\text { IP }\end{array}$ & $\begin{array}{l}\text { Inhibit metastasis } \\
\text { Inhibit angiogenesis }\end{array}$ & $\begin{array}{l}\text { Honokiol inhibited STAT-3 signalling and } \\
\text { VEGF signalling induced by calpain/SHP-1 }\end{array}$ & [87] \\
\hline SKOV3 cells & $\begin{array}{l}\text { Right axilla of BALB/c } \\
\text { nude mice }\end{array}$ & $\begin{array}{l}1 \mathrm{mg} \text { liposome-encapsulated honokiol/day } \\
48 \text { days } \\
\text { IP }\end{array}$ & $\begin{array}{l}\text { Inhibit tumour growth } \\
\text { Inhibit angiogenesis }\end{array}$ & $\begin{array}{l}\text { Reduction in tumour growth rate in } \\
\text { liposome-encapsulated honokiol-treated } \\
\text { mice by } 67-70 \% \text { compared to control }\end{array}$ & {$[73,88]$} \\
\hline A2780s cells & $\begin{array}{l}\text { Right flank of athymic } \\
\text { BALB/c nude mice }\end{array}$ & $\begin{array}{l}10 \mathrm{mg} / \mathrm{kg} \text { Lipo-Honokiol } \\
\text { Twice a week } \\
21 \text { days } \\
\text { IV }\end{array}$ & $\begin{array}{c}\text { Inhibit cancer growth } \\
\text { Prolong survival of mice } \\
\text { Increase intra-tumoural apoptosis } \\
\text { Inhibit intra-tumoural angiogenesis }\end{array}$ & $\begin{array}{l}\text { Lipo-HNK treated mice have significantly } \\
\text { smaller tumour volume } \\
\left(222 \pm 71 \mathrm{~mm}^{3}\right) \text { compared to } \\
\text { liposome-treated mice } \\
\left(1823 \pm 606 \mathrm{~mm}^{3}\right) \text { and control mice }(3921 \pm \\
\left.235 \mathrm{~mm}^{3}\right)\end{array}$ & [73] \\
\hline A2780cp cells & $\begin{array}{l}\text { Right flank of athymic } \\
\text { BALB/c nude mice }\end{array}$ & $\begin{array}{l}10 \mathrm{mg} / \mathrm{kg} \text { Lipo-Honokiol } \\
\text { Twice a week } \\
21 \text { days } \\
\text { IV }\end{array}$ & $\begin{array}{c}\text { Inhibit cancer growth } \\
\text { Prolong survival } \\
\text { Increase intra-tumoural apoptosis } \\
\text { Inhibit intra-tumoural angiogenesis }\end{array}$ & $\begin{array}{l}\text { Lipo-HNK treated mice have significantly } \\
\text { smaller tumour volume } \\
\left(408 \pm 165 \mathrm{~mm}^{3}\right) \text { compared to } \\
\text { liposome-treated mice } \\
\left(2575 \pm 701 \mathrm{~mm}^{3}\right) \text { and control mice }(2828 \pm \\
\left.796 \mathrm{~mm}^{3}\right)\end{array}$ & [73] \\
\hline
\end{tabular}




\section{Mechanism of Action of Honokiol}

\subsection{Dual Induction of Apoptotic and Necrotic Cell Death}

Apoptosis is a normal physiological process that maintains the homeostatic cellular balance in multicellular organisms [89]. Generally, apoptosis can be classified into two central pathways, namely the intrinsic pathway (mitochondrial-mediated pathway) and extrinsic pathway (death receptor-mediated pathway) [90]. The intrinsic pathway is associated with changes in mitochondrial membrane permeability that lead to imbalance in Bax/Bak ratio and release of cytochrome $c$ and other mitochondrial proteins into cytosol $[89,90]$. The released cytochrome $c$ interacts with apoptosis protease-activating factor 1 (Apaf1) and forms an apoptosome complex [91], which promotes the activation of caspase- 9 and later caspase-3, initiating the caspase cascade, which executes cell death in a coordinated way [91]. For the extrinsic pathway, the binding of ligands such as tumour necrosis factor (TNF), Fas ligand (Fas-L), and TNF-related apoptosis-inducing ligand (TRAIL) to their respective death receptors (type 1 TNF receptor (TNFR1), Fas (also called CD95/Apo-1) and TRAIL receptors will turn procaspase- 8 into active caspase-8 to induce apoptosis [91-93].

Honokiol has been shown tp initiate caspase-dependent apoptotic pathways in different types of cancer (Table 1). Chen et al. [14] found that JJ012 human chondrosarcoma cells lose their mitochondrial membrane potential when treated at $10 \mu \mathrm{M}$ of honokiol, thus leading to apoptosis. Other studies have also shown that honokiol markedly disrupted the balance of Bax/Bcl-2 ratio [13,18,34,63,94-97]. The increasing ratio of proapoptotic to antiapoptotic Bcl-2 family proteins (Bax/Bcl-2) will induce the release of cytochrome $c$ and other apoptogenic proteins through the mitochondrial membrane to the cytosol, subsequently leading to the activation of caspase cascade and apoptosis [34]. Furthermore, honokiol downregulated the expression of several other anti-apoptosis mRNA and proteins such as Bcl-xL [13,18,25,64], survivin [67,98], and MCL-1 [18], as well as upregulated other pro-apoptotic proteins such as BAD, BAX, and BAK proteins [18,25].

Moreover, honokiol has been shown to effectively induce apoptosis in p53-deficient cancer cells, such as MDA-MD-231 breast cancer cells, as well as lung and bladder cancer cell lines by inhibiting the activation of ras-phospholipase D [39,99,100]. Besides p53, other tumour suppressor genes that will be activated in honokiol treatment include p21 [53], p21/waf1 [101], p27 [53], p38 MAPK [102,103], and p62 [26,46].

Besides the intrinsic pathway, honokiol is capable of targeting death receptors TNF-related apoptosis-inducing ligand (TRAIL) receptors and tumour necrosis factor receptors (TNFR) resulting in a sequential activation of caspase- 8 and -3 , which cleaves target proteins and then leads to apoptosis [104-106]. Activation of the death receptor mediated apoptotic pathway is primarily inhibited by cellular-caspase-8/FADD-like IL-1 $\beta$-converting enzyme (FLICE) inhibitory protein (c-FLIP), which inhibits caspase-8 activation by preventing the recruitment of caspase- 8 to the death inducing signalling complex [106]. However, honokiol was able to downregulate c-FLIP through the ubiquitin/proteasome-mediated mechanism, resulting in the sensitisation of non-small cell lung cancer cells to TRAIL-mediated apoptosis [107,108].

Other than intrinsic and extrinsic pathways, honokiol can also induce apoptosis by the endoplasmic reticulum (ER) stress-induced mechanism. A variety of ER stresses result in unfolded protein accumulation responses $[109,110]$. For survival, the cells induce ER chaperone proteins to increase protein aggregation, temporarily halt translation, and activate the proteasome machinery to degrade misfolded proteins. However, under severe and prolonged ER stress, an unfolded protein response activates unique pathways that lead to cell death through apoptosis [111]. According to a study by Zhu et al. [50], honokiol can upregulate the expressions of ER stress-induced apoptotic signalling molecules such as GRP78, phosphorylated PERK, phosphorylated eIF2 $\alpha$, CHOP, Bcl-2, Bax, and cleaved caspase-9 in human lung cancer cells. Chiu et al. [112] found that honokiol also led to an increase in ER stress activity in melanoma cell lines B16F10 (mouse), human malignant melanoma, and human metastatic melanoma. Honokiol activated ER stress and down-regulated peroxisome 
proliferator-activated receptor- $\gamma(\operatorname{PPAR} \gamma)$ activity resulting in PPAR $\gamma$ and CRT degradation through calpain-II activity in human gastric cancer cell lines $[86,113,114]$ and human chondrosarcoma cells [14]. This was due to the ability of honokiol to upregulate and bind effectively to the glucose regulated protein 78 (GRP78) to activate apoptosis $[14,115]$. However, this was opposed by another study where treatment of various human gastric cancer cells with honokiol led to the induction of GRP94 cleavage but did not affect GRP78 [86].

Necrosis is known as unprogrammed cell death whereby cell swelling and destabilisation of the cell membrane results in the leakage of cellular cytoplasmic contents into the extracellular space, thus causing inflammation [116]. Besides apoptosis, honokiol has also been found to induce necrotic cell death in MCF-7 (40 $\mu \mathrm{g} / \mathrm{mL}$ honokiol) [117], human oesophageal adenocarcinoma cells CP-A and CP-C [118], and primary human acute myelogenous leukemia HL60 [85] via p16ink4a pathway by targeting cyclophilin D to affect several downstream mechanisms. This phenomenon was also observed in transformed Barrett's and oesophageal adenocarcinoma cells when treated with honokiol $(<40$ $\mu \mathrm{M}$ ) by targeting their STAT3 signalling pathway, thus resulting in a decrease of Ras activity and phosphorylated ERK1/2 expression [119]. The phosphorylation of Ser727 STAT3 induces translocation towards the mitochondria followed by ROS production, ultimately leading to the induction of necrosis [120]. Taken together, honokiol demonstrates the dual induction of apoptotic and necrotic cell death.

\subsection{Cell Cycle Arrest}

Cancer is attributed to uncontrolled proliferation resulting from abnormal activity of different cell cycle proteins. Therefore, cell cycle regulators are becoming attractive targets in cancer therapy. Honokiol can induce cell cycle arrest in several types of cancer cells, such as in lung squamous cell carcinoma [121], prostate cancer cells [75,122], oral squamous cancer [70], UVB-induced skin cancer [123], and more as listed in Table 1, by generally inducing G0/G1 and G2/M arrest. This arrest is associated with the suppression of cyclin-B1, CDC2, and cdc25C in honokiol-treated human gastric carcinoma and human neuroglioma cells [97,124,125], downregulation of cyclin dependent kinase (CDK)-2 and CDK-4, and the upregulation of cell cycle suppressors p21 and p27 in human oral squamous cell carcinoma (OSCC) cells [26,97]. In addition, the downregulation of c-Myc and class I histone deacetylases was also identified as other contributors to cell cycle arrest at the G0/G1 phase in prostate cancer cells $[97,122]$ and acute myeloid leukemia respectively $[44,101,108]$.

\subsection{Autophagy}

Autophagy is an evolutionary conserved catabolic process that involves the delivery of dysfunctional cytoplasmic components for lysosomal degradation [126,127]. The activation of autophagy promotes cell survival and regulates cell growth during harsh and stressful conditions via a reduction of cellular energy requirements by breaking down unnecessary components $[82,127]$. In cancer cells, autophagy facilitates both tumour suppression and tumourigenesis by the induction of cell death and tumour growth promotion, respectively $[128,129]$. The regulation of mTORC complexes mTORC1 and mTORC2 is involved in controlling the autophagic process. The activation of mTORC1 plays an important role in phosphorylation of autophagy-related protein (ATG) and subsequently inhibiting autophagy, whereas the inhibition of mTORC1 complements the autophagic process $[130,131]$. The inhibition of mTORC1 complex will concurrently activate Unc-51-like autophagy-activating kinase (ULK) complex, inducing localisation to the phagophore and followed by class III PI3K activation [132,133]. Beclin-1 was known to play a role in tumour suppression by recruiting several proteins associated with autophagosome elongation and maturation [134]. ATGs regulate the autophagosome elongation. For instance, ATG5-ATG12/ATG16L complexes recruit microtubule-associated protein 1 light chain 3 (LC3), followed by conversion of pro-LC3 to active cytosolic isoform LC3 I by ATG4B $[135,136]$. Thereafter, the interaction with ATG3, ATG7, and phosphatidylethanolamine (PE) converts LC3 I to LC3 II. The LC3 II enables the autophagosome to 
bind to degraded substrates and mature autophagosomes are capable of fusing with lysosomes to selectively remove damaged organelles via autophagy [137].

Generally, there are two modes of autophagy known as conventional and alternative autophagy. Conventional autophagy (also known as Atg5/Atg7-dependent pathway) involves the activation of Atg5 and Atg7 which are core regulators of autophagy, and then leads to microtubule-associated protein $1 \mathrm{~A} / 1 \mathrm{~B}$ light chain 3 (LC3) modification and translocation from cytosol to the isolation membrane. This LC3 translocation was considered as a reliable hallmark of autophagy. Contradictorily, alternative autophagy occurs independently without involving Atg5 and Atg7, as well as LC3 modification $[128,129,137]$.

The regulation of autophagy in cancer remains controversial as it plays dual roles in tumour suppression and promotion. Autophagy is believed to contribute to the properties of cancer cells stemness, induction of recurrence, and the development of anticancer drugs. However, the actual mechanism of autophagy in cancer remains unclear. Several studies have highlighted the potential of honokiol to induce cell death via autophagy in human prostate cancer cells [77], human glioma cells [138], NSCLC cells [30], and human thyroid cancer cells [60].

The activation of Atg5/Atg7-dependent pathways through the upregulation of LC3B-II, Atg5, and Atg7 levels was observed in honokiol-treated osteosarcoma HOS and U2OS cells and leads to the accumulation of autophagic vacuoles [26]. According to a study by Chang et al. [64], the expression of two critical autophagic proteins, Beclin-1 and LC3, were found to have increased in the honokiol-treated glioblastoma multiforme cells (DBTRG-05MG cell line). Similarly, the expression of autophagosomal marker LC3-II was also increased in Kirsten rat sarcoma viral oncogene homolog (KRAS) mutated cell lines of non-small cell lung cancer (NSCLC).

Other signalling pathways are also found to be involved in honokiol-induced autophagy including the involvement of AMPK-mTOR signalling pathway which leads to autophagocytosis through the coordinated phosphorylation of Ulk1 in Kirsten rat sarcoma viral oncogene homolog (KRAS) mutant lung cancer and melanoma cells $[55,60,66,97]$. Besides this, the ROS/ERK1/2 signalling pathway is also believed to play a certain role in honokiol-induced autophagy though ERK activation and the generation of ROS in treated osteosarcoma cells $[67,77,97]$. All these recent studies have further supported the potential of honokiol in the induction of autophagy in cancer cells.

\subsection{Epithelial-Mesenchymal Transition (EMT)}

Migratory mesenchymal-like cells are involved in embryonic development, tissue repair, and regeneration, as well as several pathological processes like tissue fibrosis, tumour invasiveness, and metastasis $[139,140]$. These migratory mesenchymal cells originate from the conversion of the epithelial cells, and this process is known as epithelial-mesenchymal transition (EMT). This plasticity of cellular phenotypes provides a new insight into possible therapeutic interventions in cancer [140].

EMT is characterised by the loss of epithelial markers such as cytokeratins and E-cadherin, followed by an increase in mesenchymal markers such as N-cadherin and vimentin [141]. The cellular processes of EMT are composed of several key transcription factors (such as TWIST, SNAI1, SNAI2, ZEB1/2) that act in concert with epigenetic mechanisms and post-translational protein modifications to coordinate cellular alterations $[139,142]$. The application of gene expression signatures combining multiple EMT-linked genes has proven useful to evaluate EMT as a contributing factor in tumour development in human cancers. However, the EMT process was shown to be incomplete in tumours, venturing in between multiple translational states and expressing a mixture of both epithelial and mesenchymal genes. This hybrid in partial EMT can be more aggressive than tumour cells with a complete EMT phenotype [141]. In addition, EMT contributes to tumour metastatic progression and resistance towards cancer treatment, resulting in poor clinical outcomes $[140,141]$.

Honokiol has been shown to block and inhibit EMT in many cancer cells such as breast cancer, melanoma, bladder cancer, human non-small cell lung cancer, and gastric cancer (Table 1). Honokiol reduced steroid receptor coactivator-3 (SRC-3), matrix metalloproteinase (MMP)-2, and Twist1, preventing the invasion of urinary bladder cancer cells $[108,143]$. In addition, honokiol was also 
capable of inducing E-cadherin and repressing N-cadherin expression, thus inhibiting the EMT process in J82 bladder cancer cells [108,143]. In breast cancer cells, honokiol inhibits the recruitment of Stat3 on mesenchymal transcription factor Zeb1 promoter, resulting in decreased Zeb1 expression and nuclear translocation [144]. In addition, honokiol increases E-cadherin expression via the Stat3-mediated release of Zeb1 from E-cadherin promoter [144]. Collectively, many studies have reported that honokiol effectively inhibits EMT in breast cancer cells, evidence has been found to support a cross-talk between honokiol and Stat3/Zeb1/E-cadherin axis [144]. On the other hand, EMT is inhibited by modulating the miR-141/ZEB2 signalling in renal cell carcinoma (A-498) [57].

Honokiol inhibited the EMT-driven migration of human NSCLC cells in vitro by targeting c-FLIP through N-cadherin/snail signalling as N-cadherin and snail are downstream targets of c-FLIP [145]. Twist1, a basic helix-loop-helix domain-containing transcription factor, promotes tumour metastasis by inducing EMT, and can be upregulated by multiple factors, including SRC-1, STAT3, MSX2, HIF-1 $\alpha$, integrin-linked kinase, and NF- $\mathrm{kB}$. The capability of honokiol in targeting Twist1 can be regarded as a promising therapy for metastatic cancer $[108,146]$.

Honokiol was found to inhibit breast cancer cell metastasis and eliminate human oral squamous cell carcinoma cell by blocking EMT through the modulation of Snail/Slug protein translation [147,148]. Honokiol markedly downregulated endogenous Snail, Slug, and vimentin expression and upregulated E-cadherin expression in MDA-MB-231, MCF7, and 4T1 breast cancer cells [148]. As primary EMT inducers, Snail and Slug dictate the induction of EMT by targeting E-cadherin and vimentin [144,148]. Furthermore, when cells were treated with honokiol, Snail and Slug expression levels were decreased from $12 \mathrm{~h}$ to $24 \mathrm{~h}$ in a time-dependent manner, suggesting that honokiol can reverse the EMT process via the downregulation of Snail and Slug in breast cancer cell lines [148]. Besides that, EMT was inhibited in human oral squamous cell carcinoma cell via the disruption of Wnt/ $\beta$-catenin signalling pathway [147]. It was reported that the protein levels of mesenchymal markers such as Slug and Snail were markedly suppressed, while $\beta$-catenin and its downstream Cyclin D1 were inhibited [147]. It is known that $\beta$-catenin could mediate EMT [147,149], which plays a crucial role in cancer invasion and metastasis. The EMT markers such as Snail and Slug are also the target genes of $\beta$-catenin [150]. Therefore, the suppression of Snail and Slug in honokiol treated human oral squamous cell carcinoma cells was believed to be due to the inhibition of Wnt/ $\beta$-catenin signalling pathway [147]. Similarly, in U87MG human glioblastoma cell and melanoma cells, Snail, N-cadherin and $\beta$-catenin expression levels were decreased, whereas E-cadherin expression was increased after honokiol treatment $[65,112]$.

\subsection{Suppression of Migration, Invasion and Angiogenesis of Cancer Cells}

Metastasis is known to be the major cause of death in cancer patients [151]. It involves the migration and invasion of tumour cells into neighbouring tissues and distant organs via intravasation into blood or lymphatic system [152,153]. The formation of invadopodium was stimulated by epidermal growth factor (EGF) and is crucial for the degradation of the extracellular matrix and remodelling membrane proteins, promoting metastasis [151]. Therefore, one of the important steps in cancer management is to control tumour cell metastasis, especially for early-stage cancer patients [153]. Various studies have reported that honokiol has the capability to suppress tumour metastasis in different types of cancer including breast cancer $[40,148,154]$, non-small cell lung cancer $[44,155]$ ovarian carcinoma cells [28], lung cancer [50], U251 human glioma, as well as U-87MG and T98G human glioblastoma cell [63,65,94], oral squamous cell carcinoma (OSCC) [26], bladder cancer cell [143], pancreatic cancer [58], renal cell carcinoma [156,157], and gastric cancer cells [113]. For instance, the percentage of invading urinary bladder cancer (UBC) cells was significantly reduced by $67 \%$ and $92 \%$ upon $2.4 \mu \mathrm{g} / \mathrm{mL}$ and $4.8 \mu \mathrm{g} / \mathrm{mL}$ of honokiol treatment, respectively [143]. Similarly, tumour cell migration was inhibited by 38-66\% in A549 cells, by $37-62 \%$ in H1299 cells, $12 \%$ to $58 \%$ in H460 cells and $32 \%$ to $69 \%$ in H226 cells, in a concentration-dependent manner after treatment with honokiol [44].

Furthermore, honokiol also demonstrated an inhibitory effect on the expression of matrix metalloproteinases (MMPs) such as MMP-2 and MMP-9 proteins, which play an essential role in the 
metastatic process of tumour cells, as well as the regulation of angiogenesis in the maintenance of tumour cell survivability $[44,63,143]$. MMPs are a group of extracellular matrix degrading enzymes that control various normal cellular processes, such as cell growth, differentiation, apoptosis, and migration [153]. However, MMP activity was increased in many tumour cells. The overexpression of MMP-2 and MMP-9 are associated with pro-oncogenic events such as neovascularisation, tumour cell proliferation, and metastasis because it can degrade the extracellular matrix, basement membranes, and adhesion molecules (intercellular adhesion molecule, ICAM, and vascular cell adhesion molecule) and become invasive [58,153,158].

The transition from an epithelial-to-mesenchymal (EMT) phenotype facilitates the breakdown of extracellular matrix followed by the subsequent invasion of the surrounding tissues in order to enter the bloodstream and/or lymph nodes, and travel to distant organ sites. Once cells have reached the distant organ sites, they undergo mesenchymal-to-epithelial transition and begin the establishment of distal metastasis by the surviving cancer cells followed by the outgrowth of secondary tumours [58,159]. Honokiol has been shown to inhibit the invasion of HT-1080 human fibrosarcoma cells and U937 leukemic cells by inhibiting MMP-9 [160]. In addition, honokiol also reduced the protein levels of MMP2 and MMP9 in U251 human glioma and U-87 MG human glioblastoma cell lines in a dose-dependent manner [63]. The expression of MMP-2 and MMP-9 were also found to be decreased in both honokiol-treated A549 and H1299 cells (NSCLC cell lines), consistent with the decreased nuclear accumulation of $\beta$-catenin as both MMP-2 and MMP-9 are the downstream targets of $\beta$-catenin $[44,161,162]$. In the J82 bladder cancer cell, honokiol repressed the expression of SRC-3, MMP-2, and Twist1 genes which were involved in cancer cell invasion [143].

Another proposed mechanism for the inhibitory effects of honokiol on invasion and metastasis is through the liver kinase B1 (LKB1)/adenine monophosphate-activated protein kinase (AMPK) axis. Honokiol treatment increased the expression and cytoplasmic translocation of tumour-suppressor LKB1 in breast cancer cells, which led to the phosphorylation and functional activation of AMPK and resulted in the inhibition of cell invasion and metastasis $[40,58]$. The activation of AMPK suppresses mTOR signalling, decreasing the phosphorylation of p70 kDA ribosomal protein S6 kinase 1 (p70S6K1) and eukaryotic translation initiation factor 4E (eIF4E)-binding protein (4EBP1). This will ultimately inhibit the reorganisation of the actin cytoskeleton in cells, subsequently inhibiting cell migration [40].

In human renal carcinoma cell (RCC) 786-0, honokiol significantly upregulated the expression of metastasis suppressor gene (KISS-1), genes encoding TIMP metalloproteinase inhibitor 4 (TIMP4), and KISS-1 receptor (KISS-1R). In addition, honokiol markedly suppressed the expression of genes encoding chemokine (C-X-C motif) ligand 12 (CXCL12), chemokine (C-C motif) ligand 7 (CCL7), interleukin-18 (IL18) and matrix metalloproteinase 7 (MMP7). It was proven that honokiol significantly upregulated KISS1 and KISS1R in the 786-0 cells when treated with honokiol since recent studies showed that the activation of KISS1/KISS1R signalling by kisspeptin treatment decreases the motility and invasive capacity of conventional RCC, and overexpression of KISS1 inhibits the invasion of RCC cells Caki-1 [14,163]. In short, the activation of KISS1/KISS1R signalling by honokiol suppresses the multistep process of metastasis, including invasion and colony formation, in RCC cells 786-0 [163].

Angiogenesis is the formation of new blood vessels for supplying nutrients and oxygen to tissues and cells. In tumourigenesis, angiogenesis is important for the development and progression of malignant tumours [164]. The endothelial cells in growing cancer are active due to the release of cell growth and motility promoting proteins, creating a network of blood vessels to overcome its oxygen tension [165]. Vascular endothelial growth factor (VEGF) and fibroblast growth factor-2 (FGF2) are among the factors that play an important role in tumour angiogenesis [153]. In human renal cancer cell lines (786-0 and Caki-1), honokiol induced down-regulation of the expression of VEGF and heme oxygenase-1 (HO-1) via the Ras signalling pathway thus inhibit angiogenesis [166,167].

In retinal pigment epithelial (RPE) cell lines, honokiol inhibited the binding of hypoxiainducible-factor (HIF) to hypoxia-response elements present on the VEGF promoter, thereby inhibiting the secretion of VEGF protein [168,169]. This decrement of VEGF levels resulted in reduced proliferation 
of human retinal microvascular endothelial cells (hRMVECs) [168]. Therefore, honokiol is said to possess both anti-HIF and anti-angiogenic properties.

In the overexpression of VEGF-D Lewis lung carcinoma cell-induced tumours in C57BL/6 mice, honokiol was shown to significantly inhibit tumour-associated lymphangiogenesis and metastasis. Furthermore, a remarkable delay in tumour growth and prolonged life span in honokiol-treated mice were also observed [170]. In another study, honokiol inhibited VEGF-D-induced survival, proliferation, and microcapillary tube formation in both human umbilical vein endothelial cells (HUVECs) and lymphatic vascular endothelial cells (HLECs). These observations are believed to be due to the inhibition in Akt and MAPK phosphorylation and downregulation of VEGFR-2 expressions in HUVECs as well as VEGFR-3 of HLECs $[101,160,171]$. Collectively, honokiol has been shown to exert direct and indirect effects on tumour suppression via anti-metastasis, anti-angiogenesis, and anti-lymphangiogenesis by mainly affecting HIF- and VEGF/VEGFR- dependent pathways. However, an in-depth mechanism of honokiol on the inhibition of metastatic progression and spread should be further explored in the future.

\section{Effect of Honokiol on Various Signalling Pathways}

\subsection{Nuclear Factor Kappa B (NF-kB)}

The nuclear factor kappa B (NFkB) family comprises of five DNA-binding proteins (p50, p52, p65, cRel, and RelB) that differentially modulate the transcription of genes that are involved in various cellular processes such as inflammation, migration, invasion, angiogenesis, proliferation, and apoptosis $[172,173]$. The continuous activation of NFKB has been reported in different types of cancers. Honokiol affects the constitutive activation of $\mathrm{NF \kappa B}$ and expression of NFKB-regulated gene products involved in apoptosis (survivin, Bcl-2, Bcl-xL, IAP1, IAP2, cFLIP and TRAF1), inflammation (cyclooxygenase-2, COX-2), proliferation (cyclin D1 and c-myc), invasion (ICAM-1 and MMP-9), and angiogenesis (VEGF), thereby enhancing apoptosis and suppressing cancer progression [58,174]. Several studies support the inhibitory activity of honokiol against NFKB in different types of cancer cells, including breast cancer $[42,117,175]$, head and neck squamous cell carcinoma (HNSCC) [176], colon cancer cells [177], non-small cell lung cancer (NSCLC) cells [44], pancreatic cancer cells [13], human leukemic cell [104], embryonic kidney cells, T-cell leukemia, multiple myeloma, lung adenocarcinoma, and squamous cell carcinoma [174].

Honokiol was found to repress the transcriptional activity of NFKB in both pancreatic MiaPaCa and Panc1 cancer cells. It was found that honokiol treatment significantly reduced nuclear NFKB levels with an increase of cytoplasmic NFKB fraction in MiaPaCa and Panc1 cells, in a dose-dependent manner [13]. The cellular distribution of NFKB is controlled by the relative expression of its biological inhibitor I $\kappa B$, which keeps NFkB sequestered in the cytoplasm in an inactive complex [172]. Upon honokiol treatment, IкB- $\alpha$ levels were increased due to the stabilisation of IкB- $\alpha$ post-treatment, concurrently inducing the downregulation of IкB- $\alpha$ phosphorylation [13]. Furthermore, honokiol has also been shown to inhibit the TNF- $\alpha$-induced phosphorylation and degradation of the cytosolic NFKB inhibitor IKBa and suppression of IKK activation [104,174,178]. In addition, honokiol was also found to inhibit the nuclear translocation and phosphorylation of p65 subunit of NFkB [44,104]. Honokiol suppressed NF-kB-regulated gene products including MMP-9, TNF- $\alpha$, IL-8, ICAM-1, and MCP-1 [66].

\subsection{Signal Transducers and Activators of Transcription (STATs)}

Signal transducers and activators of transcription (STATs) is a well-known oncogene that is regulated by receptor tyrosine kinases, G-protein-coupled receptors, and interleukin families [179,180]. STAT3 are a group of transcription factors that upon phosphorylation will undergo dimerization and translocation to either the nucleus or mitochondria to control cell survival, cell cycle, cellular growth, and angiogenesis. STATs are aberrantly activated in several types of malignancies due to functional loss of their negative regulators, or the overexpression of upstream tyrosine kinases [179]. 
STAT3 can also localise into the mitochondria and mediate mitochondrial biogenesis. Honokiol has been shown to target STAT3 to reduce its expression and phosphorylation in many cancer cells such as human glioblastoma $[47,63,100]$, lung cancer $[47,181]$, oral squamous cell carcinoma (OSCC) [95], breast cancer [41,144], human epidermoid carcinoma [31], colorectal cancers [182], gastric cancer [87], and esophageal adenocarcinoma [119].

Honokiol was found to inhibit EGFR expression and down-regulate STAT3 phosphorylation by reducing the CD133 and Nestin levels [63]. Similarly, honokiol also induces apoptosis through the suppression of JAK2/STAT3, Akt and Erk signalling pathways in human oral squamous cell carcinoma (SAS and OCEM-1) cell lines [95]. Similar effect was observed in oral cancer cells where honokiol suppressed JAK2/STAT3 activation and, inhibited IL-6-mediated cell migration $[95,183]$. Furthermore, another study indicated that honokiol induces apoptosis in human glioblastoma cell line U87 through suppressing the phosphorylation of STAT3 (Tyr705), down-regulating survivin, and upregulating cleaved caspase-3 expression [98].

Moreover, honokiol inhibited STAT3-phosphorylation/activation in an LKB1-dependent manner, preventing its recruitment to canonical binding-sites in the promoters of Nanog, Oct4, and Sox2 [41]. Thus, the inhibition of the coactivation function of STAT3 resulted in the suppression of expression of pluripotency factors in MCF7, MDA-MB-231, SUM149, and SUM159 breast cancer cells [41]. Furthermore, honokiol inhibited breast tumorigenesis in mice in an LKB1-dependent manner [41]. This showed that honokiol can support crosstalk between LKB1, STAT3, and pluripotency factors in breast cancer and effective anticancer modulation of this axis with honokiol treatment in both in vitro and in vivo [41]. Apart from that, honokiol suppressed metastasis and proliferation in both brain metastatic lung cancer cell lines PC9-BrM3 and H2030- BrM3 by inhibiting STAT3 phosphorylation [47].

In other studies, honokiol is proven to be an effective chemotherapeutic agent that exert its antitumour function by inhibiting the STAT3 signalling pathway. Honokiol can induce cell cycle arrest and apoptosis via the inhibition of survival signals in adult T-cell leukemia by suppressing the phosphorylation and DNA binding of different oncogene factors, such as NF- $\mathrm{kB}$, activator protein 1 , STAT3, and STAT5 [184]. Besides that, honokiol can induce necrosis and apoptosis in transformed Barrett's and oesophageal adenocarcinoma cells through the inhibition of the STAT3 signalling pathway [119]. Honokiol can inhibit the growth and peritoneal metastasis of gastric cancer in nude mice, which was correlated with the inhibition of STAT3 signalling via the upregulation of Src homology 2 (SH2)-containing tyrosine phosphatase 1 [87].

\subsection{Epidermal Growth Factor Receptor (EGFR)}

EGFR is a group of transmembrane receptor tyrosine kinases (RTKs) that are normally deregulated in various cancers $[185,186]$. The overexpression or activating mutations in EGFR results in increased cell proliferation, abnormal metabolism, and cell survival through the activation of the downstream mitogen-activated protein kinase (MAPK) and v-akt murine thymoma viral oncogene homolog 1 (AKT) signalling pathways, as well as phosphatidyl-inositol 3-kinase (PI3K)/Akt, and STAT3 signalling pathways [13,58]. EGFR activation occurs upon binding to its ligands, which then leads to its homo- or heterodimerization with other members of the ErbB family, and subsequent activation of downstream signalling cascades in many cancer cell types, including breast cancer and head and neck squamous cell carcinoma (HNSCC) $[187,188]$.

Honokiol has been shown to inhibit EGFR signalling pathway through either inhibition of EGFR expression or inhibition of EGFR phosphorylation $[78,189,190]$. Honokiol $(60 \mu \mathrm{M})$ was found to inhibit EGFR expression and down-regulate STAT3 phosphorylation in U251 and U-87 MG human glioma/glioblastoma cells via JAK-STAT3 signalling [63]. In another study, honokiol (2.5-7.5 $\mu \mathrm{M}$ ) differentially suppressed proliferation (up to $93 \%$ ) and induced the apoptosis (up to $61 \%$ ) of EGFR overexpressing tumourigenic bronchial cells. These effects were observed in parallel with the downregulation of phospho-EGFR, phospho-Akt, phospho- STAT3, and cell cycle-related proteins [189]. Furthermore, in a mouse lung tumour bioassay, intranasal instillation of liposomal honokiol $(5 \mathrm{mg} / \mathrm{kg})$ 
for 14 weeks reduced the size and multiplicity (49\%) of lung tumours and the level of total- and phospho-EGFR, phospho-Akt, and phospho-STAT3 [189]. Overall, honokiol has been proven to be a promising candidate to suppress the development and progression of lung tumours driven by EGFR deregulation. Moreover, honokiol induced mitochondria-dependent and death receptor-mediated apoptosis in multi-drug resistant (MDR) KB cells, which was associated with inhibition of EGFR-STAT3 signalling and downregulation of STAT3 target genes [31].

Furthermore, the downregulation of c-Src/EGFR-mediated signaling is involved in honokiol-induced cell cycle arrest and apoptosis in MDA-MB-231 human breast cancer cells. EGFR can also be activated in a ligand-independent manner by cellular Src (c-Src), a non-receptor tyrosine kinase. The tyrosine kinase c-Src is also upregulated in many human malignancies and promotes the activation of mitogenic signalling through EGFR [13,191]. In MDA-MB-231 human breast cancer cells, honokiol downregulated the expression and phosphorylation of c-Src, epidermal growth factor receptor (EGFR), and Akt, and consequently led to the inactivation of mTOR and its downstream signal molecules including 4E-binding protein (4E-BP) and p70 S6 kinase [43]. Besides that, inhibition of HER-2 signalling by specific human epidermal growth receptor 1/HER-2 (EGFR/HER-2) kinase inhibitor lapatinib synergistically enhanced the anti-cancer effects of honokiol in HER-2 over-expressed breast cancer cells [42].

The treatment of HNSCC cells with honokiol also decreased the expression of total EGFR as well as p-EGFR and its downstream target, mTOR. Since the activation of mTOR has been shown to contribute to tumour progression, it can be speculated that the honokiol-induced inhibition of cell proliferation in HNSCC cells is mediated through the downregulation of EGFR/mTOR signalling pathway [176,192]. These observations are consistent with the evidence that honokiol inhibits the growth of cancer cells by targeting EGFR and its downstream molecular targets and suggest that these mechanisms are in play in HNSCC.

\subsection{Mammalian Target of Rapamycin (mTOR)}

The mammalian target of rapamycin (mTOR) is a type of protein kinase which regulates cell metabolism, proliferation, and growth. The activation of PI3K/Akt pathway results in the aberrant activation of mTOR in most cancer cells $[97,193,194]$. It is known that mTOR controls the expression of many survival proteins via activating p70 S6 kinase (S6K) and inhibition of eIF4E inhibitor 4E-BP1 [193]. The mTOR signalling pathway is dysregulated in premalignant or early malignant human tissues and is highly implicated in the carcinogenic process. Honokiol suppresses the activation of mTOR and its signalling mediators (4E-BP1 and p70 S6 kinase) by inhibiting ERK and Akt pathways [43] or upregulating PTEN (Phosphatase and Tensin homolog) expression [42,157].

Honokiol was found to induce apoptosis and suppress migration and invasion in ovarian carcinoma cells (SKOV3 and Caov-3) via TSC1/TSC2 complex/AMPK/mTOR signalling pathway [28]. This is mediated via the regulation of the tumour suppressors p27, p53, and MMP-9 [28]. Furthermore, it was proven that honokiol was able to attenuate PI3K/Akt/mTOR signalling via the down-regulation of Akt phosphorylation and upregulation of PTEN expression in breast cancer cells (MCF-7, MCF-7/adr, and BT-474 cell lines) [42]. A combination of honokiol with the mTOR inhibitor rapamycin presented synergistic effects to induce apoptosis in breast cancer cells where the inhibition of PI3K/Akt/mTOR signalling by the mTOR inhibitor further sensitizes breast cancer cells to honokiol [42]. Other studies have also shown that honokiol induces autophagy in PC-3 and LNCaP prostate cancer cells via the suppression of mTOR and Akt phosphorylation [77]. Another study revealed that the treatment of neuroblastoma cells with honokiol caused significant downregulation of mTOR phosphorylation, which leads to the induction of autophagy of neuroblastoma cells (neuro-2a cells) through the PI3K/Akt/mTOR signalling pathways $[96,195]$. 


\subsection{Hypoxia-Inducible-Factor (HIF) Pathway}

The master regulator of neovascularisation, HIF, is a transcription factor that that plays an integral role in the body's response to low oxygen concentrations (i.e., hypoxia) [196,197]. Active HIF is composed of of two subunits: HIF- $\alpha$ and HIF-1/ARNT. Transcriptional regulation by oxygen is mediated by the HIF- $\alpha$ isoforms. In humans, three isoforms of $\alpha$-subunit (HIF- $1 \alpha, \mathrm{HIF}-2 \alpha$, and HIF-3 $\alpha$ ) have been identified. Recent studies suggest that transcriptional adaptation to hypoxia involves epigenetic changes in histone methylation. Strong evidence has established that the expression of pro-angiogenic factors (VEGF), which play a critical role in pathological neovascularisation in cancer, is elevated due to the activation of HIF pathway under hypoxia conditions [198].

An activation of the HIF pathway leading to hypoxia-induced neovascularisation is the central cause of pathogenesis in almost all solid tumours and ischemic retinal diseases [198,199]. There are studies reporting the capability of honokiol to inhibit HIF isoforms and the expression of hypoxic markers, as well as the binding of HIF to hypoxia-response elements present on VEGF promoter in D407 cells (human retinal pigment epithelial cells) [168]. In KRAS mutant lung cancer cells, it was discovered that Sirt3 was significantly up-regulated in honokiol-treated KRAS mutant lung cancer cells, leading to the destabilisation of its target gene Hif- $1 \alpha$ and induction of G1 arrest and apoptosis. This suggests that the anticancer property of honokiol is regulated via a novel mechanism associated with the Sirt3/Hif-1 $\alpha$ [49].

\subsection{Notch Signalling Pathway}

Notch signalling has been implicated in maintaining tissue homeostasis, including the regulation of self-renewal in adult stem cells, organ development, and embryonic development [200-202]. In mammals, the Notch receptor family comprises of four receptors (Notch-1, Notch-2, Notch-3, and Notch-4) and five ligands (Delta-like-1, Delta-like-3, Delta-like-4, Jagged-1, and Jagged-2). Each Notch receptor is activated through cell membrane-associated ligands. A series of proteolytic cleavage processes lead to the maturation and activation of Notch receptors. The first cleavage was catalysed by ADAM-family metalloprotease TACE, followed by the second cleavage mediated by $\gamma$-secretase, an enzyme complex that contains presenilin, nicastrin, presenilin enhancer 2 (PEN2), and anterior pharynx-defective 1 (APH1). The series of cleavages will lead to the release and translocation of Notch intracellular domain (NICD) into the nucleus [202]. Activated NICD is able to bind to activator proteins, including mastermind-like proteins (MAML) and recombination signalling binding protein-J (RBPJ) to form a nuclear transcriptional activator complex to regulate the transcription of downstream target genes, such as the hairy and enhancer of split (Hes) gene, Hey family genes, c-myc, cyclin D1, and p21/Waf1 [200]. The Notch pathway plays a complex role in the tumourigenesis of both hematologic and solid tissues. In fact, Notch signalling plays a vital role in regulating cellular differentiation, angiogenesis, proliferation, and apoptosis [201].

It has been shown that honokiol can eliminate cancer stem-like cells and potentiation of temozolomide (TMZ) sensitivity in glioblastoma multiforme (GBM) cells [36]. It was shown that honokiol enhanced the sensitization of GBM cells to MGMT inhibitor O6 benzylguanine (O6-BG) through the downregulation of Notch3 as well as the expression of its downstream target, Hes1 [36]. Furthermore, honokiol has been shown to inhibit B16/F-10, SKMEL-28 melanoma cell lines and SW480 colon cancer cells by targeting Notch signalling pathways [203,204]. Honokiol treatment resulted in reduced levels of cleaved Notch, particularly the Notch-2 receptor, along with a decrease in the expression of downstream target proteins, including Hes-1, cyclin D1, as well as TACE and $\gamma$-secretase complex proteins in melanoma cells [55].

Apart from that, honokiol in combination with radiation treatment reduced the number of DCLK1+ (cancer stem cell marker protein) colon cancer cells, which was accompanied by reduced levels of activated Notch-1, its ligand Jagged-1, and the downstream target gene Hes-1 [35,204]. Furthermore, the expression of components of the Notch-1 activating $\gamma$-secretase complex, presenilin 1 , nicastrin, Pen2, and APH-1 were also suppressed [35]. To determine the effect of a honokiol-IR combination on 
tumour growth in vivo, nude mice tumour xenografts were administered honokiol intraperitoneally and exposed to IR. The honokiol-IR combination significantly inhibited tumour xenograft growth [35]. In addition, there were reduced levels of DCLK1 and the Notch signalling-related proteins in the xenograft tissues. Together, these data suggest that honokiol is a potent inhibitor of colon cancer growth that targets the stem cells by inhibiting the $\gamma$-secretase complex and the Notch signalling pathway $[35,204]$.

\subsection{Downregulation of P-Glycoprotein}

The principal mechanism of multidrug resistance is due to the active transport of drugs out of cells [205]. Among the efflux transporters, P-glycoprotein (P-gp, gene symbol ABCB1) plays an important role in the resistance of cancer cells to a variety of chemotherapeutic treatments $[205,206]$. Furthermore, P-gp is distributed throughout the body where it interacts with various drugs of different structures to limit their bioavailability [207]. Therefore, the development of effective inhibitors of P-gp expression and/or functional activity should reverse drug resistance and enhance the bioavailability of P-gp substrates. One of the effective ways to overcome P-gp mediated drug resistance is either to block its drug-pump function or to inhibit its expression. To date, there are a total of three generations of P-gp inhibitors that have been discovered [207,208]. However, these compounds were not used widely due to toxicity at the doses required for attenuating P-gp activity, poor specificity, or unpredictable pharmacokinetic interactions. Honokiol was shown to downregulate the expression of P-gp at mRNA and protein levels in MCF-7/ADR, a human breast MDR cancer cell line [209,210]. The downregulation of P-gp was accompanied by a partial recovery of intracellular drug accumulation [210]. In MDR ovarian cancer cells (NCI/ADR-RES), honokiol has also been shown to downregulate the expression of $\mathrm{P}$-gp in a concentration- and time-dependent manner [208].

\section{Metabolism, Bioavailability, and Pharmacological Relevance of Honokiol}

Pharmacokinetics involves the study of drug movement within the body, which includes the time course of absorption, distribution, metabolism, and excretion (ADME). Honokiol is mainly metabolized in the liver and undergoes in vivo biotransformation, whereby glucuronidation and sulfation are the main metabolic pathways to convert honokiol into mono-glucuronide honokiol and sulphated mono-hydroxyhonokiol before elimination [23]. This extensive biotransformation of honokiol may contribute to its low bioavailability. Currently, studies are being conducted to determine whether the metabolites of honokiol possess any biological activities that can extend the half-life of honokiol while maintaining its biological properties.

Most of the studies have reported that honokiol undergoes a rapid distribution and absorption, but slow elimination after intravenous (i.v.) administration [13,58,211,212]. For i.v. administration, it has been found that there was a rapid rate of distribution followed by a slower rate of elimination (elimination half-life $\mathrm{t}_{1 / 2}=49.22 \mathrm{~min}$ and $56.2 \mathrm{~min}$ for $5 \mathrm{mg}$ or $10 \mathrm{mg}$ of honokiol, respectively) observed in Sprague Dawley rats [213]. In another study, Liang et al. [214] investigated the pharmacokinetic properties of honokiol in beagle dogs after intravenous guttae, whereby the blood plasma of both male and female dogs was assessed. The elimination half-life ( $t_{1 / 2}$ in hours) was found to be 20.13 (female), 9.27 (female), 7.06 (male), 4.70 (male), and 1.89 (male) after administration of doses of 8.8, $19.8,3.9,44.4$, and $66.7 \mathrm{mg} / \mathrm{kg}$, respectively. The $\mathrm{t}_{1 / 2}$ decreases with an increase in the dose and length of infusion [214]. In another study, Wang et al. [61] discovered for the first time that honokiol is able to cross the blood-brain barrier (BBB) and blood-cerebrospinal fluid barrier (BCSFB) after i.v. administration when tested on intracerebral gliosarcoma model in Fisher 344 rats and human U251 xenograft glioma model in nude mice. It was also reported that the honokiol was distributed in the order of: lungs $>$ plasma $>$ liver $>$ brain $>$ kidney $>$ heart $>$ spleen after i.v. administration [61].

Furthermore, honokiol has been studied via an intraperitoneal route of administration. Chen et al. [33] reported a maximum plasma concentration of honokiol at $27.179 \pm 6.252 \mathrm{~min}$, with the $t_{1 / 2}$ of $312.08 \pm 51.66 \mathrm{~min}$ after intraperitoneal injection of $250 \mathrm{mg} / \mathrm{kg}$ in BALB/c mice. On another note, studies 
have also shown that the presence of rhubarb and immature orange fruit extract in the decoction influenced the pharmacokinetics of honokiol, where a single oral dose of honokiol in Houpu decoction (a compound prescription of honokiol; $5 \mathrm{~g} / \mathrm{kg}$ body weight) in Wistar rats demonstrated an elimination $\mathrm{t}_{1 / 2}$ of $526.6 \mathrm{~min}$ [215]. Honokiol has a rapid absorption $(\operatorname{Tmax}=20 \mathrm{~min})$ and slow elimination $\left(\mathrm{t}_{1 / 2} \mathrm{z}=\right.$ $290 \mathrm{~min}$ ) after a single dose of oral gavage at $40 \mathrm{mg} / \mathrm{kg}$ in healthy rats [216]. In another study, honokiol showed a peak plasma concentration at $72 \mathrm{~min}$, and $\mathrm{t}_{1 / 2}$ of $186 \mathrm{~min}$, and the absolute bioavailability for honokiol was found to be $5.3 \%$ when rats underwent oral administration of Magnolol/Honokiol emulsion (4:1) at $50 \mathrm{mg} / \mathrm{kg}$ [217]. After the rats were administered with honokiol orally, the honokiol was distributed rapidly to all parts of organs with the highest concentration being accumulated in the liver, followed by the brain and kidneys [216]. This was opposed to their discovery in tumour-bearing mice, where the highest concentration was found in the liver, followed by the kidneys and lungs [218]. This may be due to the different types of species being used as well as the tumor-burdened mice possibly affecting drug distribution [47]. With the rectal administration of Houpo extract at a dose of $245 \mathrm{mg} / \mathrm{kg}$ (equivalent to $13.5 \mathrm{mg} / \mathrm{kg}$ of honokiol) in Wistar rats, the maximal plasma concentration of honokiol found was approximately six times to that administered orally at an identical dose, indicating that rectal dosing avoids first-pass metabolism to some extent [219].

Meanwhile, the topical application of honokiol on UVB-induced contact hypersensitivity (CHS) as a model in $\mathrm{C} 3 \mathrm{H} / \mathrm{HeN}$ mice was also evaluated $[68,220]$. The topical application of honokiol $(0.5$ and $1.0 \mathrm{mg} / \mathrm{cm}^{2}$ skin area) had a significant preventive effect on the UVB-induced suppression of the CHS response. The inflammatory mediators COX-2 and $\mathrm{PGE}_{2}$ played a key role in this effect, as indicated by the honokiol-mediated inhibition of cyclooxygenase-2 (COX-2) expression and PGE $_{2}$ production in the UVB-exposed skin. Besides that, both topical application and oral administration of honokiol significantly inhibited ( $38 \%$ to $46 \%, p<0.001$ ) UVB-induced suppression of CHS in mice compared with the mice that were not treated with honokiol but exposed to UVB radiation. Prominently, the level of inhibition of CHS was not significantly different between the two modes of administration of honokiol [220].

Apart from that, Gao et al. [221] investigated the enhancement in the transdermal and localised delivery of honokiol through breast tissue. It was reported that microneedle-porated dermatome significantly increased the delivery of honokiol by nearly three-fold $\left(97.81 \pm 18.96 \mu \mathrm{g} / \mathrm{cm}^{2}\right) \mathrm{compared}$ with passive delivery $\left(32.56 \pm 5.67 \mu \mathrm{g} / \mathrm{cm}^{2}\right)$. Oleic acid was found to be the best chemical penetration enhancer, increasing the delivery almost 27 -fold $\left(868.06 \pm 100.91 \mu \mathrm{g} / \mathrm{cm}^{2}\right)$. The addition of oleic acid also resulted in a better retention of drugs in porcine mammary papilla $\left(965.41 \pm 80.26 \mu \mathrm{g} / \mathrm{cm}^{2}\right) \mathrm{compared}$ with breast skin $\left(294.16 \pm 8.49 \mu \mathrm{g} / \mathrm{cm}^{2}\right)$ [221]. In summary, both microneedles and chemical enhancers can improve the absorption of honokiol through the skin. Directly applying honokiol on mammary papilla is a potential administration route which can increase localized delivery into breast tissue [183].

On another note, some studies have addressed the poor solubility of honokiol in hydrophilic environment. Wang et al. [222] developed polyethylene glycol-coated (PEGylated) liposomal honokiol to improve its solubility compared to free honokiol. PEGylated (polyethylene glycol coated) liposomal honokiol was shown to enhance the serum honokiol concentration and decrease clearance. The pharmacokinetic analysis of PEGylated liposomal honokiol showed a two-fold increase in elimination $t_{1 / 2}$ value as compared to that of free honokiol when being injected through the i.v. route $(20 \mathrm{mg} / \mathrm{kg}$ body weight) in Balb/c mice (from $26 \mathrm{~min}$ in PEGylated liposomal honokiol to $13 \mathrm{~min}$ in free honokiol) [222]. Moreover, the $\mathrm{AUC}_{0 \rightarrow \infty}$ (mean concentration of drug in plasma) of PEGylated liposomal honokiol was about 1.85 -fold higher than free honokiol. The protein-binding ability of honokiol in plasma was reported to be between $60 \%$ and $65 \%$ as revealed by equilibrium dialysis [222]. In another study, plasma honokiol concentrations were maintained above 30 and $10 \mu \mathrm{g} / \mathrm{mL}$ for 24 and $48 \mathrm{~h}$, respectively, in liposomal honokiol-treated mice. However, it was reduced rapidly $(<5 \mu \mathrm{g} / \mathrm{mL})$ by $12 \mathrm{~h}$ in free honokiol-treated mice bearing A549 xenograft tumors, suggesting that liposomal honokiol extended blood circulation times in tumor-bearing mice compared to free honokiol [223]. 


\section{Potential Drug Delivery of Honokiol}

Due to the low water solubility and bioavailability of honokiol, multiple studies have been performed to develop proper honokiol delivery systems to improve its pharmacological effectiveness. A few studies have been performed to develop efficient drug carriers to deliver honokiol to its respective target, including the development of nanoparticles [224-226], micelles [227-229], and liposomes [73,171,223].

For honokiol delivery in the form of nanoparticles, Zheng et al. [230] developed monomethoxy poly(ethylene glycol)-poly(lactic acid) (MPEG-PLA) via ring opening polymerisation and then processed into nanoparticle for honokiol delivery. The honokiol-loaded MPEG-PLA nanoparticles were mono-dispersed and stable in the aqueous solution [230]. It was found that only 53\% of honokiol was released from the nanoparticles within $24 \mathrm{~h}$, while $100 \%$ of free honokiol was released into the outside media, suggesting that the honokiol loaded MPEG-PLA nanoparticle is a novel honokiol formulation which could meet the requirement of intravenous injection. In comparison, honokiol loaded MPEG-PLA nanoparticles significantly decreased the viability of A2780s cells (human ovarian cancer cells) than free honokiol, indicating that honokiol loaded MPEG-PLA nanoparticles might possess great potential applications for anticancer effect on cisplatin-sensitive A2780s cells in vitro [230]. In addition, the incorporation of both honokiol and doxorubicin in MPEG-PLA nanoparticles exhibited stronger anticancer activity than its individual form against A2780s cells [231].

In another study, emulsion solvent evaporation was used to develop the active targeting nanoparticle-loaded honokiol (ATNH) using copolymerpoly ( $\varepsilon$-caprolactone)-poly (ethylene glycol)-poly ( $\varepsilon$-caprolactone) (PCEC), which was modified with folate (FA) by introducing polyethylenimine (PEI) [30]. It was reported that ATNH showed a suitable size distribution, high encapsulation efficiency, gradual release, and targeting uptake by human nasopharynx carcinoma cells (HNE-1). Moreover, ATNH significantly inhibited tumour growth, metabolism, proliferation, micro-vessel generation, and caused cell-cycle arrest at the G1 phase [30]. Apart from that, epigallocatechin-3-gallate functionalized chitin loaded with honokiol nanoparticles (CE-HK NP), developed by Tang et al. [224], inhibit HepG2 cell growth and induce apoptosis through the suppression of mitochondrial membrane potential. Furthermore, CE-HK NPs (40 mg/kg) inhibited tumour growth by $83.55 \%$ ( $p<0.05)$, which was far higher than the $30.15 \%$ inhibition of free honokiol $(40 \mathrm{mg} / \mathrm{kg})$. The proposed delivery system exhibits better tumour selectivity and growth reduction in both in vitro and in vivo models (male BALB/c nude mice treated with honokiol administrated by intertumoral injection) and did not induce any side effects [224]. Therefore, the CE-HK NPs may act as an effective delivery system for liver cancer. Recently, Yu et al. [232] further improved the design of nanoparticles for targeted delivery in breast cancer by surface modifying the honokiol nanoparticles through conjugation with folic acid to the surface of honokiol nanoparticles coated with polydopamine (HK-PDA-FA-NPs) as a $\mathrm{pH}$-sensitive targeting anchor for nanoparticles. The targeted nanoparticles (HK-PDA-FA-NPs) can be stably present in various physiological media and exhibit $\mathrm{pH}$ sensitivity during drug release in vitro. HK-PDA-FA-NPs have better targeting ability to $4 \mathrm{~T} 1$ cells than normal HK-NPs. Targeted nanoparticles have a tumour inhibition rate of greater than $80 \%$ in vivo (female Balb/c mice injected intraperitoneally with $40 \mathrm{mg} / \mathrm{kg}$ HK-PDA-FA-NPs), which is significantly higher than conventional HK-NPs [232].

For honokiol delivery in the form of micelles, researchers developed poly(ethylene glycol)-poly( $\varepsilon$-caprolactone)-poly(ethylene glycol) (PECE) micelle loaded with honokiol [229]. The cytotoxicity results showed that the composite drug delivery system is a safe carrier and the encapsulated honokiol retained its potent antitumor effect when tested against murine melanoma cell line B16 [233]. The $\mathrm{IC}_{50}$ values of free honokiol, honokiol nanoparticles, and honokiol micelles were 5.357, 6.274, and $6.746 \mu \mathrm{g} / \mathrm{mL}$, respectively. The result indicated that the cytotoxicity of the honokiol micelles was lower than that of free honokiol, which was attributed to the sustained release behaviour of honokiol from honokiol micelles [233]. Further, comparing with honokiol nanoparticles, the cytotoxicity of honokiol micelles was a little lower, which might be due to the absence of organic solvent and 
surfactant in the honokiol micelles [233]. To increase the hydrophilicity of honokiol, Qiu et al. [234] developed an amphiphilic polymer-drug conjugate via the condensation of low molecular weight monomethoxy-poly(ethylene glycol) (MPEG)-2000 with honokiol through an ester linkage. The MPEG-honokiol (MPEG-HK) conjugate prepared formed nano-sized micelles, with a mean particle size of less than $20 \mathrm{~nm}$ (MPEG-HK, $360 \mu \mathrm{g} \cdot \mathrm{mL}^{-1}$ ) in water, in which they could be well dispersed, and the results showed that only $20 \%$ of the conjugated honokiol was released in $2 \mathrm{~h}$ in beagle dog plasma, while in phosphate-buffered saline, the time required to reach $20 \%$ of honokiol release was $>200 \mathrm{~h}$ [234]. Meanwhile, the inhibitory activity of the honokiol conjugate was found to be retained in vitro against $\mathrm{LL} / 2$ cell lines with an $\mathrm{IC}_{50}$ value of $10.7 \mu \mathrm{g} / \mathrm{mL}$ [234]. These results suggest that the polymer-drug conjugate provides a potential new approach to hydrophobic drugs, such as honokiol, in formulation design. In another study, nanomicellar honokiol (HNK-NM) with the size range of 20-40 nm was developed and compared against honokiol free drug (HNK-FD) [212]. Compared to HNK-FD, HNK-NM resulted in a significant increase in oral bioavailability. Cmax (4.06 and 3.60-fold) and AUC (6.26 and 5.83-fold) were significantly increased in comparison to oral 40 and $80 \mathrm{mg} / \mathrm{kg}$ HNK-FD, respectively, when tested in triple negative breast cancer cell lines (MDA-MB-231, MDA-MB-453, and MDA-MB-468). The anticancer effects of these formulations were also studied in BALB/c nude mice transplanted with orthotopic MDA-MB-231 cell induced xenografts [212]. After four weeks of daily oral administration of HNK-NM formulation, a significant reduction in the tumour volumes and weights compared to free drug $(p<0.001)$ treated groups was observed. Furthermore, in $25 \%$ of the mice, the treatment resulted in a complete eradication of tumours. Increased apoptosis and antiangiogenic effects were observed in HNK-NM groups compared to HNK-FD and untreated control mice [212].

Wang et al. [228] prepared paclitaxel (PTX) and honokiol (HK) combination methoxy poly(ethylene glycol) poly(caprolactone) micelles $(\mathrm{P}-\mathrm{H} / \mathrm{M})$ via the solid dispersion method against breast cancer (4T1). The particle size of $\mathrm{P}-\mathrm{H} / \mathrm{M}$ was $28.7 \pm 2.5 \mathrm{~nm}$ and spherical in shape. Both the cytotoxicity and the cellular uptake of $\mathrm{P}-\mathrm{H} / \mathrm{M}$ were increased in $4 \mathrm{~T} 1$ cells, and $\mathrm{P}-\mathrm{H} / \mathrm{M}$ induced more apoptosis than PTX-loaded micelles or HK-loaded micelles. Furthermore, the antitumor effect of P-H/M was significantly improved compared with PTX-loaded micelles or HK-loaded micelles in vivo (Female $\mathrm{Balb} / \mathrm{c}$ mice and female Balb/c nude mice treated with intravenous injection) [31,228]. P-H/M were more effective in inhibiting tumour proliferation, inducing tumour apoptosis, and decreasing the density of microvasculature accumulated more in tumour tissues compared to the free drug. After that, Wang et al. [235] developed paclitaxel (PTX) and honokiol (HNK) which are co-encapsulated into pH-sensitive polymeric micelles based on poly(2-ethyl-2-oxazoline)-poly(D,L-lactide) (PEOz-PLA). Results showed efficient inhibition of tumour metastasis by dual drug-loaded PEOz-PLA micelles in vitro anti-invasion and anti-migration assessment in MDA-MB-231 cells and in vivo in nude mice [235]. The suppression of MDR and metastasis by the micelles was assigned to the synergistic effects of $\mathrm{pH}$-triggered drug release and HNK/PEOz-PLA-aroused P-gp inhibition, and $\mathrm{pH}$-triggered drug release and PTX/HNK-aroused MMPs inhibition, respectively. After that, Wang et al. [236] proceeded to modify the paclitaxel plus honokiol micelles with dequalinium and tested it in non-small-cell lung cancer. When tested on Lewis lung tumour (LLT) cells, the polymeric micelles show powerful cytotoxicity, effective suppression on vasculogenic mimicry (VM) channels and tumour metastasis, as well as the activation of apoptotic enzymes caspase-3 and caspase-9, and down-regulation of FAK, PI3K, MMP-2, and MMP-9 [236]. In vivo assays (C57BL/6 mice treated through intravenous injection) indicated that polymeric micelles could increase the selective accumulation of chemotherapeutic drugs at tumour sites and showed a conspicuous anti-tumour efficacy [236].

For liposomes loaded with honokiol, Luo et al. [73] created liposomal honokiol and tested it on cisplatin-sensitive (A2780s) and -resistant (A2780cp) human ovarian cancer models. The administration of liposomal honokiol resulted in significant inhibition (84-88\% maximum inhibition relative to controls) in the growth of A2780s and A2780cp tumour xenografts and prolonged the survival of the treated mice (treated twice weekly with intravenous administration) [73]. These anti-tumour responses were 
associated with marked increases in tumour apoptosis, and reductions in intratumoural microvessel density. Jiang et al. [223] incorporated honokiol in combination with cisplatin in the liposomes and tested it in A549 lung cancer xenograft nude mice model through intraperitoneal administration. This combination effectively suppressed tumour growth and significantly increased life span of treated mice compared to liposomal honokiol alone [223]. A similar result was observed in murine CT26 colon cancer models, where the systemic administration of liposomal honokiol with cisplatin resulted in the inhibition of subcutaneous tumour growth beyond the effects observed with either liposomal honokiol or cisplatin alone due to elevated levels of apoptosis and reduced endothelial cell density significantly [237]. In a recent study, hyaluronic acid (HA) modified daunorubicin plus honokiol cationic liposomes were prepared and characterised for the treatment of breast cancer by eliminating vasculogenic mimicry (VM) [238]. Studies found that the HA modified daunorubicin plus honokiol cationic liposomes enhanced the cellular uptake and destroyed VM channels. In addition, these liposomes prolonged their circulation time in the blood, and significantly accumulated at the tumour site to maximise its anticancer efficacy.

\section{Future Perspective}

Up to date, many in vitro and in vivo studies have identified the protective effects of honokiol in various types of cancers. However, the exact anticancer mechanism of honokiol is still insufficiently elucidated, especially its application in treating human cancer clinically. Since honokiol is being extensively metabolised in the body into different metabolites, it is vital to recognise the different types of metabolites circulating in the body in order to gain a better insight into the fate of honokiol after administration. The characterisation of honokiol metabolites would enable a better understanding of the overall bioactivity of honokiol as well as to determine the relationship between the bioactivity of the core molecule and its metabolites circulating within the target tissue. Moreover, future studies could focus on improving the methods used for in vitro studies to mimic more favourable in vivo conditions by considering the actual metabolites detected and concentrations found in the respective cancer tissues in order to better understand the mode of action of honokiol in cancer. Apart from that, it is essential to study the anticancer properties of the derivatives of honokiol as very few studies have been performed on the derivatives. It is important to study its derivatives as they might have improved and enhanced anticancer properties due to the change in structures and functional groups.

In short, more research can be done to confirm the anticancer properties of honokiol in more detail in order to come up with a safe and effective dosage to be used in chemoprevention and chemotherapy. Furthermore, more research can be done on the metabolism of honokiol via different routes of administration to find out the most effective route of administration for different types of cancer. The pre-formulation as well as formulation of honokiol can also be developed to prepare the transition of honokiol from pre-clinical to clinical studies in the future.

\section{Conclusions}

For centuries, researchers have been searching for strategies to control cancer progression through different approaches. Honokiol is a potential natural compound that exerts multiple effects on different cellular processes in various cancer models. Honokiol has been shown to regulate cell cycle arrest, induction of apoptosis, necrosis, and autophagy, as well as the inhibition of metastasis and angiogenesis through various signalling pathways. In addition, its effects are also validated in several in vivo studies with promising results where it can inhibit tumour growth and prolong survival in mouse cancer models. Current efforts are focusing on developing numerous drug delivery systems to improve the pharmacological, pharmacokinetics, and pharmacodynamic properties of honokiol. This review concludes that honokiol may be considered as a potential candidate for anticancer drug development. 
Author Contributions: The literature searches and data collection were performed by W.L.L., C.P.O. and Y.Q.T. The manuscript was written by W.L.L., C.P.O., Y.Q.T. and W.H.Y. The manuscript was critically reviewed and edited by Y.Q.T. and W.H.Y. The project was conceptualized by W.H.Y. All authors have read and agreed to the published version of the manuscript.

Funding: This work was supported by the Ministry of Education (MOE) Fundamental Research Grant Scheme (FRGS/1/2019/SKK08/TAYLOR/02/2) awarded to W.H.Y. and Taylor's Internal Research Grant Scheme-Emerging Research Funding Scheme (TRGS/ERFS/1/2018/SBS/035) awarded to Y.Q.T.

Conflicts of Interest: The authors declare no conflict of interest.

\section{References}

1. Foster, I. Cancer: A cell cycle defect. Radiography 2008, 14, 144-149. [CrossRef]

2. Cabral, C.; Efferth, T.; Pires, I.M.; Severino, P.; Lemos, M.F.L. Natural Products as a Source for New Leads in Cancer Research and Treatment. Evid.-Based Complement. Altern. Med. 2018, 2018, 8243680. [CrossRef] [PubMed]

3. Wu, S.; Zhu, W.; Thompson, P.; Hannun, Y.A. Evaluating intrinsic and non-intrinsic cancer risk factors. Nat. Commun. 2018, 9, 3490. [CrossRef] [PubMed]

4. Siegel, R.L.; Miller, K.D.; Jemal, A. Cancer statistics, 2019. CA Cancer J. Clin. 2019, 69, 7-34. [CrossRef]

5. Bray, F.; Ferlay, J.; Soerjomataram, I.; Siegel, R.L.; Torre, L.A.; Jemal, A. Global cancer statistics 2018: GLOBOCAN estimates of incidence and mortality worldwide for 36 cancers in 185 countries. CA Cancer J. Clin. 2018, 68, 394-424. [CrossRef]

6. DeVita, V.T.; Canellos, G.P. New therapies and standard of care in oncology. Nat. Rev. Clin. Oncol. 2011, 8, 67-68. [CrossRef]

7. Marqus, S.; Pirogova, E.; Piva, T.J. Evaluation of the use of therapeutic peptides for cancer treatment. J. Biomed. Sci. 2017, 24, 21. [CrossRef]

8. Mitra, S.; Dash, R. Natural Products for the Management and Prevention of Breast Cancer. Evid.-Based Complement. Altern. Med. 2018, 2018, 8324696. [CrossRef]

9. Bayat Mokhtari, R.; Homayouni, T.S.; Baluch, N.; Morgatskaya, E.; Kumar, S.; Das, B.; Yeger, H. Combination therapy in combating cancer. Oncotarget 2017, 8, 38022-38043. [CrossRef]

10. Robinson, M.M.Z.; Zhang, X. The World Medicines Situation 2011. Traditional Medicines: Global Situation, Issues and Challenges; World Health Organization: Geneva, Switzerland, 2011.

11. Seelinger, M.; Popescu, R.; Giessrigl, B.; Jarukamjorn, K.; Unger, C.; Wallnöfer, B.; Fritzer-Szekeres, M.; Szekeres, T.; Diaz, R.; Jäger, W.; et al. Methanol extract of the ethnopharmaceutical remedy Smilax spinosa exhibits anti-neoplastic activity. Int. J. Oncol. 2012, 41, 1164-1172. [CrossRef]

12. Amaral, R.G.; dos Santos, S.A.; Andrade, L.N.; Severino, P.; Carvalho, A.A. Natural Products as Treatment against Cancer: A Historical and Current Vision. Clin. Oncol. 2019, 4, 1562.

13. Arora, S.; Singh, S.; Piazza, G.A.; Contreras, C.M.; Panyam, J.; Singh, A.P. Honokiol: A novel natural agent for cancer prevention and therapy. Curr. Mol. Med. 2012, 12, 1244-1252. [CrossRef] [PubMed]

14. Chen, Y.J.; Wu, C.L.; Liu, J.F.; Fong, Y.C.; Hsu, S.F.; Li, T.M.; Su, Y.C.; Liu, S.H.; Tang, C.H. Honokiol induces cell apoptosis in human chondrosarcoma cells through mitochondrial dysfunction and endoplasmic reticulum stress. Cancer Lett. 2010, 291, 20-30. [CrossRef] [PubMed]

15. Lee, J.D.; Lee, J.Y.; Baek, B.J.; Lee, B.D.; Koh, Y.W.; Lee, W.-S.; Lee, Y.-J.; Kwon, B.-M. The inhibitory effect of honokiol, a natural plant product, on vestibular schwannoma cells. Laryngoscope 2012, 122, 162-166. [CrossRef]

16. Amblard, F.; Delinsky, D.; Arbiser, J.L.; Schinazi, R.F. Facile purification of honokiol and its antiviral and cytotoxic properties. J. Med. Chem. 2006, 49, 3426-3427. [CrossRef]

17. Woodbury, A.; Yu, S.P.; Wei, L.; García, P. Neuro-modulating effects of honokiol: A review. Front. Neurol. 2013, 4, 130. [CrossRef]

18. Hahm, E.R.; Arlotti, J.A.; Marynowski, S.W.; Singh, S.V. Honokiol, a constituent of oriental medicinal herb magnolia officinalis, inhibits growth of PC-3 xenografts in vivo in association with apoptosis induction. Clin. Cancer Res. 2008, 14, 1248-1257. [CrossRef]

19. Chen, L. Rapid purification and scale-up of honokiol and magnolol using high-capacity high-speed counter-current chromatography A. J. Chromatogr. 2007, 1142, 115-122. [CrossRef] 
20. Chen, C.-M.; Liu, Y.-C. ChemInform Abstract: A Concise Synthesis of Honokiol. Tetrahedron Lett. 2009, 50, 1151-1152. [CrossRef]

21. Gupta, M. Pharmacological Properties and Traditional Therapeutic Uses of Important Indian Spices: A Review. Int. J. Food Prop. 2010, 13, 1092-1116. [CrossRef]

22. Anand, K.W.; Wakode, S. Development of drugs based on Benzimidazole Heterocycle: Recent advancement and insights. Int. J. Chem. Stud. 2017, 5, 350-362.

23. Bohmdorfer, M.; Maier-Salamon, A.; Taferner, B.; Reznicek, G.; Thalhammer, T.; Hering, S.; Hufner, A.; Schuhly, W.; Jager, W. In vitro metabolism and disposition of honokiol in rat and human livers. J. Pharm. Sci. 2011, 100, 3506-3516. [CrossRef] [PubMed]

24. Lin, J.M.; Prakasha Gowda, A.S.; Sharma, A.K.; Amin, S. In vitro growth inhibition of human cancer cells by novel honokiol analogs. Bioorg. Med. Chem. 2012, 20, 3202-3211. [CrossRef] [PubMed]

25. Yang, S.E.; Hsieh, M.T.; Tsai, T.H.; Hsu, S.L. Down-modulation of Bcl-XL, release of cytochrome c and sequential activation of caspases during honokiol-induced apoptosis in human squamous lung cancer $\mathrm{CH} 27$ cells. Biochem. Pharmacol. 2002, 63, 1641-1651. [CrossRef]

26. Huang, K.J.; Kuo, C.H.; Chen, S.H.; Lin, C.Y.; Lee, Y.R. Honokiol inhibits in vitro and in vivo growth of oral squamous cell carcinoma through induction of apoptosis, cell cycle arrest and autophagy. J. Cell. Mol. Med. 2018, 22, 1894-1908. [CrossRef] [PubMed]

27. Huang, L.; Zhang, K.; Guo, Y.; Huang, F.; Yang, K.; Chen, L.; Huang, K.; Zhang, F.; Long, Q. Honokiol protects against doxorubicin cardiotoxicity via improving mitochondrial function in mouse hearts. Sci. Rep. 2017, 7, 11989. [CrossRef] [PubMed]

28. Lee, J.S.; Sul, J.Y.; Park, J.B.; Lee, M.S.; Cha, E.Y.; Ko, Y.B. Honokiol induces apoptosis and suppresses migration and invasion of ovarian carcinoma cells via AMPK/mTOR signaling pathway. Int. J. Mol. Med. 2019, 43, 1969-1978. [CrossRef]

29. Olusanya, T.O.B.; Haj Ahmad, R.R.; Ibegbu, D.M.; Smith, J.R.; Elkordy, A.A. Liposomal Drug Delivery Systems and Anticancer Drugs. Molecules 2018, 23, 907. [CrossRef]

30. Yang, B.; Ni, X.; Chen, L.; Zhang, H.; Ren, P.; Feng, Y.; Chen, Y.; Fu, S.; Wu, J. Honokiol-loaded polymeric nanoparticles: An active targeting drug delivery system for the treatment of nasopharyngeal carcinoma. Drug Deliv. 2017, 24, 660-669. [CrossRef]

31. Wang, X.; Beitler, J.J.; Wang, H.; Lee, M.J.; Huang, W.; Koenig, L.; Nannapaneni, S.; Amin, A.R.M.R.; Bonner, M.; Shin, H.J.C.; et al. Honokiol Enhances Paclitaxel Efficacy in Multi-Drug Resistant Human Cancer Model through the Induction of Apoptosis. PLoS ONE 2014, 9, e86369. [CrossRef]

32. Rajendran, P.; Li, F.; Shanmugam, M.K.; Vali, S.; Abbasi, T.; Kapoor, S.; Ahn, K.S.; Kumar, A.P.; Sethi, G. Honokiol inhibits signal transducer and activator of transcription-3 signaling, proliferation, and survival of hepatocellular carcinoma cells via the protein tyrosine phosphatase SHP-1. J. Cell. Physiol. 2012, 227, 2184-2195. [CrossRef] [PubMed]

33. Chen, F.; Wang, T.; Wu, Y.-F.; Gu, Y.; Xu, X.-L.; Zheng, S.; Hu, X. Honokiol: A potent chemotherapy candidate for human colorectal carcinoma. World J. Gastroenterol. 2004, 10, 3459-3463. [CrossRef] [PubMed]

34. He, Z.; Subramaniam, D.; Ramalingam, S.; Dhar, A.; Postier, R.G.; Umar, S.; Zhang, Y.; Anant, S. Honokiol radiosensitizes colorectal cancer cells: Enhanced activity in cells with mismatch repair defects. Am. J. Physiol.-Gastrointest. Liver Physiol. 2011, 301, G929-G937. [CrossRef] [PubMed]

35. Ponnurangam, S.; Mammen, J.M.; Ramalingam, S.; He, Z.; Zhang, Y.; Umar, S.; Subramaniam, D.; Anant, S. Honokiol in combination with radiation targets notch signaling to inhibit colon cancer stem cells. Mol. Cancer Ther. 2012, 11, 963-972. [CrossRef] [PubMed]

36. Lai, I.C.; Shih, P.-H.; Yao, C.-J.; Yeh, C.-T.; Wang-Peng, J.; Lui, T.-N.; Chuang, S.-E.; Hu, T.-S.; Lai, T.-Y.; Lai, G.-M. Elimination of Cancer Stem-Like Cells and Potentiation of Temozolomide Sensitivity by Honokiol in Glioblastoma Multiforme Cells. PLoS ONE 2015, 10, e0114830. [CrossRef] [PubMed]

37. Battle, T.E.; Arbiser, J.; Frank, D.A. The natural product honokiol induces caspase-dependent apoptosis in B-cell chronic lymphocytic leukemia (B-CLL) cells. Blood 2005, 106, 690-697. [CrossRef]

38. Gao, D.Q.; Qian, S.; Ju, T. Anticancer activity of Honokiol against lymphoid malignant cells via activation of ROS-JNK and attenuation of Nrf2 and NF-kappaB. J. BUON 2016, 21, 673-679.

39. Wolf, I.; O’Kelly, J.; Wakimoto, N.; Nguyen, A.; Amblard, F.; Karlan, B.Y.; Arbiser, J.L.; Koeffler, H.P. Honokiol, a natural biphenyl, inhibits in vitro and in vivo growth of breast cancer through induction of apoptosis and cell cycle arrest. Int. J. Oncol. 2007, 30, 1529-1537. [CrossRef] 
40. Nagalingam, A.; Arbiser, J.L.; Bonner, M.Y.; Saxena, N.K.; Sharma, D. Honokiol activates AMP-activated protein kinase in breast cancer cells via an LKB1-dependent pathway and inhibits breast carcinogenesis. Breast Cancer Res. 2012, 14, R35. [CrossRef]

41. Sengupta, S.; Nagalingam, A.; Muniraj, N.; Bonner, M.Y.; Mistriotis, P.; Afthinos, A.; Kuppusamy, P.; Lanoue, D.; Cho, S.; Korangath, P.; et al. Activation of tumor suppressor LKB1 by honokiol abrogates cancer stem-like phenotype in breast cancer via inhibition of oncogenic Stat3. Oncogene 2017, 36, 5709-5721. [CrossRef]

42. Liu, H.; Zang, C.; Emde, A.; Planas-Silva, M.D.; Rosche, M.; Kuhnl, A.; Schulz, C.O.; Elstner, E.; Possinger, K.; Eucker, J. Anti-tumor effect of honokiol alone and in combination with other anti-cancer agents in breast cancer. Eur. J. Pharmacol. 2008, 591, 43-51. [CrossRef] [PubMed]

43. Park, E.J.; Min, H.Y.; Chung, H.J.; Hong, J.Y.; Kang, Y.J.; Hung, T.M.; Youn, U.J.; Kim, Y.S.; Bae, K.; Kang, S.S.; et al. Down-regulation of c-Src/EGFR-mediated signaling activation is involved in the honokiol-induced cell cycle arrest and apoptosis in MDA-MB-231 human breast cancer cells. Cancer Lett. 2009, 277, 133-140. [CrossRef] [PubMed]

44. Singh, T.; Katiyar, S.K. Honokiol Inhibits Non-Small Cell Lung Cancer Cell Migration by Targeting PGE2-Mediated Activation of $\beta$-Catenin Signaling. PLoS ONE 2013, 8, e60749. [CrossRef] [PubMed]

45. Singh, T.; Prasad, R.; Katiyar, S.K. Inhibition of class I histone deacetylases in non-small cell lung cancer by honokiol leads to suppression of cancer cell growth and induction of cell death in vitro and in vivo. Epigenetics 2013, 8, 54-65. [CrossRef]

46. Lv, X.; Liu, F.; Shang, Y.; Chen, S.Z. Honokiol exhibits enhanced antitumor effects with chloroquine by inducing cell death and inhibiting autophagy in human non-small cell lung cancer cells. Oncol. Rep. 2015, 34, 1289-1300. [CrossRef]

47. Pan, J.; Lee, Y.; Zhang, Q.; Xiong, D.; Wan, T.C.; Wang, Y.; You, M. Honokiol Decreases Lung Cancer Metastasis through Inhibition of the STAT3 Signaling Pathway. Cancer Prev. Res. 2017, 10, 133-141. [CrossRef]

48. Liou, S.-F.; Hua, K.-T.; Hsu, C.-Y.; Weng, M.-S. Honokiol from Magnolia spp. induces G1 arrest via disruption of EGFR stability through repressing HDAC6 deacetylated Hsp90 function in lung cancer cells. J. Funct. Foods 2015, 15, 84-96. [CrossRef]

49. Luo, L.-X.; Li, Y.; Liu, Z.-Q.; Fan, X.-X.; Duan, F.-G.; Li, R.-Z.; Yao, X.-J.; Leung, E.L.-H.; Liu, L. Honokiol Induces Apoptosis, G1 Arrest, and Autophagy in KRAS Mutant Lung Cancer Cells. Front. Pharmacol. 2017, 8, 199. [CrossRef]

50. Zhu, J.; Xu, S.; Gao, W.; Feng, J.; Zhao, G. Honokiol induces endoplasmic reticulum stress-mediated apoptosis in human lung cancer cells. Life Sci. 2019, 221, 204-211. [CrossRef]

51. Chae, J.I.; Jeon, Y.J.; Shim, J.H. Downregulation of Sp1 is involved in honokiol-induced cell cycle arrest and apoptosis in human malignant pleural mesothelioma cells. Oncol. Rep. 2013, 29, 2318-2324. [CrossRef]

52. Mannal, P.W.; Schneider, J.; Tangada, A.; McDonald, D.; McFadden, D.W. Honokiol produces anti-neoplastic effects on melanoma cells in vitro. J. Surg. Oncol. 2011, 104, 260-264. [CrossRef] [PubMed]

53. Chilampalli, C.; Guillermo, R.; Kaushik, R.S.; Young, A.; Chandrasekher, G.; Fahmy, H.; Dwivedi, C. Honokiol, a chemopreventive agent against skin cancer, induces cell cycle arrest and apoptosis in human epidermoid A431 cells. Exp. Biol. Med. 2011, 236, 1351-1359. [CrossRef] [PubMed]

54. Kaushik, G.; Ramalingam, S.; Subramaniam, D.; Rangarajan, P.; Protti, P.; Rammamoorthy, P.; Anant, S.; Mammen, J.M. Honokiol induces cytotoxic and cytostatic effects in malignant melanoma cancer cells. Am. J. Surg. 2012, 204, 868-873. [CrossRef] [PubMed]

55. Kaushik, G.; Kwatra, D.; Subramaniam, D.; Jensen, R.A.; Anant, S.; Mammen, J.M.V. Honokiol affects melanoma cell growth by targeting the AMP-activated protein kinase signaling pathway. Am. J. Surg. 2014, 208, 995-1002. [CrossRef] [PubMed]

56. Guillermo-Lagae, R.; Santha, S.; Thomas, M.; Zoelle, E.; Stevens, J.; Kaushik, R.S. Antineoplastic Effects of Honokiol on Melanoma. Biomed Res. Int. 2017, 2017, 5496398. [CrossRef] [PubMed]

57. Li, W.; Wang, Q.; Su, Q.; Ma, D.; An, C.; Ma, L.; Liang, H. Honokiol suppresses renal cancer cells' metastasis via dual-blocking epithelial-mesenchymal transition and cancer stem cell properties through modulating miR-141/ZEB2 signaling. Mol. Cells 2014, 37, 383-388. [CrossRef] [PubMed]

58. Averett, C.; Bhardwaj, A.; Arora, S.; Srivastava, S.K.; Khan, M.A.; Ahmad, A.; Singh, S.; Carter, J.E.; Khushman, M.D.; Singh, A.P. Honokiol suppresses pancreatic tumor growth, metastasis and desmoplasia by interfering with tumor-stromal cross-talk. Carcinogenesis 2016, 37, 1052-1061. [CrossRef] [PubMed] 
59. Arora, S.; Bhardwaj, A.; Srivastava, S.K.; Singh, S.; McClellan, S.; Wang, B.; Singh, A.P. Honokiol arrests cell cycle, induces apoptosis, and potentiates the cytotoxic effect of gemcitabine in human pancreatic cancer cells. PLOS ONE 2011, 6, e21573. [CrossRef] [PubMed]

60. Lu, C.H.; Chen, S.H.; Chang, Y.S.; Liu, Y.W.; Wu, J.Y.; Lim, Y.P.; Yu, H.I.; Lee, Y.R. Honokiol, a potential therapeutic agent, induces cell cycle arrest and program cell death in vitro and in vivo in human thyroid cancer cells. Pharmacol. Res. 2017, 115, 288-298. [CrossRef]

61. Wang, X.; Duan, X.; Yang, G.; Zhang, X.; Deng, L.; Zheng, H.; Deng, C.; Wen, J.; Wang, N.; Peng, C.; et al. Honokiol crosses BBB and BCSFB, and inhibits brain tumor growth in rat 9L intracerebral gliosarcoma model and human U251 xenograft glioma model. PLOS ONE 2011, 6, e18490. [CrossRef]

62. Jeong, J.J.; Lee, J.H.; Chang, K.C.; Kim, H.J. Honokiol exerts an anticancer effect in T98G human glioblastoma cells through the induction of apoptosis and the regulation of adhesion molecules. Int. J. Oncol. 2012, 41, 1358-1364. [CrossRef] [PubMed]

63. Fan, Y.; Xue, W.; Schachner, M.; Zhao, W. Honokiol Eliminates Glioma/Glioblastoma Stem Cell-Like Cells Via JAK-STAT3 Signaling and Inhibits Tumor Progression by Targeting Epidermal Growth Factor Receptor. Cancers 2018, 11, 22. [CrossRef] [PubMed]

64. Chang, K.H.; Yan, M.D.; Yao, C.J.; Lin, P.C.; Lai, G.M. Honokiol-induced apoptosis and autophagy in glioblastoma multiforme cells. Oncol. Lett. 2013, 6, 1435-1438. [CrossRef] [PubMed]

65. Joo, Y.N.; Eun, S.Y.; Park, S.W.; Lee, J.H.; Chang, K.C.; Kim, H.J. Honokiol inhibits U87MG human glioblastoma cell invasion through endothelial cells by regulating membrane permeability and the epithelial-mesenchymal transition. Int. J. Oncol. 2014, 44, 187-194. [CrossRef]

66. Lin, C.J.; Chen, T.L.; Tseng, Y.Y.; Wu, G.J.; Hsieh, M.H.; Lin, Y.W.; Chen, R.M. Honokiol induces autophagic cell death in malignant glioma through reactive oxygen species-mediated regulation of the p53/PI3K/Akt/mTOR signaling pathway. Toxicol. Appl. Pharmacol. 2016, 304, 59-69. [CrossRef]

67. Huang, K.; Chen, Y.; Zhang, R.; Wu, Y.; Ma, Y.; Fang, X.; Shen, S. Honokiol induces apoptosis and autophagy via the ROS/ERK1/2 signaling pathway in human osteosarcoma cells in vitro and in vivo. Cell Death Dis. 2018, 9, 157. [CrossRef]

68. Steinmann, P.; Walters, D.K.; Arlt, M.J.; Banke, I.J.; Ziegler, U.; Langsam, B.; Arbiser, J.; Muff, R.; Born, W.; Fuchs, B. Antimetastatic activity of honokiol in osteosarcoma. Cancer 2012, 118, 2117-2127. [CrossRef]

69. Yang, J.; Zou, Y.; Jiang, D. Honokiol suppresses proliferation and induces apoptosis via regulation of the miR21/PTEN/PI3K/AKT signaling pathway in human osteosarcoma cells. Int. J. Mol. Med. 2018, 41, 1845-1854. [CrossRef]

70. Kim, D.W.; Ko, S.M.; Jeon, Y.J.; Noh, Y.W.; Choi, N.J.; Cho, S.D.; Moon, H.S.; Cho, Y.S.; Shin, J.C.; Park, S.M.; et al. Anti-proliferative effect of honokiol in oral squamous cancer through the regulation of specificity protein 1. Int. J. Oncol. 2013, 43, 1103-1110. [CrossRef]

71. Xu, Q.; Tong, F.; He, C.; Song, P.; Xu, Q.; Chen, Z. The inhibition effect of Honokiol in liver cancer. Int. J. Clin. Exp. Med. 2018, 11, 10673-10678.

72. Han, L.L.; Xie, L.P.; Li, L.H.; Zhang, X.W.; Zhang, R.Q.; Wang, H.Z. Reactive oxygen species production and Bax/Bcl-2 regulation in honokiol-induced apoptosis in human hepatocellular carcinoma SMMC-7721 cells. Environ. Toxicol. Pharmacol. 2009, 28, 97-103. [CrossRef] [PubMed]

73. Luo, H.; Zhong, Q.; Chen, L.J.; Qi, X.R.; Fu, A.F.; Yang, H.S.; Yang, F.; Lin, H.G.; Wei, Y.Q.; Zhao, X. Liposomal honokiol, a promising agent for treatment of cisplatin-resistant human ovarian cancer. J. Cancer Res. Clin. Oncol. 2008, 134, 937-945. [CrossRef] [PubMed]

74. Li, Z.; Liu, Y.; Zhao, X.; Pan, X.; Yin, R.; Huang, C.; Chen, L.; Wei, Y. Honokiol, a natural therapeutic candidate, induces apoptosis and inhibits angiogenesis of ovarian tumor cells. Eur. J. Obstet. Gynecol. Reprod. Biol. 2008, 140, 95-102. [CrossRef] [PubMed]

75. Hahm, E.R.; Singh, S.V. Honokiol causes G0-G1 phase cell cycle arrest in human prostate cancer cells in association with suppression of retinoblastoma protein level/phosphorylation and inhibition of E2F1 transcriptional activity. Mol. Cancer Ther. 2007, 6, 2686-2695. [CrossRef] [PubMed]

76. Shigemura, K.; Arbiser, J.L.; Sun, S.Y.; Zayzafoon, M.; Johnstone, P.A.; Fujisawa, M.; Gotoh, A.; Weksler, B.; Zhau, H.E.; Chung, L.W. Honokiol, a natural plant product, inhibits the bone metastatic growth of human prostate cancer cells. Cancer 2007, 109, 1279-1289. [CrossRef] [PubMed]

77. Hahm, E.R.; Sakao, K.; Singh, S.V. Honokiol activates reactive oxygen species-mediated cytoprotective autophagy in human prostate cancer cells. Prostate 2014, 74, 1209-1221. [CrossRef] 
78. Leeman-Neill, R.J.; Cai, Q.; Joyce, S.C.; Thomas, S.M.; Bhola, N.E.; Neill, D.B.; Arbiser, J.L.; Grandis, J.R. Honokiol inhibits epidermal growth factor receptor signaling and enhances the antitumor effects of epidermal growth factor receptor inhibitors. Clin. Cancer Res. 2010, 16, 2571-2579. [CrossRef]

79. Lin, J.W.; Chen, J.T.; Hong, C.Y.; Lin, Y.L.; Wang, K.T.; Yao, C.J.; Lai, G.M.; Chen, R.M. Honokiol traverses the blood-brain barrier and induces apoptosis of neuroblastoma cells via an intrinsic bax-mitochondrion-cytochrome c-caspase protease pathway. Neuro-Oncology 2012, 14, 302-314. [CrossRef]

80. Yeh, P.S.; Wang, W.; Chang, Y.A.; Lin, C.J.; Wang, J.J.; Chen, R.M. Honokiol induces autophagy of neuroblastoma cells through activating the PI3K/Akt/mTOR and endoplasmic reticular stress/ERK1/2 signaling pathways and suppressing cell migration. Cancer Lett. 2016, 370, 66-77. [CrossRef]

81. Zhang, Q.; Zhao, W.; Ye, C.; Zhuang, J.; Chang, C.; Li, Y.; Huang, X.; Shen, L.; Li, Y.; Cui, Y.; et al. Honokiol inhibits bladder tumor growth by suppressing EZH2/miR-143 axis. Oncotarget 2015, 6, 37335-37348. [CrossRef]

82. Bao, L.; Jaramillo, M.C.; Zhang, Z.; Zheng, Y.; Yao, M.; Zhang, D.D.; Yi, X. Induction of autophagy contributes to cisplatin resistance in human ovarian cancer cells. Mol. Med. Rep. 2015, 11, 91-98. [CrossRef] [PubMed]

83. Zhang, Q.; Cheng, J.; Xin, Q. Effects of tetracycline on developmental toxicity and molecular responses in zebrafish (Danio rerio) embryos. Ecotoxicology 2015, 24, 707-719. [CrossRef] [PubMed]

84. Hill, D.; Chen, L.; Snaar-Jagalska, E.; Chaudhry, B. Embryonic zebrafish xenograft assay of human cancer metastasis. F1000Research 2018, 7, 1682. [CrossRef] [PubMed]

85. Li, L.; Han, W.; Gu, Y.; Qiu, S.; Lu, Q.; Jin, J.; Luo, J.; Hu, X. Honokiol Induces a Necrotic Cell Death through the Mitochondrial Permeability Transition Pore. Cancer Res. 2007, 67, 4894. [CrossRef] [PubMed]

86. Sheu, M.L.; Liu, S.H.; Lan, K.H. Honokiol induces calpain-mediated glucose-regulated protein-94 cleavage and apoptosis in human gastric cancer cells and reduces tumor growth. PLoS ONE 2007, 2, e1096. [CrossRef]

87. Liu, S.H.; Wang, K.B.; Lan, K.H.; Lee, W.J.; Pan, H.C.; Wu, S.M.; Peng, Y.C.; Chen, Y.C.; Shen, C.C.; Cheng, H.C.; et al. Calpain/SHP-1 Interaction by Honokiol Dampening Peritoneal Dissemination of Gastric Cancer in nu/nu Mice. PLoS ONE 2012, 7, e43711. [CrossRef]

88. Liu, Y.; Chen, L.; He, X.; Fan, L.; Yang, G.; Chen, X.; Lin, X.; Du, L.; Li, Z.; Ye, H.; et al. Enhancement of therapeutic effectiveness by combining liposomal honokiol with cisplatin in ovarian carcinoma. Int. J. Gynecol. Cancer 2008, 18, 652-659. [CrossRef]

89. Goldar, S.; Khaniani, M.S.; Derakhshan, S.M.; Baradaran, B. Molecular mechanisms of apoptosis and roles in cancer development and treatment. Asian Pac. J. Cancer Prev. 2015, 16, 2129-2144. [CrossRef]

90. Hassan, M.; Watari, H.; AbuAlmaaty, A.; Ohba, Y.; Sakuragi, N. Apoptosis and molecular targeting therapy in cancer. Biomed Res. Int. 2014, 2014, 150845. [CrossRef]

91. Wong, R.S.Y. Apoptosis in cancer: From pathogenesis to treatment. J. Exp. Clin. Cancer Res. 2011, $30,87$. [CrossRef]

92. Gerl, R.; Vaux, D.L. Apoptosis in the development and treatment of cancer. Carcinogenesis 2005, 26, 263-270. [CrossRef] [PubMed]

93. Letai, A. Apoptosis and Cancer. Annu. Rev. Cancer Biol. 2017, 1, 275-294. [CrossRef]

94. Jeong, Y.-H.; Hur, J.H.; Jeon, E.-J.; Park, S.-J.; Hwang, T.J.; Lee, S.A.; Lee, W.K.; Sung, J.M. Honokiol Improves Liver Steatosis in Ovariectomized Mice. Molecules 2018, 23, 194. [CrossRef] [PubMed]

95. Huang, J.-S.; Yao, C.-J.; Chuang, S.-E.; Yeh, C.-T.; Lee, L.-M.; Chen, R.-M.; Chao, W.-J.; Whang-Peng, J.; Lai, G.-M. Honokiol inhibits sphere formation and xenograft growth of oral cancer side population cells accompanied with JAK/STAT signaling pathway suppression and apoptosis induction. BMC Cancer 2016, 16, 245. [CrossRef] [PubMed]

96. Prasad, R.; Katiyar, S.K. Honokiol, an Active Compound of Magnolia Plant, Inhibits Growth, and Progression of Cancers of Different Organs. Adv. Exp. Med. Biol. 2016, 928, 245-265. [CrossRef] [PubMed]

97. Banik, K.; Ranaware, A.M.; Deshpande, V.; Nalawade, S.P.; Padmavathi, G.; Bordoloi, D.; Sailo, B.L.; Shanmugam, M.K.; Fan, L.; Arfuso, F.; et al. Honokiol for cancer therapeutics: A traditional medicine that can modulate multiple oncogenic targets. Pharmacol. Res. 2019, 144, 192-209. [CrossRef] [PubMed]

98. Wang, X.; Beitler, J.J.; Huang, W.; Chen, G.; Qian, G.; Magliocca, K.; Patel, M.R.; Chen, A.Y.; Zhang, J.; Nannapaneni, S.; et al. Honokiol Radiosensitizes Squamous Cell Carcinoma of the Head and Neck by Downregulation of Survivin. Clin. Cancer Res. 2018, 24, 858-869. [CrossRef] 
99. Garcia, A.; Zheng, Y.; Zhao, C.; Toschi, A.; Fan, J.; Shraibman, N.; Brown, H.A.; Bar-Sagi, D.; Foster, D.A.; Arbiser, J.L. Honokiol Suppresses Survival Signals Mediated by Ras-Dependent Phospholipase D Activity in Human Cancer Cells. Clin. Cancer Res. 2008, 14, 4267. [CrossRef]

100. Fried, L.E.; Arbiser, J.L. Honokiol, a multifunctional antiangiogenic and antitumor agent. Antioxid. Redox Signal. 2009, 11, 1139-1148. [CrossRef]

101. Li, H.Y.; Ye, H.G.; Chen, C.Q.; Yin, L.H.; Wu, J.B.; He, L.C.; Gao, S.M. Honokiol induces cell cycle arrest and apoptosis via inhibiting class I histone deacetylases in acute myeloid leukemia. J. Cell. Biochem. 2015, 116, 287-298. [CrossRef]

102. Deng, J.; Qian, Y.; Geng, L.; Chen, J.; Wang, X.; Xie, H.; Yan, S.; Jiang, G.; Zhou, L.; Zheng, S. Involvement of p38 mitogen-activated protein kinase pathway in honokiol-induced apoptosis in a human hepatoma cell line (hepG2). Liver Int. 2008, 28, 1458-1464. [CrossRef] [PubMed]

103. Hasegawa, S.; Yonezawa, T.; Ahn, J.Y.; Cha, B.Y.; Teruya, T.; Takami, M.; Yagasaki, K.; Nagai, K.; Woo, J.T. Honokiol inhibits osteoclast differentiation and function in vitro. Biol. Pharm. Bull. 2010, 33, 487-492. [CrossRef] [PubMed]

104. Tse, A.K.; Wan, C.K.; Shen, X.L.; Yang, M.; Fong, W.F. Honokiol inhibits TNF-alpha-stimulated NF-kappaB activation and NF-kappaB-regulated gene expression through suppression of IKK activation. Biochem. Pharmacol. 2005, 70, 1443-1457. [CrossRef] [PubMed]

105. Li, J.; Shao, X.; Wu, L.; Feng, T.; Jin, C.; Fang, M.; Wu, N.; Yao, H. Honokiol: An effective inhibitor of tumor necrosis factor-alpha-induced up-regulation of inflammatory cytokine and chemokine production in human synovial fibroblasts. Acta Biochim. Biophys. Sin. 2011, 43, 380-386. [CrossRef]

106. Xu, H.L.; Tang, W.; Du, G.H.; Kokudo, N. Targeting apoptosis pathways in cancer with magnolol and honokiol, bioactive constituents of the bark of Magnolia officinalis. Drug Discov. Ther. 2011, 5, 202-210. [CrossRef]

107. Raja, S.M.; Chen, S.; Yue, P.; Acker, T.M.; Lefkove, B.; Arbiser, J.L.; Khuri, F.R.; Sun, S.Y. The natural product honokiol preferentially inhibits cellular FLICE-inhibitory protein and augments death receptor-induced apoptosis. Mol. Cancer Ther. 2008, 7, 2212-2223. [CrossRef]

108. Rauf, A.; Patel, S.; Imran, M.; Maalik, A.; Arshad, M.U.; Saeed, F.; Mabkhot, Y.N.; Al-Showiman, S.S.; Ahmad, N.; Elsharkawy, E. Honokiol: An anticancer lignan. Biomed. Pharmacother. 2018, 107, 555-562. [CrossRef]

109. Schroder, M.; Kaufman, R.J. ER stress and the unfolded protein response. Mutat. Res. 2005, 569, $29-63$. [CrossRef]

110. Cao, S.S.; Kaufman, R.J. Endoplasmic reticulum stress and oxidative stress in cell fate decision and human disease. Antioxid. Redox Signal. 2014, 21, 396-413. [CrossRef]

111. Ferri, K.F.; Kroemer, G. Organelle-specific initiation of cell death pathways. Nat. Cell Biol. 2001, 3, E255-E263. [CrossRef]

112. Chiu, C.-S.; Tsai, C.-H.; Hsieh, M.-S.; Tsai, S.-C.; Jan, Y.-J.; Lin, W.-Y.; Lai, D.-W.; Wu, S.-M.; Hsing, H.-Y.; Arbiser, J.L.; et al. Exploiting Honokiol-induced ER stress CHOP activation inhibits the growth and metastasis of melanoma by suppressing the MITF and $\beta$-catenin pathways. Cancer Lett. 2019, 442, 113-125. [CrossRef] [PubMed]

113. Liu, S.H.; Shen, C.C.; Yi, Y.C.; Tsai, J.J.; Wang, C.C.; Chueh, J.T.; Lin, K.L.; Lee, T.C.; Pan, H.C.; Sheu, M.L. Honokiol inhibits gastric tumourigenesis by activation of 15-lipoxygenase-1 and consequent inhibition of peroxisome proliferator-activated receptor- $\gamma$ and COX-2-dependent signals. Br. J. Pharmacol. 2010, 160, 1963-1972. [CrossRef] [PubMed]

114. Liu, S.H.; Lee, W.J.; Lai, D.W.; Wu, S.M.; Liu, C.Y.; Tien, H.R.; Chiu, C.S.; Peng, Y.C.; Jan, Y.J.; Chao, T.H.; et al. Honokiol confers immunogenicity by dictating calreticulin exposure, activating ER stress and inhibiting epithelial-to-mesenchymal transition. Mol. Oncol. 2015, 9, 834-849. [CrossRef] [PubMed]

115. Martin, S.; Lamb, H.K.; Brady, C.; Lefkove, B.; Bonner, M.Y.; Thompson, P.; Lovat, P.E.; Arbiser, J.L.; Hawkins, A.R.; Redfern, C.P. Inducing apoptosis of cancer cells using small-molecule plant compounds that bind to GRP78. Br. J. Cancer 2013, 109, 433-443. [CrossRef] [PubMed]

116. Lee, S.Y.; Ju, M.K.; Jeon, H.M.; Jeong, E.K.; Lee, Y.J.; Kim, C.H.; Park, H.G.; Han, S.I.; Kang, H.S. Regulation of Tumor Progression by Programmed Necrosis. Oxidative Med. Cell. Longev. 2018, 2018, 3537471. [CrossRef]

117. Tian, W.; Xu, D.; Deng, Y.-C. Honokiol, a multifunctional tumor cell death inducer. Die Pharm. Int. J. Pharm. Sci. 2012, 67, 811-816. [CrossRef] 
118. Chen, G.; Izzo, J.; Demizu, Y.; Wang, F.; Guha, S.; Wu, X.; Hung, M.-C.; Ajani, J.A.; Huang, P. Different redox states in malignant and nonmalignant esophageal epithelial cells and differential cytotoxic responses to bile acid and honokiol. Antioxid. Redox Signal. 2009, 11, 1083-1095. [CrossRef]

119. Yu, C.; Zhang, Q.; Zhang, H.Y.; Zhang, X.; Huo, X.; Cheng, E.; Wang, D.H.; Arbiser, J.L.; Spechler, S.J.; Souza, R.F. Targeting the intrinsic inflammatory pathway: Honokiol exerts proapoptotic effects through STAT3 inhibition in transformed Barrett's cells. Am. J. Physiol. Gastrointest. Liver Physiol. 2012, 303, G561-G569. [CrossRef]

120. Meier, J.A.; Hyun, M. Stress-induced dynamic regulation of mitochondrial STAT3 and its association with cyclophilin D reduce mitochondrial ROS production. Sci. Signal. 2017, 10. [CrossRef]

121. Cen, M.; Yao, Y.; Cui, L.; Yang, G.; Lu, G.; Fang, L.; Bao, Z.; Zhou, J. Honokiol induces apoptosis of lung squamous cell carcinoma by targeting FGF2-FGFR1 autocrine loop. Cancer Med. 2018, 7, 6205-6218. [CrossRef]

122. Hahm, E.R.; Singh, K.B.; Singh, S.V. c-Myc is a novel target of cell cycle arrest by honokiol in prostate cancer cells. Cell Cycle 2016, 15, 2309-2320. [CrossRef] [PubMed]

123. Vaid, M.; Sharma, S.D.; Katiyar, S.K. Honokiol, a phytochemical from the Magnolia plant, inhibits photocarcinogenesis by targeting UVB-induced inflammatory mediators and cell cycle regulators: Development of topical formulation. Carcinogenesis 2010, 31, 2004-2011. [CrossRef] [PubMed]

124. Guo, C.; Ma, L.; Zhao, Y.; Peng, A.; Cheng, B.; Zhou, Q.; Zheng, L.; Huang, K. Inhibitory effects of magnolol and honokiol on human calcitonin aggregation. Sci. Rep. 2015, 5, 13556. [CrossRef] [PubMed]

125. Yan, B.; Peng, Z.Y. Honokiol induces cell cycle arrest and apoptosis in human gastric carcinoma MGC-803 cell line. Int. J. Clin. Exp. Med. 2015, 8, 5454-5461. [PubMed]

126. Grimmel, M.; Backhaus, C.; Proikas-Cezanne, T. WIPI-Mediated Autophagy and Longevity. Cells 2015, 4, 202-217. [CrossRef] [PubMed]

127. Yun, C.W.; Lee, S.H. The Roles of Autophagy in Cancer. Int. J. Mol. Sci. 2018, 19, 3466. [CrossRef]

128. Galluzzi, L.; Pietrocola, F.; Bravo-San Pedro, J.M.; Amaravadi, R.K.; Baehrecke, E.H.; Cecconi, F.; Codogno, P.; Debnath, J.; Gewirtz, D.A.; Karantza, V.; et al. Autophagy in malignant transformation and cancer progression. EMBO J. 2015, 34, 856-880. [CrossRef]

129. Lin, L.; Baehrecke, E.H. Autophagy, cell death, and cancer. Mol. Cell Oncol. 2015, 2, e985913. [CrossRef]

130. Paquette, M.; El-Houjeiri, L.; Pause, A. mTOR Pathways in Cancer and Autophagy. Cancers 2018, $10,18$. [CrossRef]

131. Murray, J.T.; Tee, A.R. Mechanistic Target of Rapamycin (mTOR) in the Cancer Setting. Cancers 2018, 10, 168. [CrossRef]

132. Itakura, E.; Mizushima, N. Atg14 and UVRAG: Mutually exclusive subunits of mammalian Beclin 1-PI3K complexes. Autophagy 2009, 5, 534-536. [CrossRef] [PubMed]

133. Torii, S.; Yoshida, T.; Arakawa, S.; Honda, S.; Nakanishi, A.; Shimizu, S. Identification of PPM1D as an essential Ulk1 phosphatase for genotoxic stress-induced autophagy. EMBO Rep. 2016, 17, 1552-1564. [CrossRef] [PubMed]

134. Maiuri, M.C.; Criollo, A.; Kroemer, G. Crosstalk between apoptosis and autophagy within the Beclin 1 interactome. EMBO J. 2010, 29, 515-516. [CrossRef] [PubMed]

135. Carlsson, S.R.; Simonsen, A. Membrane dynamics in autophagosome biogenesis. J. Cell Sci. 2015, $128,193$. [CrossRef] [PubMed]

136. Mochida, K.; Oikawa, Y.; Kimura, Y.; Kirisako, H.; Hirano, H.; Ohsumi, Y.; Nakatogawa, H. Receptor-mediated selective autophagy degrades the endoplasmic reticulum and the nucleus. Nature 2015, 522, 359-362. [CrossRef]

137. Wrighton, K.H. Selecting ER for eating. Nat. Rev. Mol. Cell Biol. 2015, 16, 389. [CrossRef]

138. Chio, C.C.; Chen, K.Y.; Chang, C.K.; Chuang, J.Y.; Liu, C.C.; Liu, S.H.; Chen, R.M. Improved effects of honokiol on temozolomide-induced autophagy and apoptosis of drug-sensitive and -tolerant glioma cells. BMC Cancer 2018, 18, 379. [CrossRef]

139. Nieto, M.A.; Huang, R.Y.; Jackson, R.A.; Thiery, J.P. EMT: 2016. Cell 2016, 166, 21-45. [CrossRef]

140. Brabletz, T.; Kalluri, R.; Nieto, M.A.; Weinberg, R.A. EMT in cancer. Nat. Rev. Cancer 2018, 18, $128-134$. [CrossRef]

141. Roche, J. The Epithelial-to-Mesenchymal Transition in Cancer. Cancers 2018, 10, 52. [CrossRef] 
142. Røsland, G.V.; Dyrstad, S.E.; Tusubira, D.; Helwa, R.; Tan, T.Z.; Lotsberg, M.L.; Pettersen, I.K.N.; Berg, A.; Kindt, C.; Hoel, F.; et al. Epithelial to mesenchymal transition (EMT) is associated with attenuation of succinate dehydrogenase (SDH) in breast cancer through reduced expression of SDHC. Cancer Metab. 2019, 7, 6. [CrossRef] [PubMed]

143. Shen, L.; Zhang, F.; Huang, R.; Yan, J.; Shen, B. Honokiol inhibits bladder cancer cell invasion through repressing SRC-3 expression and epithelial-mesenchymal transition. Oncol. Lett. 2017, 14, 4294-4300. [CrossRef] [PubMed]

144. Avtanski, D.B.; Nagalingam, A.; Bonner, M.Y.; Arbiser, J.L.; Saxena, N.K.; Sharma, D. Honokiol inhibits epithelial-mesenchymal transition in breast cancer cells by targeting signal transducer and activator of transcription 3/Zeb1/E-cadherin axis. Mol. Oncol. 2014, 8, 565-580. [CrossRef] [PubMed]

145. Lv, X.-Q.; Qiao, X.-R.; Su, L.; Chen, S.-Z. Honokiol inhibits EMT-mediated motility and migration of human non-small cell lung cancer cells in vitro by targeting c-FLIP. Acta Pharmacol. Sin. 2016, 37, 1574-1586. [CrossRef]

146. Qin, L.; Liu, Z.; Chen, H.; Xu, J. The steroid receptor coactivator-1 regulates twist expression and promotes breast cancer metastasis. Cancer Res. 2009, 69, 3819-3827. [CrossRef]

147. Yao, C.-J.; Lai, G.-M.; Yeh, C.-T.; Lai, M.-T.; Shih, P.-H.; Chao, W.-J.; Whang-Peng, J.; Chuang, S.-E.; Lai, T.-Y. Honokiol Eliminates Human Oral Cancer Stem-Like Cells Accompanied with Suppression of Wnt/ $\beta$-Catenin Signaling and Apoptosis Induction. Evid.-Based Complement. Altern. Med. 2013, 2013, 146136. [CrossRef]

148. Wang, W.D.; Shang, Y.; Li, Y.; Chen, S.Z. Honokiol inhibits breast cancer cell metastasis by blocking EMT through modulation of Snail/Slug protein translation. Acta Pharm. Sin. 2019, 40, 1219-1227. [CrossRef]

149. Galichon, P.; Hertig, A. Epithelial to mesenchymal transition as a biomarker in renal fibrosis: Are we ready for the bedside? Fibrogenesis Tissue Repair 2011, 4, 11. [CrossRef]

150. Conacci-Sorrell, M.; Ngouenet, C.; Anderson, S.; Brabletz, T.; Eisenman, R.N. Stress-induced cleavage of Myc promotes cancer cell survival. Genes Dev. 2014, 28, 689-707. [CrossRef]

151. Yamaguchi, H.; Wyckoff, J.; Condeelis, J. Cell migration in tumors. Curr. Opin. Cell Biol. 2005, 17, 559-564. [CrossRef]

152. Seyfried, T.N.; Huysentruyt, L.C. On the origin of cancer metastasis. Crit. Rev. Oncog. 2013, 18, $43-73$. [CrossRef] [PubMed]

153. Tay, R.Y.; Fernández-Gutiérrez, F.; Foy, V.; Burns, K.; Pierce, J.; Morris, K.; Priest, L.; Tugwood, J.; Ashcroft, L.; Lindsay, C.R.; et al. Prognostic value of circulating tumour cells in limited-stage small-cell lung cancer: Analysis of the concurrent once-daily versus twice-daily radiotherapy (CONVERT) randomised controlled trial. Ann. Oncol. 2019, 30, 1114-1120. [CrossRef] [PubMed]

154. Singh, T.; Katiyar, S.K. Honokiol, a phytochemical from Magnolia spp., inhibits breast cancer cell migration by targeting nitric oxide and cyclooxygenase-2. Int. J. Oncol. 2011, 38, 769-776. [CrossRef]

155. Zhang, J.; Zhang, Y.; Shen, W.; Fu, R.; Ding, Z.; Zhen, Y.; Wan, Y. Cytological effects of honokiol treatment and its potential mechanism of action in non-small cell lung cancer. Biomed. Pharmacother. 2019, 117, 109058. [CrossRef] [PubMed]

156. Cheng, S.; Castillo, V.; Welty, M.; Eliaz, I.; Sliva, D. Honokiol inhibits migration of renal cell carcinoma through activation of RhoA/ROCK/MLC signaling pathway. Int. J. Oncol. 2016, 49, 1525-1530. [CrossRef]

157. Balan, M.; Chakraborty, S.; Flynn, E.; Zurakowski, D.; Pal, S. Honokiol inhibits c-Met-HO-1 tumor-promoting pathway and its cross-talk with calcineurin inhibitor-mediated renal cancer growth. Sci. Rep. 2017, 7, 5900. [CrossRef]

158. Alizadeh, A.M.; Shiri, S.; Farsinejad, S. Metastasis review: From bench to bedside. Tumor Biol. 2014, 35, 8483-8523. [CrossRef]

159. Klein, C.A. Cancer. The metastasis cascade. Science 2008, 321, 1785-1787. [CrossRef]

160. Bai, X.; Cerimele, F.; Ushio-Fukai, M.; Waqas, M.; Campbell, P.M.; Govindarajan, B.; Der, C.J.; Battle, T.; Frank, D.A.; Ye, K.; et al. Honokiol, a small molecular weight natural product, inhibits angiogenesis in vitro and tumor growth in vivo. J. Biol. Chem. 2003, 278, 35501-35507. [CrossRef]

161. Kolligs, F.T.; Bommer, G.; Goke, B. Wnt/beta-catenin/tcf signaling: A critical pathway in gastrointestinal tumorigenesis. Digestion 2002, 66, 131-144. [CrossRef]

162. Hlubek, F.; Spaderna, S.; Jung, A.; Kirchner, T.; Brabletz, T. Beta-catenin activates a coordinated expression of the proinvasive factors laminin-5 gamma2 chain and MT1-MMP in colorectal carcinomas. Int. J. Cancer 2004, 108, 321-326. [CrossRef] [PubMed] 
163. Cheng, S.; Castillo, V.; Eliaz, I.; Sliva, D. Honokiol suppresses metastasis of renal cell carcinoma by targeting KISS1/KISS1R signaling. Int. J. Oncol. 2015, 46, 2293-2298. [CrossRef] [PubMed]

164. Nishida, N.; Yano, H.; Nishida, T.; Kamura, T.; Kojiro, M. Angiogenesis in cancer. Vasc. Health Risk Manag. 2006, 2, 213-219. [CrossRef] [PubMed]

165. Rajabi, M.; Mousa, S.A. The Role of Angiogenesis in Cancer Treatment. Biomedicines 2017, 5, 34. [CrossRef] [PubMed]

166. Tonini, T.; Rossi, F.; Claudio, P.P. Molecular basis of angiogenesis and cancer. Oncogene 2003, 22, $6549-6556$. [CrossRef] [PubMed]

167. Banerjee, P.; Basu, A.; Arbiser, J.L.; Pal, S. The natural product honokiol inhibits calcineurin inhibitor-induced and Ras-mediated tumor promoting pathways. Cancer Lett. 2013, 338, 292-299. [CrossRef]

168. Vavilala, D.T.; Ponnaluri, V.K.C.; Kanjilal, D.; Mukherji, M. Evaluation of anti-HIF and anti-angiogenic properties of honokiol for the treatment of ocular neovascular diseases. PLoS ONE 2014, 9, e113717. [CrossRef]

169. Vavilala, D.T.; O’Bryhim, B.E.; Ponnaluri, V.K.; White, R.S.; Radel, J.; Symons, R.C.; Mukherji, M. Honokiol inhibits pathological retinal neovascularization in oxygen-induced retinopathy mouse model. Biochem. Biophys. Res. Commun. 2013, 438, 697-702. [CrossRef]

170. Wen, J.; Wang, X.; Pei, H.; Xie, C.; Qiu, N.; Li, S.; Wang, W.; Cheng, X.; Chen, L. Anti-psoriatic effects of Honokiol through the inhibition of NF-kappaB and VEGFR-2 in animal model of K14-VEGF transgenic mouse. J. Pharmacol. Sci. 2015, 128, 116-124. [CrossRef]

171. Hu, J.; Chen, L.J.; Liu, L.; Chen, X.; Chen, P.L.; Yang, G.; Hou, W.L.; Tang, M.H.; Zhang, F.; Wang, X.H.; et al. Liposomal honokiol, a potent anti-angiogenesis agent, in combination with radiotherapy produces a synergistic antitumor efficacy without increasing toxicity. Exp. Mol. Med. 2008, 40, 617-628. [CrossRef]

172. Xia, Y.; Shen, S.; Verma, I.M. NF-kB, an active player in human cancers. Cancer Immunol. Res. 2014, 2, 823-830. [CrossRef] [PubMed]

173. Xia, L.; Tan, S.; Zhou, Y.; Lin, J.; Wang, H.; Oyang, L.; Tian, Y.; Liu, L.; Su, M.; Wang, H.; et al. Role of the NFkB-signaling pathway in cancer. Onco Targets Ther. 2018, 11, 2063-2073. [CrossRef] [PubMed]

174. Ahn, K.S.; Sethi, G.; Shishodia, S.; Sung, B.; Arbiser, J.L.; Aggarwal, B.B. Honokiol Potentiates Apoptosis, Suppresses Osteoclastogenesis, and Inhibits Invasion through Modulation of Nuclear Factor- $\mathrm{B}$ Activation Pathway. Mol. Cancer Res. 2006, 4, 621. [CrossRef] [PubMed]

175. Wang, Z.; Zhang, X. Chemopreventive Activity of Honokiol against 7, 12-Dimethylbenz[a]anthracene-Induced Mammary Cancer in Female Sprague Dawley Rats. Front. Pharmacol. 2017, 8, 320. [CrossRef]

176. Katiyar, S.K. Emerging Phytochemicals for the Prevention and Treatment of Head and Neck Cancer. Molecules 2016, 21, 1610. [CrossRef]

177. Hua, H.; Chen, W.; Shen, L.; Sheng, Q.; Teng, L. Honokiol augments the anti-cancer effects of oxaliplatin in colon cancer cells. Acta Biochim. Biophys. Sin. 2013, 45, 773-779. [CrossRef]

178. Nabekura, T.; Hiroi, T.; Kawasaki, T.; Uwai, Y. Effects of natural nuclear factor-kappa B inhibitors on anticancer drug efflux transporter human P-glycoprotein. Biomed. Pharmacother. 2015, 70, 140-145. [CrossRef]

179. Furqan, M.; Akinleye, A.; Mukhi, N.; Mittal, V.; Chen, Y.; Liu, D. STAT inhibitors for cancer therapy. J. Hematol. Oncol. 2013, 6, 90. [CrossRef]

180. Yu, H.; Pardoll, D.; Jove, R. STATs in cancer inflammation and immunity: A leading role for STAT3. Nat. Rev. Cancer 2009, 9, 798-809. [CrossRef]

181. Pan, J.; Lee, Y.; Cheng, G.; Zielonka, J.; Zhang, Q.; Bajzikova, M.; Xiong, D.; Tsaih, S.-W.; Hardy, M.; Flister, M.; et al. Mitochondria-Targeted Honokiol Confers a Striking Inhibitory Effect on Lung Cancer via Inhibiting Complex I Activity. iScience 2018, 3, 192-207. [CrossRef]

182. He, Z.; Subramaniam, D.; Zhang, Z.; Zhang, Y.; Anant, S. Honokiol as a Radiosensitizing Agent for Colorectal cancers. Curr. Colorectal Cancer Rep. 2013, 9, 358-364. [CrossRef] [PubMed]

183. Bi, L.; Yu, Z.; Wu, J.; Yu, K.; Hong, G.; Lu, Z.; Gao, S. Honokiol Inhibits Constitutive and Inducible STAT3 Signaling via PU.1-Induced SHP1 Expression in Acute Myeloid Leukemia Cells. Tohoku J. Exp. Med. 2015, 237, 163-172. [CrossRef] [PubMed]

184. Ishikawa, C.; Arbiser, J.L.; Mori, N. Honokiol induces cell cycle arrest and apoptosis via inhibition of survival signals in adult T-cell leukemia. Biochim. Biophys. Acta 2012, 1820, 879-887. [CrossRef] [PubMed]

185. Sasaki, T.; Hiroki, K.; Yamashita, Y. The role of epidermal growth factor receptor in cancer metastasis and microenvironment. BioMed Res. Int. 2013, 2013, 546318. [CrossRef] [PubMed] 
186. Normanno, N.; De Luca, A.; Bianco, C.; Strizzi, L.; Mancino, M.; Maiello, M.R.; Carotenuto, A.; De Feo, G.; Caponigro, F.; Salomon, D.S. Epidermal growth factor receptor (EGFR) signaling in cancer. Gene 2006, 366, 2-16. [CrossRef] [PubMed]

187. Kari, C.; Chan, T.O.; Rocha de Quadros, M.; Rodeck, U. Targeting the Epidermal Growth Factor Receptor in Cancer. Cancer Res. 2003, 63, 1. [PubMed]

188. Yewale, C.; Baradia, D.; Vhora, I.; Patil, S.; Misra, A. Epidermal growth factor receptor targeting in cancer: A review of trends and strategies. Biomaterials 2013, 34, 8690-8707. [CrossRef]

189. Song, J.M.; Anandharaj, A.; Upadhyaya, P.; Kirtane, A.R.; Kim, J.-H.; Hong, K.H.; Panyam, J.; Kassie, F. Honokiol suppresses lung tumorigenesis by targeting EGFR and its downstream effectors. Oncotarget 2016, 7, 57752-57769. [CrossRef]

190. Dai, X.; Li, R.-Z.; Jiang, Z.-B.; Wei, C.-L.; Luo, L.-X.; Yao, X.-J.; Li, G.-P.; Leung, E.L.-H. Honokiol Inhibits Proliferation, Invasion and Induces Apoptosis Through Targeting Lyn Kinase in Human Lung Adenocarcinoma Cells. Front. Pharmacol. 2018, 9. [CrossRef]

191. Biscardi, J.S.; Ishizawar, R.C.; Silva, C.M.; Parsons, S.J. Tyrosine kinase signalling in breast cancer: Epidermal growth factor receptor and c-Src interactions in breast cancer. Breast Cancer Res. 2000, 2, 203-210. [CrossRef]

192. Singh, T.; Gupta, N.A.; Xu, S.; Prasad, R.; Velu, S.E.; Katiyar, S.K. Honokiol inhibits the growth of head and neck squamous cell carcinoma by targeting epidermal growth factor receptor. Oncotarget 2015, 6, 21268-21282. [CrossRef] [PubMed]

193. Dufour, M.; Dormond-Meuwly, A.; Demartines, N.; Dormond, O. Targeting the Mammalian Target of Rapamycin (mTOR) in Cancer Therapy: Lessons from Past and Future Perspectives. Cancers 2011, 3, 2478-2500. [CrossRef] [PubMed]

194. Hua, H.; Kong, Q.; Zhang, H.; Wang, J.; Luo, T.; Jiang, Y. Targeting mTOR for cancer therapy. J. Hematol. Oncol. 2019, 12, 71. [CrossRef] [PubMed]

195. Li, Z.; Dong, H.; Li, M.; Wu, Y.; Liu, Y.; Zhao, Y.; Chen, X.; Ma, M. Honokiol induces autophagy and apoptosis of osteosarcoma through PI3K/Akt/mTOR signaling pathway. Mol. Med. Rep. 2018, 17, 2719-2723. [CrossRef]

196. Pezzuto, A.; Carico, E. Role of HIF-1 in Cancer Progression: Novel Insights. A Review. Curr. Mol. Med. 2018, 18, 343-351. [CrossRef]

197. Masoud, G.N.; Li, W. HIF-1 $\alpha$ pathway: Role, regulation and intervention for cancer therapy. Acta Pharm. Sin. B 2015, 5, 378-389. [CrossRef]

198. Semenza, G.L. Targeting HIF-1 for cancer therapy. Nat. Rev. Cancer 2003, 3, 721-732. [CrossRef]

199. Soni, S.; Padwad, Y.S. HIF-1 in cancer therapy: Two decade long story of a transcription factor. Acta Oncol. 2017, 56, 503-515. [CrossRef]

200. Aster, J.C.; Pear, W.S.; Blacklow, S.C. The Varied Roles of Notch in Cancer. Annu. Rev. Pathol. 2017, 12, 245-275. [CrossRef]

201. Venkatesh, V.; Nataraj, R.; Thangaraj, G.S.; Karthikeyan, M.; Gnanasekaran, A.; Kaginelli, S.B.; Kuppanna, G.; Kallappa, C.G.; Basalingappa, K.M. Targeting Notch signalling pathway of cancer stem cells. Stem Cell Investig. 2018, 5, 5. [CrossRef]

202. Nowell, C.S.; Radtke, F. Notch as a tumour suppressor. Nat. Rev. Cancer 2017, 17, 145-159. [CrossRef] [PubMed]

203. Kaushik, G.; Venugopal, A.; Ramamoorthy, P.; Standing, D.; Subramaniam, D.; Umar, S.; Jensen, R.A.; Anant, S.; Mammen, J.M. Honokiol inhibits melanoma stem cells by targeting notch signaling. Mol. Carcinog. 2015, 54, 1710-1721. [CrossRef] [PubMed]

204. Wynn, M.L.; Consul, N.; Merajver, S.D.; Schnell, S. Inferring the Effects of Honokiol on the Notch Signaling Pathway in SW480 Colon Cancer Cells. Cancer Inform. 2014, 13, 1-12. [CrossRef] [PubMed]

205. Callaghan, R.; Luk, F.; Bebawy, M. Inhibition of the multidrug resistance P-glycoprotein: Time for a change of strategy? Drug Metab. Dispos. 2014, 42, 623-631. [CrossRef]

206. Waghray, D.; Zhang, Q. Inhibit or Evade Multidrug Resistance P-Glycoprotein in Cancer Treatment. J. Med. Chem. 2018, 61, 5108-5121. [CrossRef]

207. Nanayakkara, A.K.; Follit, C.A.; Chen, G.; Williams, N.S.; Vogel, P.D.; Wise, J.G. Targeted inhibitors of P-glycoprotein increase chemotherapeutic-induced mortality of multidrug resistant tumor cells. Sci. Rep. 2018, 8, 967. [CrossRef]

208. Han, H.K.; Van Anh, L.T. Modulation of P-glycoprotein expression by honokiol, magnolol and 4-O-methylhonokiol, the bioactive components of Magnolia officinalis. Anticancer Res. 2012, 32, 4445-4452. 
209. Wang, X.; Cho, K.; Chen, Z.; Arbiser, J.; Shin, D. Honokiol reduces drug resistance by inhibition of P-glycoprotein expression in multidrug resistant (MDR) squamous cell carcinoma of the head and neck (SCCHN). Cancer Res. 2007, 67, 2776.

210. Xu, D.; Lu, Q.; Hu, X. Down-regulation of P-glycoprotein expression in MDR breast cancer cell MCF-7/ADR by honokiol. Cancer Lett. 2006, 243, 274-280. [CrossRef]

211. Wang, H.; Liao, Z.; Sun, X.; Shi, Q.; Huo, G.; Xie, Y.; Tang, X.; Zhi, X.; Tang, Z. Intravenous administration of Honokiol provides neuroprotection and improves functional recovery after traumatic brain injury through cell cycle inhibition. Neuropharmacology 2014, 86, 9-21. [CrossRef]

212. Godugu, C.; Doddapaneni, R.; Singh, M. Honokiol nanomicellar formulation produced increased oral bioavailability and anticancer effects in triple negative breast cancer (TNBC). Colloids Surf. B 2017, 153, 208-219. [CrossRef] [PubMed]

213. Tsai, T.H.; Chou, C.J.; Cheng, F.C.; Chen, C.F. Pharmacokinetics of honokiol after intravenous administration in rats assessed using high-performance liquid chromatography. J. Chromatogr. B 1994, 655, 41-45. [CrossRef]

214. Liang, Y.; Cui, G.; Wang, X.; Zhang, W.; An, Q.; Lin, Z.; Wang, H.; Chen, S. Pharmacokinetics of honokiol after intravenous guttae in beagle dogs assessed using ultra-performance liquid chromatography-tandem mass spectrometry. Biomed. Chromatogr. 2014, 28, 1378-1383. [CrossRef] [PubMed]

215. Su, W.J.; Huang, X.; Qin, E.; Jiang, L.; Ren, P. Pharmacokinetics of honokiol in rat after oral administration of Cortex of Magnolia officinalis and its compound preparation Houpu Sanwu Decoction. J. Chin. Med. Mater. 2008, 31, 255-258.

216. Wang, J.; Miao, X.L.; Chen, J.Y.; Chen, Y. The Pharmacokinetics and Tissue Distribution of Honokiol and its Metabolites in Rats. Eur. J. Drug Metab. Pharmacokinet. 2016, 41, 587-594. [CrossRef]

217. Sheng, Y.L.; Xu, J.H.; Shi, C.H.; Li, W.; Xu, H.Y.; Li, N.; Zhao, Y.Q.; Zhang, X.R. UPLC-MS/MS-ESI assay for simultaneous determination of magnolol and honokiol in rat plasma: Application to pharmacokinetic study after administration emulsion of the isomer. J. Ethnopharmacol. 2014, 155, 1568-1574. [CrossRef]

218. Han, M.; Yu, X.; Guo, Y.; Wang, Y.; Kuang, H.; Wang, X. Honokiol nanosuspensions: Preparation, increased oral bioavailability and dramatically enhanced biodistribution in the cardio-cerebro-vascular system. Colloids Surf. B 2014, 116, 114-120. [CrossRef]

219. Wu, X.; Chen, X.; Hu, Z. High-performance liquid chromatographic method for simultaneous determination of honokiol and magnolol in rat plasma. Talanta 2003, 59, 115-121. [CrossRef]

220. Prasad, R.; Singh, T.; Katiyar, S.K. Honokiol inhibits ultraviolet radiation-induced immunosuppression through inhibition of ultraviolet-induced inflammation and DNA hypermethylation in mouse skin. Sci. Rep. 2017, 7, 1657. [CrossRef]

221. Gao, X.; Patel, M.G.; Bakshi, P.; Sharma, D.; Banga, A.K. Enhancement in the Transdermal and Localized Delivery of Honokiol Through Breast Tissue. AAPS PharmSciTech 2018, 19, 3501-3511. [CrossRef]

222. Wang, X.H.; Cai, L.L.; Zhang, X.Y.; Deng, L.Y.; Zheng, H.; Deng, C.Y.; Wen, J.L.; Zhao, X.; Wei, Y.Q.; Chen, L.J. Improved solubility and pharmacokinetics of PEGylated liposomal honokiol and human plasma protein binding ability of honokiol. Int. J. Pharm. 2011, 410, 169-174. [CrossRef] [PubMed]

223. Jiang, Q.Q.; Fan, L.Y.; Yang, G.L.; Guo, W.H.; Hou, W.L.; Chen, L.J.; Wei, Y.Q. Improved therapeutic effectiveness by combining liposomal honokiol with cisplatin in lung cancer model. BMC Cancer 2008, 8, 242. [CrossRef] [PubMed]

224. Tang, P.; Sun, Q.; Yang, H.; Tang, B.; Pu, H.; Li, H. Honokiol nanoparticles based on epigallocatechin gallate functionalized chitin to enhance therapeutic effects against liver cancer. Int. J. Pharm. 2018, 545, 74-83. [CrossRef] [PubMed]

225. Wu, W.; Wang, L.; Wang, L.; Zu, Y.; Wang, S.; Liu, P.; Zhao, X. Preparation of honokiol nanoparticles by liquid antisolvent precipitation technique, characterization, pharmacokinetics, and evaluation of inhibitory effect on HepG2 cells. Int. J. Nanomed. 2018, 13, 5469-5483. [CrossRef] [PubMed]

226. Guo, Y.; Zhao, Y.; Wang, T.; Zhao, S.; Qiu, H.; Han, M.; Wang, X. Honokiol nanoparticles stabilized by oligoethylene glycols codendrimer: In vitro and in vivo investigations. J. Mater. Chem. B 2017, 5, 697-706. [CrossRef]

227. Li, X.; Hou, X.; Ding, W.; Cong, S.; Zhang, Y.; Chen, M.; Meng, Y.; Lei, J.; Liu, Y.; Li, G. Sirolimus-loaded polymeric micelles with honokiol for oral delivery. J. Pharm. Pharmacol. 2015, 67, 1663-1672. [CrossRef] [PubMed] 
228. Wang, N.; Wang, Z.; Nie, S.; Song, L.; He, T.; Yang, S.; Yang, X.; Yi, C.; Wu, Q.; Gong, C. Biodegradable polymeric micelles coencapsulating paclitaxel and honokiol: A strategy for breast cancer therapy in vitro and in vivo. Int. J. Nanomed. 2017, 12, 1499-1514. [CrossRef]

229. Gong, C.; Wei, X.; Wang, X.; Wang, Y.; Guo, G.; Mao, Y.; Luo, F.; Qian, Z. Biodegradable self-assembled PEG-PCL-PEG micelles for hydrophobic honokiol delivery: I. Preparation and characterization. Nanotechnology 2010, 21, 215103. [CrossRef]

230. Zheng, X.; Kan, B.; Gou, M.; Fu, S.; Zhang, J.; Men, K.; Chen, L.; Luo, F.; Zhao, Y.; Zhao, X.; et al. Preparation of MPEG-PLA nanoparticle for honokiol delivery in vitro. Int. J. Pharm. 2010, 386, 262-267. [CrossRef]

231. Wang, B.; Gou, M.; Zheng, X.; Wei, X.; Gong, C.; Wang, X.; Zhao, Y.; Luo, F.; Chen, L.; Qian, Z.; et al. Co-delivery honokiol and doxorubicin in MPEG-PLA nanoparticles. J. Nanosci. Nanotechnol. 2010, 10, 4166-4172. [CrossRef]

232. Yu, R.; Zou, Y.; Liu, B.; Guo, Y.; Wang, X.; Han, M. Surface modification of pH-sensitive honokiol nanoparticles based on dopamine coating for targeted therapy of breast cancer. Colloids Surf. B 2019, 177, 1-10. [CrossRef] [PubMed]

233. Gong, C.; Shi, S.; Wang, X.; Wang, Y.; Fu, S.; Dong, P.; Chen, L.; Zhao, X.; Wei, Y.; Qian, Z. Novel composite drug delivery system for honokiol delivery: Self-assembled poly(ethylene glycol)-poly(epsilon-caprolactone)-poly(ethylene glycol) micelles in thermosensitive poly(ethylene glycol)-poly(epsilon-caprolactone)-poly(ethylene glycol) hydrogel. J. Phys. Chem. B 2009, 113, 10183-10188. [CrossRef] [PubMed]

234. Qiu, N.; Cai, L.L.; Xie, D.; Wang, G.; Wu, W.; Zhang, Y.; Song, H.; Yin, H.; Chen, L. Synthesis, structural and in vitro studies of well-dispersed monomethoxy-poly(ethylene glycol)-honokiol conjugate micelles. Biomed. Mater. 2010, 5, 065006. [CrossRef] [PubMed]

235. Wang, Z.; Li, X.; Wang, D.; Zou, Y.; Qu, X.; He, C.; Deng, Y.; Jin, Y.; Zhou, Y.; Zhou, Y.; et al. Concurrently suppressing multidrug resistance and metastasis of breast cancer by co-delivery of paclitaxel and honokiol with pH-sensitive polymeric micelles. Acta Biomater. 2017, 62, 144-156. [CrossRef] [PubMed]

236. Wang, X.; Cheng, L.; Xie, H.-J.; Ju, R.-J.; Xiao, Y.; Fu, M.; Liu, J.-J.; Li, X.-T. Functional paclitaxel plus honokiol micelles destroying tumour metastasis in treatment of non-small-cell lung cancer. Artif. Cells Nanomed. Biotechnol. 2018, 46, 1154-1169. [CrossRef] [PubMed]

237. Cheng, N.; Xia, T.; Han, Y.; He, Q.J.; Zhao, R.; Ma, J.R. Synergistic antitumor effects of liposomal honokiol combined with cisplatin in colon cancer models. Oncol. Lett. 2011, 2, 957-962. [CrossRef] [PubMed]

238. Ju, R.J.; Cheng, L.; Qiu, X.; Liu, S.; Song, X.L.; Peng, X.M.; Wang, T.; Li, C.Q.; Li, X.T. Hyaluronic acid modified daunorubicin plus honokiol cationic liposomes for the treatment of breast cancer along with the elimination vasculogenic mimicry channels. J. Drug Target. 2018, 26, 793-805. [CrossRef] 